Instituto de Psicologia da Universidade de São Paulo

Departamento de Psicologia Experimental

Tatiana Hideko Kawamoto

\title{
Tenacidade e investimento em seda em aranhas de teia orbicular
}




\section{Tatiana Hideko Kawamoto}

\section{Tenacidade e investimento em seda em aranhas de teia orbicular}

Dissertação apresentada ao Instituto de Psicologia da Universidade de São Paulo para a obtenção do título de Mestre em Psicologia

Área de concentração: Psicologia Experimental Orientador: Hilton Ferreira Japyassú 


\title{
AUTORIZO A REPRODUÇÃO E DIVULGAÇÃO TOTAL OU \\ PARCIAL DESTE TRABALHO, POR QUALQUER MEIO \\ CONVENCIONAL OU ELETRÔNICO, PARA FINS DE \\ ESTUDO E PESQUISA, DESDE QUE CITADA A FONTE.
}

\author{
Catalogação na publicação \\ Serviço de Biblioteca e Documentação \\ Instituto de Psicologia da Universidade de São Paulo
}

Kawamoto, Tatiana Hideko.

Tenacidade e investimento em seda em aranhas de teia orbicular/ Tatiana Hideko Kawamoto; orientador Hilton Ferreira Japyassú. -- São Paulo, 2007.

$106 \mathrm{p}$.

Dissertação (Mestrado - Programa de Pós-Graduação em Psicologia. Área de Concentração: Psicologia Experimental) - Instituto de Psicologia da Universidade de São Paulo.

1. Aracnídeos 2. Construção da teia 3. Metabolismo 4. Evolução (etologia animal) I. Título. 


\section{Folha de Aprovação}

Tatiana Hideko Kawamoto

Tenacidade e investimento em seda em aranhas de teia orbicular

Dissertação apresentada ao Instituto de Psicologia da Universidade de São Paulo para a obtenção do título de Mestre.

Área de Concentração: Psicologia Experimental

Aprovado em:

Banca Examinadora

Prof. Dr.:

Instituição:

Assinatura:

Prof. Dr.:

Instituição: Assinatura: 


\begin{abstract}
A minha querida batchan, que pouco tempo tive para ouzir suas bistórias. Que seu coração guerreiro encontre paz, finalmente.
\end{abstract}




\section{Agradecimentos}

Agradeço à minha família, por ser minha estrutura formadora e pelo seu amor. Aos amigos, todos os verdadeiros. Vocês dispensam apresentações e listagens: sabem quem são. Viver seria insuportável sem vocês.

Ao meu amado Lagosta pelo apoio, presença nos momentos de crise e de crescimento pessoal, além de uma ajuda mais concreta com as figuras e as dúvidas sobre informática.

Agradeço aos amigos e colegas Igor Cizauskas, Carolina Ribeiro Martins Garcia e Vanessa Penna, por estarem lá nas noites frias, em cima de um bote bambo, coletando aranhas minúsculas para os meus experimentos.

Agradecimento especial, também, ao Laboratório de Ecofisiologia Animal do Departamento de Fisiologia do IBUSP e ao professor Dr. Carlos A. Navas, que me deu as primeiras orientações e direções sobre o metabolismo energético, que vim a conhecer um pouco mais a fundo, e gentilmente cedeu o equipamento para que eu pudesse realizar as medidas; e a todos os alunos pela convivência tranqüila e agradável nas longas sessões de coleta de dados. Dentre eles destaca-se a ajuda intensiva do doutorando Gustavo E. Kaneto.

Ao professor Dr. Antônio D. Brescovit pela identificação das espécies usadas e empréstimo de artigos de seu acervo pessoal e à sua aluna, a doutoranda Cristina Rheims, pela ajuda com os grupos taxonômicos e dúvidas sobre a filogenia das Araneomorphae.

À Ms. Dalva M. Hashimoto, primeiramente pela amizade e exemplo de vida, e pela sua contribuição no presente trabalho guiando-me na incursão em uma estatística nova para mim, a Análise de Sobrevivência.

À empresa Dalkia e ao Shopping Center Eldorado que permitiram e deram suporte para as coletas de Zosis geniculata. A todos os seguranças e pessoal da manutenção que sempre me receberam com zelo e atenção. 
Ao meu orientador primeiramente pela amizade e, principalmente, por ser meu norteador: você me ensinou a enxergar novos horizontes e pensamentos, me ensinou a alçar vôos mais altos.

A Capes pela bolsa de estudos sem a qual teria sido impossível realizar tanto.

Ao Dept. de Psicologia Experimental do IPUSP por permitir a minha formação como mestre. Aqui destaca-se o apoio da professora. Dr ${ }^{\mathrm{a}}$. Emma Otta e do Professor Dr. Eduardo B. Ottoni.

Ao Laboratório de Artrópodes do Instituto Butantan por permitir a realização dos procedimentos experimentais em suas dependências. 
"Uma única aranba fica em silêncio. Aranbas cultivam o silêncio. Mesmo aquelas que fazem barulbo normalmente permanecem o mais quietas que puderem, esperando. Esperar é basicamente o que as aranbas fazem." Os filhos de Anansi, Neil Gaiman 


\section{Resumo}

KAWAMOTO, T.H. Tenacidade e investimento em seda em aranhas de teia orbicular. 2007. $106 f$.

Dissertação (Mestrado) - Instituto de Psicologia, Universidade de São Paulo, São Paulo, 2007.

As orbitelas de fio viscoso dão origem ao ramo mais diverso (Araneoidea) de Orbiculariae.

Várias hipóteses foram levantadas para o aumento de diversidade de Araneoidea, mas nenhuma delas parece explicar completamente o fenômeno. O presente trabalho investigou uma nova hipótese: o surgimento do fio viscoso permitiu uma redução da tenacidade, o que permitiria a exploração de uma maior diversidade de microlocais, levand2,00cmo a maior diversificação das espécies no tempo evolutivo (Capítulo 1). A literatura mostra que a decisão de permanecer/desertar o microlocal (tenacidade) está associada ao investimento na construção da teia: aranhas de teias de alto custo (teias de lençol) tendem a apresentar tenacidade maior do que aranhas de teias de baixo custo (orbitelas). Para verificar se essa tendência existe entre orbitelas com diferentes graus de investimento em teia, avaliamos a resposta de duas orbitelas, uma de fio viscoso (Metazygia rogenhoferi, Araneidae) e outra de fio cribelado (Zosis geniculata, Uloboridae) em função da redução na dieta. Acompanhamos mudanças no abandono de microlocal e alterações de investimento em teia. A espécie ecribelada não muda a taxa de abandonos com a redução na dieta, e mantém uma tenacidade baixa. Ao contrário, a espécie cribelada aumenta a tenacidade e diminui o investimento em seda. No segundo experimento (Capítulo 2), medimos o custo de construção dessas duas espécies, para verificar se as teias orbiculares cribeladas têm um custo efetivamente maior do que o das teias orbiculares ecribeladas. Para tanto, realizamos medidas diretas do consumo de $\mathrm{O}_{2}$ (técnica de respirometria fechada intermitente) em situação de repouso e durante a construção da teia. Essas medidas mostram que $Z$. geniculata mantém o metabolismo de repouso mais baixo, indício de uma adaptação metabólica para enfrentar uma restrição energética maior. $\mathrm{O}$ consumo de $\mathrm{O}_{2}$ é três vezes maior na construção de cada centímetro de fio cribelado quando 
comparado ao fio viscoso. O fato da teia orbicular ecribelada ser mais econômica pode ajudar a entender a maior diversidade que este grupo apresenta em relação ao ancestral de teia orbicular cribelada. Apresentando um metabolismo de atividade de construção de teia mais econômico, as orbitelas de fio viscoso puderam aumentar o seu nível geral de atividade, deslocando-se mais freqüentemente pelo ambiente, apresentando uma estratégia mais ativa de forrageamento. Isto leva a abandono mais freqüente de microlocais expondo, assim, as orbitelas ecribeladas a uma maior diversidade de ambientes que, no longo prazo, poderia ser a chave para o aumento evolutivo na diversidade deste grupo. A perda do cribelo está associada a um aumento significativo na diversidade de espécies não apenas entre as orbitelas, mas também em vários outros grupos dentro de Araneomorphae (Capítulo 3). Sendo o ponto comum, que se correlaciona a um aumento de diversidade em contextos morfológicos variados (diferentes grupos taxonômicos), bem como em situações ecologicamente distintas, a perda do cribelo surge como um fator causal privilegiado neste processo evolutivo. A hipótese de que a perda do fio cribelado de alto custo de construção é responsável pela maior diversificação dos táxons ganha peso a partir da análise das múltiplas perdas do cribelo ao longo da filogenia de Araneomorphae.

Palavras-chave: aracnídeos, construção da teia, metabolismo, evolução 


\begin{abstract}
KAWAMOTO, T.H. Tenacity and silk investment in orb web spiders. 2007. 106f. Dissertação (Mestrado) Instituto de Psicologia, Universidade de São Paulo, São Paulo, 2007.
\end{abstract}

The origin of the most diverse branch of orbweavers, the Araneoidea, coincides with the origin of the viscid silk in the group Orbiculariae. Many hypotheses were proposed to explain the increased diversity in Araneoidea, however none of them explain this phenomena completely. The present work investigates a new hypothesis: the disappearance of the cribellate silk (substituted by the viscid silk) allowed a reduction in tenacity, which in turn allowed the exploration of a major diversity of microhabitats, leading to a major diversification in the evolutionary time (Chapter 1). The literature shows that the decision of stay/leave the microhabitat (tenacity) is associated to the investment in web construction: spiders with costly webs (sheet web spiders) tend to present higher tenacity than spiders with low cost webs (orb web spiders). In order to test if this tendency also occurs among orbweavers with different web costs, we evaluated the response of a viscid (Metazygia rogenhoferi, Araneidae) and a cribellate silk orbweaver (Zosis geniculata, Uloboridae) to a reduction in food supply. We measured web parameters and the latency to abandon the site. The ecribellate spider maintain unaltered its low tenacity levels, even after the reduction in food supply. On other hand, the cribellate spider increases the tenacity and reduces web investment. In the second experiment (Chapter 2) we measured the construction and maintenance costs of the two species in order to verify if the cribellate orb webs have effectively a higher cost than the ecribellate ones. This was made through direct measurement of the spider $0_{2}$ consumption (closed intermittent respirometry technique) while resting and building the web. These measurements show that $Z$. geniculata keeps a lower resting metabolism, what suggests a metabolic adaptation to energetic restrictions. While building the web, the consumption of $\mathrm{O}_{2}$ per centimeter of adhesive silk was three times higher in the cribellate than in the ecribellate web. The lower 
cost of the ecribellate orb web can help us understand the higher diversity of this group in relation to the basal cribellate orb web. With a low cost web, the viscid silk orbweavers can have sustain a higher activity level, moving more frequently and showing a more active foraging strategy. The frequent abandonment of microhabitats expose these spiders to a higher environmental diversity. In the long evolutionary run this can be the key to the high diversity in this group. Loosing the cribellum is associated to a significant increase in species diversity not only among orbweavers, but also in many other Araneomorphae groups (Chapter 3). As a common theme uniting the increase in diversity in such disparate groups, with such diverse morphologies and ecologies, the loss of the cribellum emerges as a favored causal factor in this evolutionary process. The analysis of the multiple losses of the cribellum along the phylogeny of Araneomorphae gives strength to the hypothesis that the loss of the high cost cribellate thread leads to major taxonomic diversifications.

Keywords: arachnids, web construction, metabolism, evolution 


\section{Sumário}

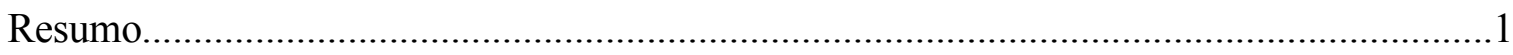

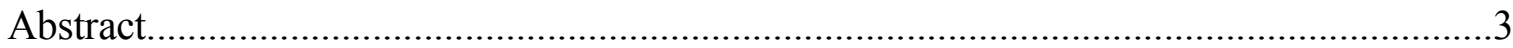

Capítulo 1 - Tenacidade e Investimento em Seda em orbitelas

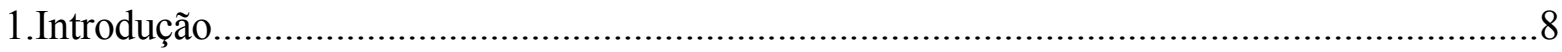

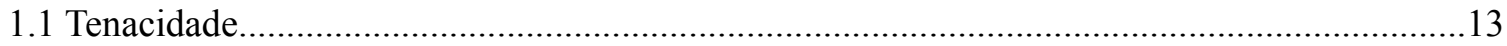

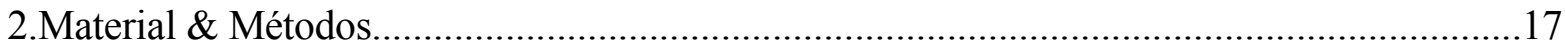

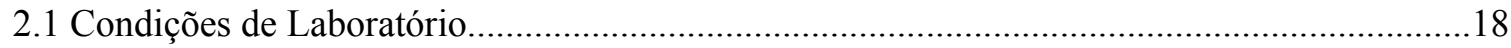

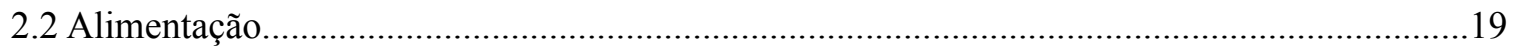

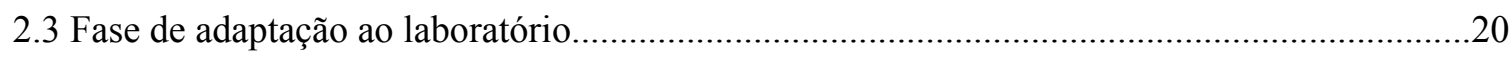

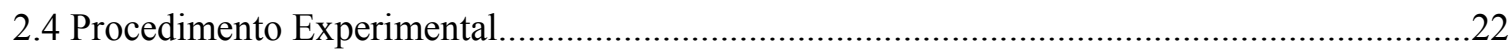

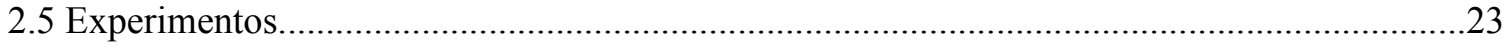

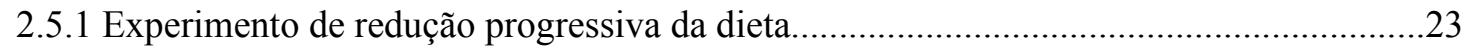

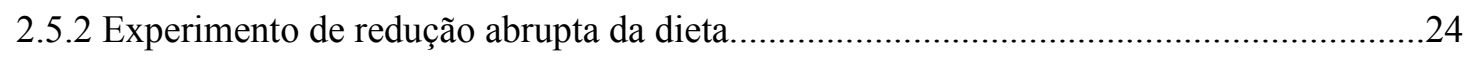

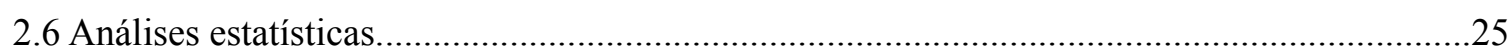

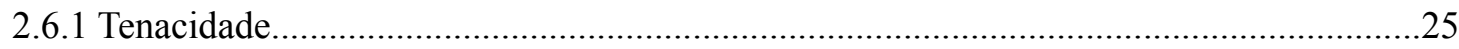

2.6.2 Investimento acumulado em espiral adesiva e os outros parâmetros da teia...................26

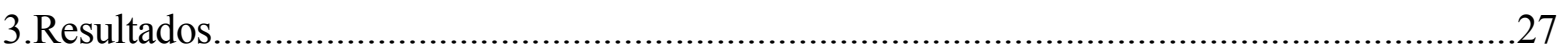

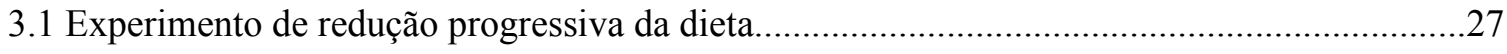

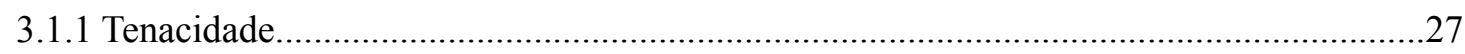

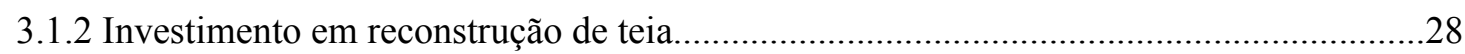

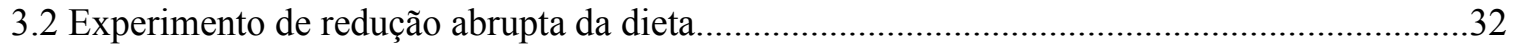

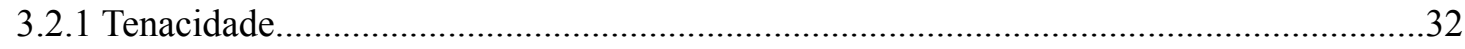

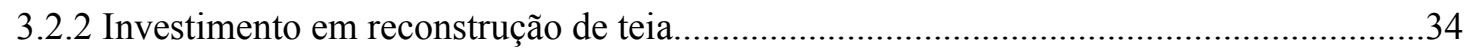

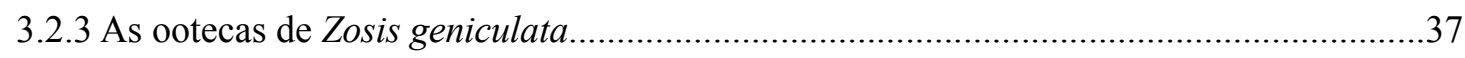

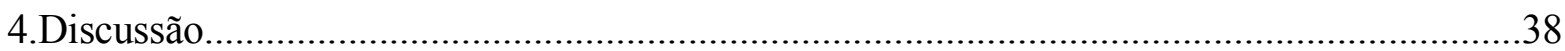

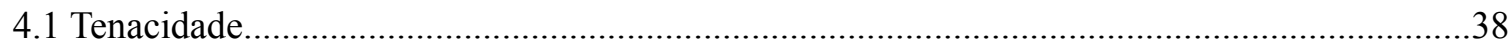

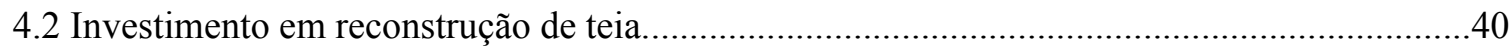

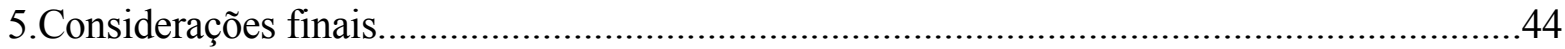


CAPítulo 2 - Metabolismo energético e a CONSTRUÇÃo da teia orbicular

1.Introdução. .48

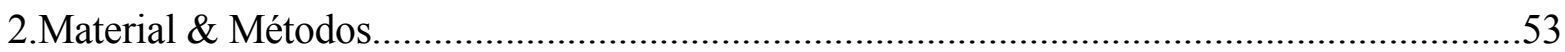

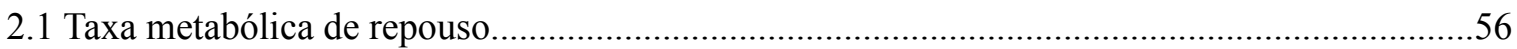

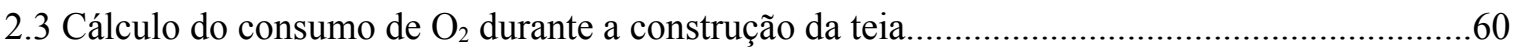

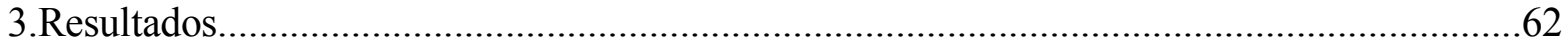

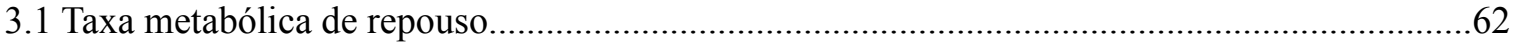

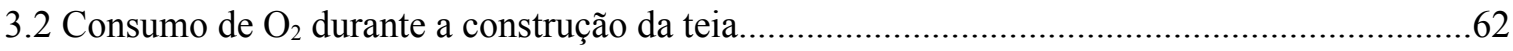

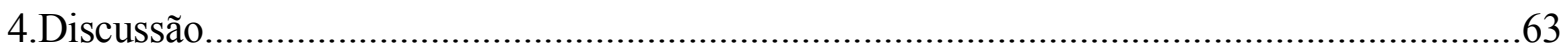

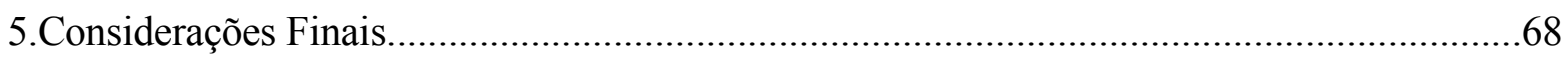

CAPÍtUlo 3 - DiversificaÇÃo DAS ARANHAS E A PERDA DO CRIBELO

1.Evolução \& Diversificação em Araneomorphae...................................................................70

1.1 Por que a monofilia de Cribellatae é incompatível com a monofilia de Orbiculariae?........71

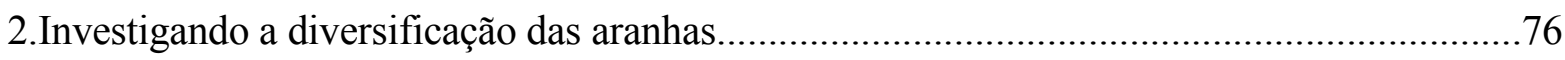

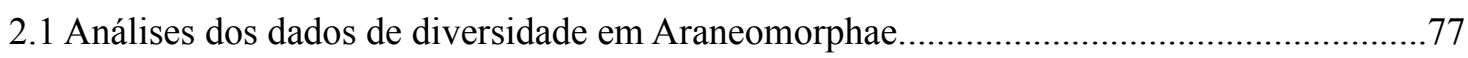

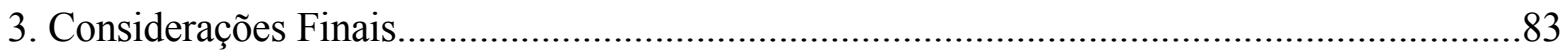

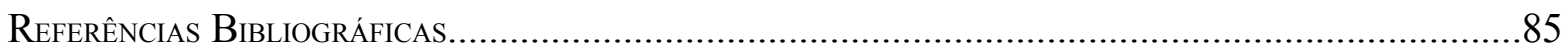

Anexos

A - Planilha do experimento de redução progressiva da dieta de M. rogenhoferi.............................93

B - Planilha do experimento de redução progressiva da dieta de Z. geniculata ................................95

C - Planilha do experimento de redução abrupta da dieta de $M$. rogenhoferi..................................97

D - Planilha do experimento de redução abrupta da dieta de Z. geniculata ....................................100

E - Tabela de fugas do experimento de redução progressiva da dieta...........................................104

F - Tabela de fugas do experimento de redução abrupta da dieta.................................................105

$\mathrm{G}$ - Como foi construída a caixa respirométrica para medidas de construção da teia orbicular.......106 
Capítulo 1

Tenacidade e

Investimento em Seda em Orbitelas 


\section{INTRODUÇÃo}

As aranhas são divididas por Foelix (1996) em dois grandes grupos quanto ao estilo de vida: as andarilhas e as construtoras de armadilhas aéreas. Dentre as construtoras de armadilhas aéreas, as mais impressionantes, devido à sua geometria e diversidade, são as aranhas de teia orbicular, também chamadas de orbitelas. As aranhas de teia orbicular, por sua vez, podem ser divididas em dois grupos de acordo com o elemento adesivo do fio de captura: cribeladas (fio cribelado) e ecribeladas (fio viscoso).

Nas aranhas cribeladas, inúmeros e finos fios de seda são produzidos a partir do cribelo e penteados repetidamente pelo calamistro, produzindo o fio cribelado. O cribelo é uma placa achatada, homóloga à fiandeira anterior mediana das aranhas não-cribeladas, repleta de fúsulas que fiam os minúsculos fios; já o calamistro é uma peça em forma de pente presente no metatarso das pernas IV. Segundo Opell (1999), a adesividade do fio cribelado está diretamente relacionada ao número de fúsulas presentes no cribelo. As orbitelas ecribeladas, por sua vez, possuem como elemento adesivo da armadilha o fio viscoso, cuja adesividade deve-se a um composto aquoso de moléculas orgânicas de baixo peso molecular (Higgins et al., 2001).

O taxon Orbiculariae (figura 1), que atualmente reúne as aranhas construtoras de teia orbicular, é formado pela Superfamília cribelada Deinopoidea e a Superfamília ecribelada Araneoidea. Bond \& Opell (1998) demonstram que Araneoidea é significativamente mais diversificado que Deinopoidea, diferença que surgiu juntamente com a evolução da armadilha com fio de captura viscoso, ou seja, na base da separação entre tais grupos. Uma pista de como pode ter ocorrido a mudança estrutural do fio de captura cribelado para o viscoso surge de estudos de Hawthorn \& Opell (2002 e 2003) que descrevem uma propriedade higroscópica associada, possivelmente, a nódulos presentes no fio cribelado de Uloboridae. De qualquer 
modo, mesmo que esses nódulos higroscópicos sejam realmente correspondentes à estrutura ancestral que deu origem às gotículas viscosas, há ainda que se dar conta da intensa mudança comportamental associada à alteração estrutural do fio de captura.

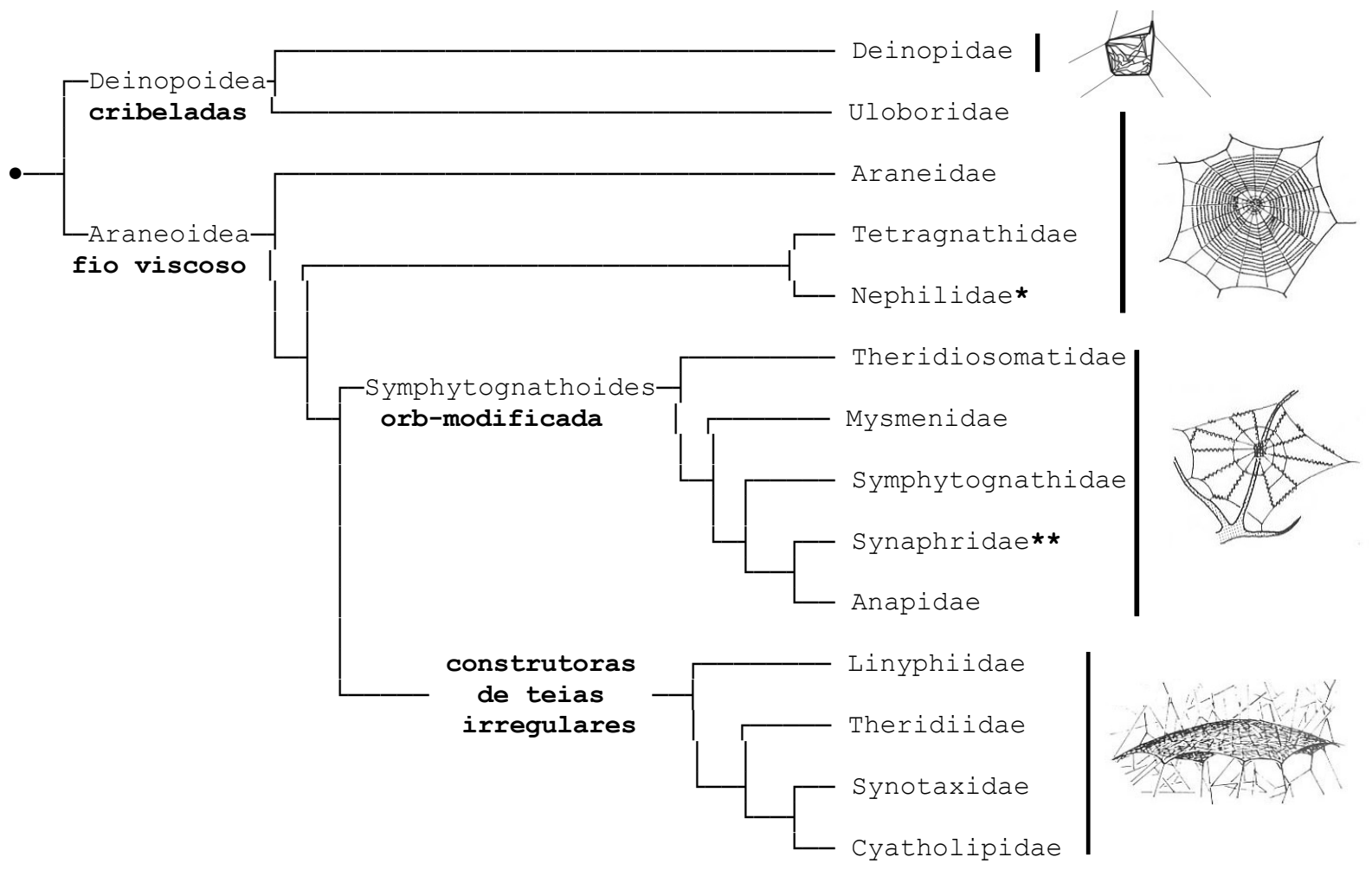

Figura 1. Cladograma das Orbiculariae: grupo de aranhas construtoras de teia orbicular. A teia orbicular é basal e surge entre as aranhas cribeladas. A perda do cribelo ocorre simultaneamente ao surgimento do fio viscoso. Dentro de Araneoidea há ainda a perda do padrão de teia orbicular, parcialmente em Symphytognathoides e, totalmente, nas aranhas construtoras de teias irregulares. Filogenia reproduzida e adaptada de Griswold et al. (1998) e as figuras das teias de Foelix (1996).* atualizado segundo Kuntner (2006). ** atualizado segundo Marusik \& Lehtinen (2003).

Baseadas na comparação de armadilhas orbiculares (tabela 1) de aranhas da família Uloboridae (cribelada) e Araneidae (fio viscoso), diversas explicações foram apresentadas tentando dar conta da maior diversificação de Araneoidea em relação a Deinopoidea: 
1) Eberhard (1989) mostrou que a teia orbicular ecribelada vertical retém a presa por mais tempo do que a mesma na horizontal. Entretanto, o estudo limita-se a colocar a teia de uma Araneidae na posição horizontal. Um experimento complementar foi realizado recentemente por Opell et al. (2006). Neste experimento, os pesquisadores colocaram secções centrais de teias orbiculares cribeladas (Uloborus glomosus) e viscosas (Leucage venusta, Tetragnathidae, e Micrathena gracilis, Araneidae) sem as aranhas, tanto na posição horizontal quanto na vertical, e registraram a quantidade de presas interceptadas. Os resultados mostraram que a teia cribelada de U. glomosus intercepta mais presas na vertical do que na horizontal, posição que ocorre normalmente na natureza. Apesar dos resultados corroborarem a hipótese de que a posição vertical confere vantagem adaptativa às aranhas de teia orbicular, os próprios autores admitem a necessidade de mais testes, com mais espécies. Além disso, Lubin (1986) descreve uma ampla variedade de orientações de teia em Uloboridae e questiona a ênfase na atribuição de orientação principalmente horizontal às teias de aranhas desta família.

2) A maior adesividade do fio viscoso poderia explicar um sucesso de captura maior para Araneoidea (Köhler \& Vollrath, 1995), porém Opell (1996, 1998b) demonstra que não é a adesividade absoluta do fio viscoso a grande inovação evolutiva e, sim, o seu baixo custo de produção mantendo uma adesividade equivalente.

3) Craig e colaboradores (1994) demonstram que a baixa reflexão de UV é derivada na filogenia de Araneoidea e explica a maior diversidade através da menor visibilidade da teia para as presas; entretanto trabalhos da própria autora, entre outros, apresentam a reflexão de UV como uma característica atrativa para insetos (Craig \& Ebert, 1994; Li, et al. 2004; Watanabe, 1999), ou como uma defesa contra predadores (Bruce et al., 2005; Craig \& Freeman, 1991; Zschokke, 2002), entre outras funções (Herberstein, et 
al., 2000). Além disso, a distribuição dos tipos de reflexão de UV na filogenia pode ser reflexo da ocupação de diferentes nichos ao longo da evolução. Por exemplo, cada habitat pode estar associado à ocorrência predominante de um tipo de presa, ou um determinado tipo de predador, que irá ditar a reflexão de UV mais eficiente da armadilha.

4) Köhler \& Vollrath (1995) sugeriram que a superioridade da teia orbicular ecribelada deve-se à maior extensibilidade dos fios de captura, o que permite uma melhor absorção da energia cinética da presa que colide com a teia. Opell \& Bond (2000), entretanto, não encontram diferenças significativas de extensibilidade ao realizar medidas corrigindo o resultado pela massa das espécies de aranha estudadas. Lubin (1986) descreve duas características estruturais da teia cribelada ${ }^{1}$ que permitem uma maior absorção do impacto do que o previsto somente pela extensibilidade do fio de captura. Além disso, a teia vertical de Araneidae é estruturada para interceptar presas que voam em alta velocidade: a espira adesiva com a qual a presa entra em contato primeiramente absorve a energia cinética desta ao esticar e mesmo ao romper-se; com a perda de energia cinética, a presa cai e é retida pelas espiras adesiva logo abaixo. Já para uma teia horizontal de Uloboridae, possuir uma estrutura um pouco mais rígida pode impedir que a presa atravesse totalmente a teia, ficando assim fora do alcance da aranha, tendo em vista que não haveriam espiras logo abaixo para reter a presa. Assim, as diferenças na extensibilidade da espira adesiva da teia orbicular podem corresponder a estruturas de captura adaptadas a modos distintos de interceptação de presas. Essa hipótese é corroborada pelo gênero Cyrtophora, uma Araneidae que possui teias horizontais com uma estrutura relativamente mais rígida como consequência de uma quantidade elevada de raios.

\footnotetext{
1. A junção da espiral adesiva não ocorre em todos os raios, permitindo que esta fique mais frouxa; e os fios cribelados, ao sofrerem estresse físico, são capazes de afastar-se dos fios axiais, mais rígidos.
} 


\section{Uloboridae}

Araneidae

\begin{tabular}{|c|c|c|}
\hline tipo de teia & $\begin{array}{l}\text { orbicular ( } 5 \text { gêneros) } \\
\text { redução ao longo da filogenia }\end{array}$ & orbicular \\
\hline elemento adesivo & fio cribelado & fio viscoso \\
\hline posição da teia & variável & variável - predominantemente vertical \\
\hline reflexão de $U V$ & reflete muita UV & variável \\
\hline extensibilidade & pouca - independente do clima & $\begin{array}{l}\text { muita, maior quanto maior Umidade } \\
\text { Relativa (UR) }\end{array}$ \\
\hline adesividade & $\begin{array}{l}\text { alta - independente do clima } \\
\text { longa duração }\end{array}$ & $\begin{array}{l}\text { alta quando a UR está } \pm 70 \% \text {; abaixo disso } \\
\text { perde adesividade progressivamente; curta } \\
\text { duração }\end{array}$ \\
\hline raios & $\begin{array}{l}\checkmark \text { colocados diretamente no fio de quadro } \\
\text { principal (não há secundário) } \\
\checkmark \text { podem ser primários e secundários }\end{array}$ & $\begin{array}{l}\checkmark \text { colocados no fio de quadro principal e } \\
\text { secundário } \\
\checkmark \text { primários, raramente secundários }\end{array}$ \\
\hline espiral adesiva & $\begin{array}{l}\checkmark \text { espira mais externa é mais irregular e } \\
\text { pode ser depositada em qualquer fio seco } \\
\checkmark \text { junções das espiras/raios não deslizam } \\
\checkmark \text { alguns raios ficam sem junção com } \\
\text { espiras } \\
\checkmark \text { espiras preenchem todo espaço interno } \\
\text { do quadro, com muitas retornos em } Z\end{array}$ & $\begin{array}{l}\checkmark \text { depositada sempre sobre os raios } \\
\checkmark \text { junções das espiras/raios deslizam } \\
\checkmark \text { espiras conectam-se a todos os raios } \\
\text { pelos quais passam } \\
\checkmark \text { espiras preferencialmente em um sentido } \\
\text { concêntrico, com poucos retornos (Z) } \\
\text { causados pela assimetria vertical }\end{array}$ \\
\hline $\begin{array}{l}n^{o} \text { de } \\
\text { gêneros/espécies }\end{array}$ & $\begin{array}{l}18 \text { gêneros } / 263 \text { espécies } \\
\text { Deinopoidea }=320 \text { espécies }\end{array}$ & $\begin{array}{l}166 \text { gêneros } / 2841 \text { espécies } \\
\text { Araneoidea }=11.201 \text { espécies }\end{array}$ \\
\hline microlocal & $\begin{array}{l}\text { variável - geralmente áreas mais } \\
\text { protegidas }\end{array}$ & variável - predominantemente áreas abertas \\
\hline presas & variável & $\begin{array}{l}\text { variável - predominantemente insetos } \\
\text { voadores }\end{array}$ \\
\hline
\end{tabular}

tamanho das espécies sempre relativamente pequenos e pardos; sem muita variação de forma ou cor

grande variedade de tamanho, forma e cor

Tabela 1. Comparação de características de Uloboridae e Araneidae. Informações obtidas em Opell (1979), Eberhard (1980) e Lubin (1986) para Uloboridae, Coddington (1986) para Araneidae e Platnick (2007) para contagem de gênero e espécies. UR = umidade relativa do ar.

Tendo em vista o baixo suporte destas hipóteses explicativas, cabe perguntar se haveriam outros fatores relacionados a essa diversificação tão pronunciada em Araneoidea. Uma abordagem promissora refere-se à tenacidade. Diferenças de tenacidade teriam, como 
conseqüência, diferentes padrões de dispersão das aranhas no ambiente, como resultado das mudanças e permanências das várias espécies de aranhas, cada uma com sua própria estratégia. Uma tenacidade menor poderia levar à ocupação de ambientes mais variados e estar menos vulnerável à diminuição da disponibilidade de presas do que uma estratégia relativamente mais "sedentária". A maior diversificação de Araneoidea poderia ser explicada, então, por uma melhor capacidade de resposta às flutuações de presas, normalmente encontrada no ambiente, possibilitada pela armadilha viscosa de baixo custo.

\subsection{Tenacidade}

Os aracnídeos, primeiros animais a ocuparem o ambiente terrestre, são organismos adaptados à escassez e a grandes flutuações na oferta de presas (Wise, 1993). A resposta rápida e ajustada a essa flutuação é uma adaptação que se espera encontrar em seu repertório comportamental. Sendo animais delimitados pela disponibilidade de recurso energético com o qual regulam seu crescimento (Vollrath, 1985), a deposição de ootecas (Eberhard, 1979), a construção de teia (Pasquet et al., 1994; Sandoval, 1994) e até mesmo a socialidade (Kim, 2000; Rypstra, 1985), o balanço energético para esses organismos é uma questão crítica de sobrevivência e adaptabilidade às mudanças ambientais. Foi pensando nisso que alguns pesquisadores procuraram explorar modelos de forrageamento ótimo com aranhas (Janetos, 1982; Kuno, 1981; Nakata et al., 2003) e, observando padrões de abandono de microlocal, buscaram a regra comportamental subjacente ao padrão de ocupação. Uma tentativa mais recente de estabelecer um modelo de decisão foi realizada por Nakata et al. (2003), usando diferentes regras de tenacidade. Segundo esse modelo, uma vez estabelecida em um microlocal estrutural e climaticamente adequado, a disponibilidade de presas precisa ser suficiente para manter a demanda nutricional da aranha. A diminuição da taxa de captura leva à decisão de abandono, como uma forma de ajuste à alteração das condições do microlocal. 
A ocupação de microlocal é um processo de decisão estratégica em que é avaliada a qualidade do ambiente, e que leva em conta fatores como: suportes físicos para a construção da armadilha; estresse fisiológico, geralmente relacionado à umidade e temperatura; quantidade de presas; freqüência dos danos sofridos pela teia; exposição a predadores; e desenvolvimento, ou seja, mudanças de necessidades referentes ao amadurecimento da aranha (Higgins, 1995; Janetos, 1986; Uetz, 1992; Vollrath, 1985). O estudo da ocupação de microlocais pelas aranhas pode ser abordado de duas maneiras: através das regras de escolha, ou através da permanência/deserção (tenacidade) dos microlocais.

A escolha do microlocal de estabelecimento da teia é de extrema importância para as aranhas, pois dela depende diretamente seu crescimento, sobrevivência e sucesso reprodutivo (Riechert \& Gillespie, 1986). Os estudos de escolha de microlocal investigam os fatores e mecanismos de escolha importantes para o estabelecimento da armadilha. Entretanto, a dificuldade em determinar com exatidão e clareza os fatores envolvidos nessa escolha ativa da aranha por um microlocal específico levaram os pesquisadores a enfatizarem estudos de tenacidade (Janetos, 1986). O estudo de tenacidade se propõe a investigar os padrões de decisão da aranha de permanecer/desertar o microlocal já estabelecido frente às condições ambientais listadas acima (Janetos, 1986). No caso das orbitelas (estudos realizados essencialmente com Araneidae e Tetragnathidae), a dificuldade em obter resultados de escolha ativa pode ser efeito de uma seleção pouco rígida do microlocal, já que a reconstrução diária de uma teia de baixo custo permitiria abandoná-lo mais facilmente quando comparada a teias de aranhas de lençol (Janetos, 1982; Riechert \& Gillespie, 1986).

A existência de suportes com pontos de fixação mínimos para a sustentação da armadilha (Colebourn, 1974; Gunnarsson, 1992; Janetos, 1986; Jocqué, 1981; Robinson, 1981) é essencial para a escolha do microlocal. Sendo assim, a aranha construtora de teia orbicular, ao encontrar um local com suportes mínimos para estabelecer sua teia e ao perceber a presença de presas pela vibração do ar (Pasquet et al., 1994), constrói sua teia para, a partir 
daí, decidir permanecer ou abandonar o microlocal. Um fato que apóia a idéia de uma importância secundária de condições como umidade e temperatura é a existência de estratégias comportamentais e fisiológicas para tolerar condições ambientais subótimas, e até mesmo adversas (Pulz, 1987; Riechert \& Tracy, 1975). Apesar da generalização acima, algumas aranhas mostram grande dependência de acesso a corpos d'água com o risco de morte por desidratação se estes lhe forem negados (Gillespie, 1987), ou de perda de funcionalidade de uma teia altamente higroscópica (Gonzaga et al., 2006).

O dano à armadilha também é um dos fatores que favorecem o abandono, já que o custo de construção de uma nova armadilha no mesmo local, com o risco de perdê-la novamente, pode ser maior do que o custo de mudar de microlocal (Gillespie \& Caraco, 1987). A insistência ou não em permanecer no mesmo local depende diretamente do custo de produção da armadilha: com a teia totalmente destruída, a aranha que possui um alto investimento na armadilha (por exemplo, uloborídeos - Eberhard, 1971) muda de microlocal de imediato, enquanto a aranha que constrói sua teia diariamente (por exemplo, araneídeos), constrói outra no mesmo microlocal mais algumas vezes (Craig, 1989).

O investimento na construção de teia é um fator importante que influencia o processo decisório como um todo, e soma-se ao risco de estabelecimento em um novo microlocal desfavorável. O efeito desse investimento resulta em um comportamento de ocupação de microhabitat mais tenaz nas aranhas de lençol quando comparado às aranhas construtoras de armadilhas orbiculares (Janetos, 1986; Riechert \& Gillespie, 1986). Taxas elevadas de tenacidade também ocorrem em aranhas de deserto que estão sujeitas a estresse fisiológico extremo (Riechert \& Gillespie, 1986; Henschel \& Lubin, 1997). Ou seja, tenacidades maiores geralmente estão ligadas a algum tipo de custo energético, ou de sobrevivência da aranha.

Torna-se interessante, então, verificar comparativamente as diferentes tenacidades de Uloboridae e Araneidae (tabela 1), já que essas duas famílias possuem representantes com armadilhas similares em estrutura (orbicular), mas com diferentes custos de construção (fio 
cribelado versus viscoso). Indícios de que o fio cribelado tem um custo maior vêm: a) do tempo maior de construção da teia - cerca de 3,5 horas em Uloboridae e cerca de 30 minutos em Araneidae (Lubin, 1986; Zschokke \& Vollrath, 1995a,b); b) da construção do fio cribelado com a intensa movimentação das pernas IV (Eberhard, 1988) enquanto o fio viscoso é construído a partir da simples locomoção da aranha pelos raios (Peakall \& Witt, 1976); e c) da menor taxa de reciclagem da teia cribelada, quando comparada a Araneidae (Lubin, 1986, Opell, 1998b). Outra medida de custo que poderia ajudar na compreensão de semelhanças e diferenças desses dois tipos de teia orbicular vêm de estudos de metabolismo energético. Porém, não há trabalhos sobre metabolismo referente a Uloboridae (Lubin, 1986), e tendo em vista as diferenças apontadas acima, as medidas de gasto energético (consumo de oxigênio) durante a construção da teia (Peakall \& Witt, 1976) e as extrapolações feitas para Araneidae (Olive, 1981; Prestwich, 1977) não são aplicáveis a Uloboridae.

Uma baixa tenacidade, como é esperado para Araneidae devido ao menor custo de construção proporcionado pela composição do fio adesivo (cerca de $80 \%$ do volume é composto por água, enquanto todo o fio cribelado é composto inteiramente por proteína Opell, 1998a), e pela reciclagem diária da teia (araneídeos reciclam sua teia com maior frequência do que uloborídeos - Lubin, 1986; Opell, 1998b) teriam como conseqüência a ocupação de microlocais mais variados em relação ao que é esperado para Uloboridae. Colocase então em questão o efeito ampliado de uma mudança estrutural da teia (surgimento do fio viscoso) nas estratégias de ocupação do ambiente. Uma tenacidade mais lábil (e uma escolha de microlocal menos rígida), pode ter levado Araneidae a uma maior diversificação de ocupação de microlocais. Para começar a explorar esta questão é fundamental verificar se realmente existem diferenças na tenacidade e investimento entre orbitelas cribeladas e ecribeladas, e esse é o principal objetivo desta pesquisa. 


\section{Material \& Métodos}

O presente trabalho pretende testar a hipótese de que a mudança estrutural da teia orbicular dada pelo surgimento do fio viscoso, levou a alterações na tenacidade e no investimento em seda nas orbitelas. A flutuação de presas que ocorre na natureza foram simuladas por períodos de diminuição e ausência na oferta de presas.

As famílias que ainda possuem o padrão de teia orbicular estão na base de Orbiculariae. Todas as espécies de orbitelas cribeladas estão na família Uloboridae (5 dentre 18 gêneros que compõe a família) e as orbitelas ecribeladas estão na família Araneidae, Tetragnathidae e Nephilidae (figura 1). Dentre as famílias ecribeladas, Araneidae foi escolhida devido à sua posição mais basal e próxima de Uloboridae. O segundo critério usado foi a escolha de espécies de tamanhos semelhantes. Este cuidado diminui a necessidade de correções e considerações alométricas. O terceiro cuidado com a escolha das espécies estudadas foi a seleção de representantes que não possuíam uma sazonalidade muito marcada (p.e. ciclo de vida de um ano) que adicionaria o fator idade e período de vida nas análises. As duas espécies escolhidas ocorrem o ano todo nos locais em que foram coletadas.

As duas espécies que preencheram os requisitos foram: a aranha cribelada Zosis geniculata (Olivier, 1789) e a ecribelada (fio viscoso) Metazygia rogenhoferi (Keyserling, 1878). O tamanho da tpl (tíbia+patela) de Metazygia rogenhoferi variou entre $2,4 \mathrm{~mm}$ e $3,3 \mathrm{~mm}$ (média $=2,9 \pm 0,3 \mathrm{~mm}, \mathrm{~N}=39)$ e de Zosis geniculata variou entre $3,2 \mathrm{~mm}$ e 4,6mm (média $=$ $3,7 \pm 0,4 \mathrm{~mm}, \mathrm{~N}=46$ ). Foram usadas apenas fêmeas adultas, identificadas pela presença do epígino, com o intuito de diminuir o efeito do desenvolvimento na decisão de abandono (Higgins, 1995; Janetos, 1986; Lubin et al., 1993; Uetz, 1992; Vollrath, 1985). Não foram usados machos, pois, após a última muda, estes tendem a não construir mais teias e a dispersar à procura das fêmeas. 
Zosis geniculata (Olivier, 1789): espécie abundante nas construções humanas das regiões tropicais, foram encontradas próximas às lâmpadas do estacionamento do Shopping Center Eldorado, cidade de São Paulo. Sendo uma espécie sinantrópica fácil de coletar e manter, a literatura é uma ampla base de informação (Bruce et al., 2005; Jackson et al., 2002; Lubin, 1986; Opell, 1979; Opell \& Eberhard, 1984; Tarsitano et al., 2000; Zschokke \& Vollrath, 1995b).

Metazygia rogenhoferi (Keyserling, 1878): espécie pertencente à família Araneidae, abundantemente encontrada na Represa Guarapiranga, Parelheiros, cidade de São Paulo. Essa região encontra-se, atualmente, cercada pelo acelerado crescimento da Grande São Paulo e, apesar do grande efeito antrópico que disso resulta, ainda apresenta alguns fragmentos de mata secundária. As coletas foram realizadas através de inspeção visual noturna, período em que as aranhas estão ativas e as teias bem visíveis em campo.

\subsection{Condições de Laboratório}

As aranhas foram mantidas em caixas-suporte de acrílico com tampas de vidro (figura 2), acondicionadas em uma sala de período invertido (12 horas de claro / 12 horas de escuro) com pouca variabilidade de temperatura $\left(24^{\circ} \mathrm{C}\right.$ a $\left.26^{\circ} \mathrm{C}\right)$ e umidade relativa do ar $(76 \%$ a $81 \%$ UR). Optou-se pelo ambiente de laboratório como forma de restringir os fatores que afetam o abandono do microlocal, como dano à teia e presença de predadores (Janetos, 1986). 


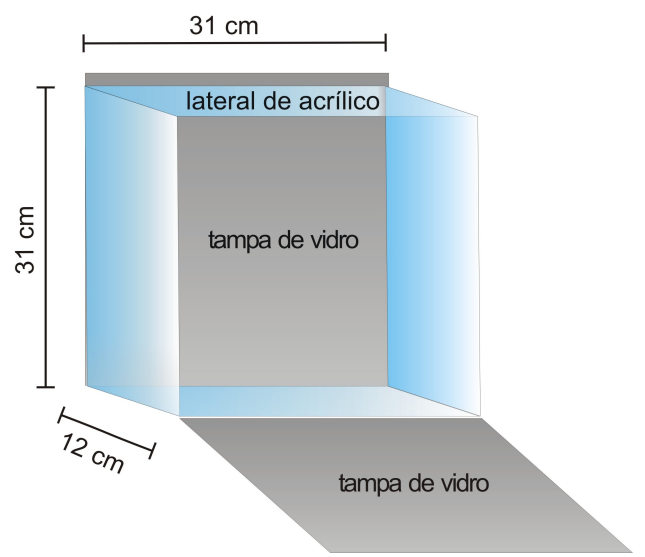

Figura 2. Caixas-suporte de acrílico (espessura 0,5cm) e tampas de vidro usadas nos experimentos. As tampas foram retiradas no início do experimento.

\subsection{Alimentação}

Como forma de diminuir possíveis efeitos de diferenças na composição da dieta na tenacidade fez-se uso de ninfas de grilos da mesma espécie (Grillus sp.) de diferentes idades e tamanhos. Experimentos-piloto prévios indicaram que, mesmo uma alimentação diária com grilos recém-nascidos (tamanho equivalente a de uma mosca-de-frutas, peso médio = $0,88 \pm 0,50 \mathrm{mg}, \mathrm{N}=10$ ), resultava em aranhas superalimentadas e que não condiziam com a situação de diminuição de presas desejada. Desse modo, o intervalo de alimentações a cada quatro dias foi definido. A única diferença entre a alimentação regular (grilos de 3 semanas) e a alimentação reduzida (grilo recém-nascido) era o tamanho do grilo oferecido (figura 3).

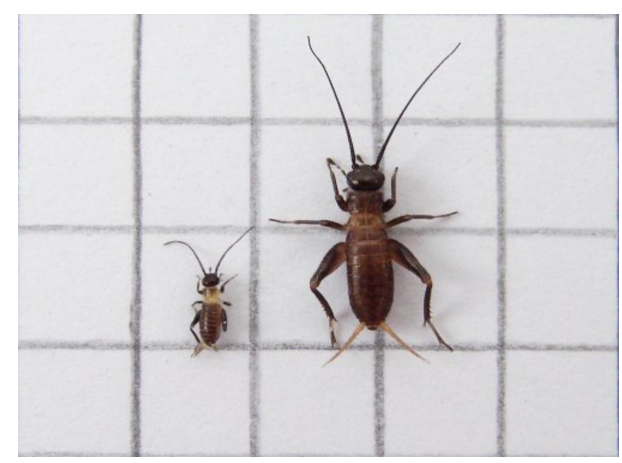

Figura 3. Grilos ofertados às aranhas como presas. À esquerda está o grilo recém-nascido, à direita está o grilo de 3 semanas. Cada quadrado possui $0,5 \mathrm{~cm}$ de lado. 


\subsection{Fase de adaptação ao laboratório}

Logo após a construção da primeira teia no laboratório, as aranhas foram alimentadas, marcadas com tinta hidrossolúvel atóxica e devolvidas às suas teias. As caixas-suporte também foram marcadas com a cor correspondente à aranha residente. A partir de então, as aranhas foram mantidas fechadas nas caixas-suporte dentro da sala de período invertido. A sala de período invertido agilizou a tomada de dados ao permitir a manipulação das aranhas (fotos e medições) no período de claro da sala e as alimentações no período de escuro, quando as orbitelas estão mais ativas, sem precisar aguardar o anoitecer natural.

A fase de adaptação ao ambiente de laboratório durou pelo menos vinte dias após a construção da primeira teia. Nessa fase as aranhas foram alimentadas a cada quatro dias com um grilo de três semanas (figura 3, peso médio $=7,23 \pm 0,50 \mathrm{mg}, \mathrm{N}=10$ ), tamanho mais próximo do corpo (cefalotórax+opistossoma) das aranhas testadas. Esse regime alimentar foi suficiente para manter as aranhas superalimentadas até o início do experimento. Esse alto grau de saciedade foi reconhecido através dos restos cada vez maiores dos grilos deixados e pelo tamanho do abdômen das aranhas (figura $4 \mathrm{c}$ e d). Esta fase terminou quando as aranhas passaram a construir teias regularmente e tinham sido alimentadas pelo menos 5 vezes com grilos de mesmo tamanho (3 semanas de vida).

Esta fase foi importante, também, para triar as aranhas que vieram do campo, principalmente $M$. rogenhoferi. Esta aranha parece intensamente parasitada por nematóides e fungos (cerca de metade das aranhas coletadas morreram com o abdômen fungado ou com nematóides, ou ainda, sem causa visível, figura 5), enquanto Z. geniculata, não apresentou morte por parasitose. A alta incidência de parasitas em M. rogenhoferi, principalmente no caso de fungos, pode estar relacionada à ocupação de regiões próximas a corpos d'água (Gonzaga et al., 2006). As aranhas parasitadas morreram logo após a coleta, e no decorrer da primeira semana no laboratório. Mortes após esse período não foram registrados. 

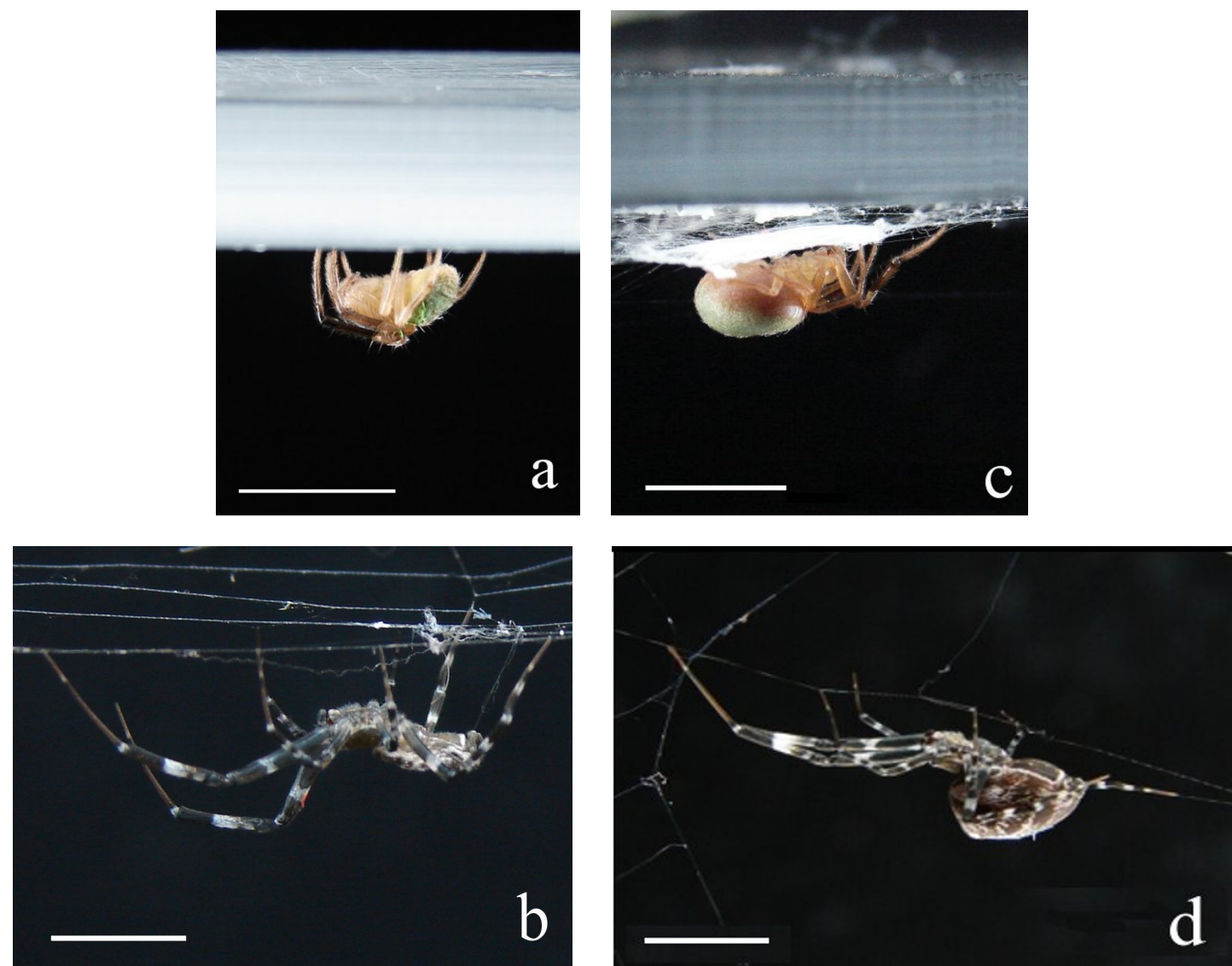

Figura 4. Fotos de M. rogenhoferi (a) e Z. geniculata (b) mostrando o abdômen muito reduzido devido à falta de alimentação e de $M$. rogenhoferi (c) e Z. geniculata (d) alimentadas regularmente. Escalas de $0,5 \mathrm{~cm}$.
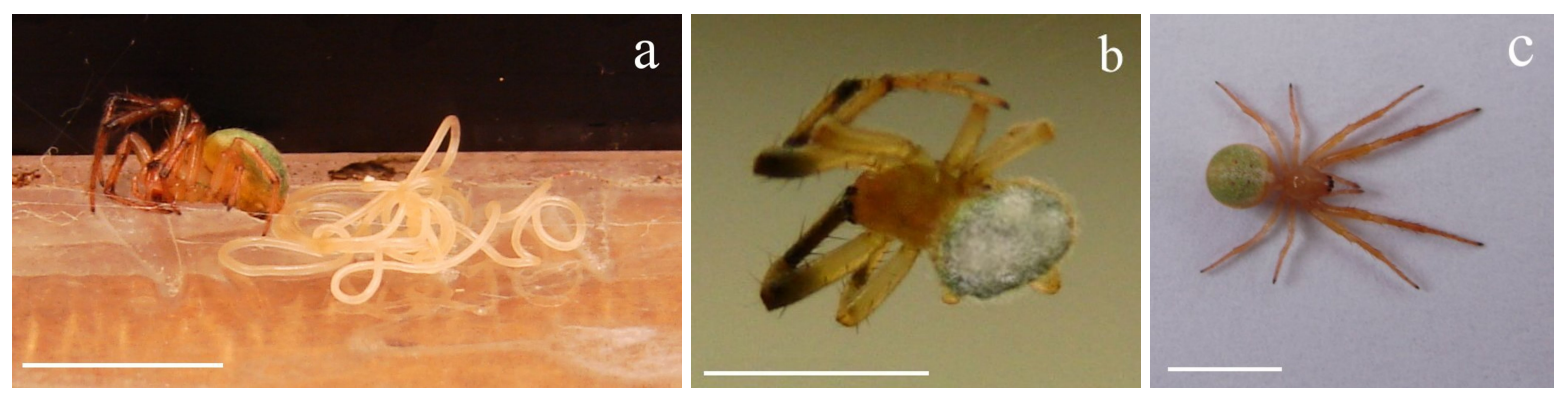

Figura 5. M. rogenhoferi encontradas mortas na fase de adaptação: a) no fundo da caixa-suporte morta pela saída de nematóide parasita do abdômen, b) com abdômen intensamente fungado; esse estado era alcançado no intervalo de apenas um dia, c) morta sem motivo aparente. Escalas de $0,5 \mathrm{~cm}$. 


\subsection{Procedimento Experimental}

O experimento começou após o término da fase de adaptação quando a última aranha a construir sua primeira teia foi alimentada 5 vezes com grilos de 3 semanas de vida. No dia da 6 a alimentação dessa aranha, as aranhas foram alimentadas com um grilo de 3 semanas e a tampa das caixas removidas. Os parâmetros medidos a partir desse momento foram:

1. Medida de tenacidade. Foi considerada no presente trabalho como o total de dias desde o início do experimento até o dia de abandono do microlocal. Foi considerada como abandono de microlocal a simples ausência da aranha em sua respectiva caixa-suporte.

2. Parâmetros da teia. A mudança na dieta das aranhas pode provocar alterações no tamanho e na estrutura da teia (Sherman, 1994). Foram medidas diariamente: a) o comprimento da espiral adesiva a cada reconstrução, b) a área reconstruída, c) o tamanho da teia, d) a densidade de fios, e e) freqüência de reconstruções das teias. Comparações antes e depois da mudança de dieta foram realizadas. O programa gratuito UTHSCSA Image Tool 3.0 para Windows permite a medição direta do comprimento da espiral adesiva a partir da seqüência de fotos digitais obtidas de cada teia. As fotos digitais das teias reconstruídas foram feitas com uma câmera Sony DSC-H1 (5.1 mega pixels). Cada foto foi comparada com a foto da reconstrução imediatamente anterior para eliminar possíveis medidas repetidas da mesma teia. A comparação consistia em analisar a disposição das espiras, dos raios e, principalmente, da região central da teia, área sempre afetada pelas reconstruções.

3. Medida de investimento acumulado em espiral adesiva. A partir do somatório dos dados de comprimento da espiral adesiva obtidos a cada reconstrução obteve-se o investimento acumulado em espiral adesiva, por aranha, de cada período experimental (controle e tratamento). 
4. Presença de ootecas. A mudança na dieta das aranhas influencia o investimento e sucesso reprodutivo (Eberhard, 1979; Uetz, 1992; Wise, 1993). Portanto, as ootecas foram contabilizadas para verificar os efeitos da redução progressiva e da ausência de dieta.

\subsection{Experimentos}

\subsubsection{EXPERIMENTO DE REDUÇÃO PROGRESSIVA DA DIETA}

Este primeiro experimento foi planejado com um período controle e dois tratamentos: período de diminuição da dieta (tratamento 1) e período de ausência de alimentação (tratamento 2). Cada espécie de aranha teve um grupo controle $(\mathrm{N}=5)$ e um grupo experimental $(\mathrm{N}=5)$ no qual os tratamentos de redução progressiva da alimentação eram aplicados (tabela 2).

\begin{tabular}{|c|c|c|c|c|}
\hline & & & \\
\hline & & período controle & tratamento 1 & tratamento 2 \\
\hline \multirow{2}{*}{$\begin{array}{l}\text { Metazygia } \\
\text { rogenhoferi }\end{array}$} & $\begin{array}{l}\text { grupo controle } \\
(\mathbf{n}=\mathbf{5})\end{array}$ & $\begin{array}{c}5 x \text { grilos de } 3 \text { semanas } \\
\text { (A) }\end{array}$ & $\begin{array}{l}5 x \text { grilos de } 3 \text { semanas } \\
\text { (B) }\end{array}$ & $5 x$ grilos de 3 semanas \\
\hline & $\begin{array}{l}\text { grupo experimental } \\
(\mathbf{n}=\mathbf{5})\end{array}$ & $\begin{array}{l}5 x \text { grilos de } 3 \text { semanas } \\
\text { (C) }\end{array}$ & $\begin{array}{l}5 x \text { grilos recém-nascidos } \\
\text { (D) }\end{array}$ & sem presas \\
\hline \multirow{2}{*}{$\begin{array}{l}\text { Zosis } \\
\text { geniculata }\end{array}$} & $\begin{array}{l}\text { grupo controle } \\
(\mathbf{n}=5)\end{array}$ & $\begin{array}{l}5 x \text { grilos de } 3 \text { semanas } \\
\text { (E) }\end{array}$ & $\begin{array}{c}5 x \text { grilos de } 3 \text { semanas } \\
\text { (F) }\end{array}$ & $5 x$ grilos de 3 semanas \\
\hline & $\begin{array}{l}\text { grupo experimental } \\
(\mathbf{n}=5)\end{array}$ & $\begin{array}{c}5 x \text { grilos de } 3 \text { semanas } \\
\text { (G) }\end{array}$ & $\begin{array}{c}5 x \text { grilos recém-nascidos } \\
(\mathbf{H})\end{array}$ & sem presas \\
\hline
\end{tabular}

Tabela 2. Alimentação de cada grupo ao longo dos períodos controle e tratamentos do experimento de redução progressiva da dieta. As letras identificam as amostras a serem comparadas nas análises. O período tratamento 2 não foi comparado com os demais devido ao baixo tamanho amostral.

Desta forma, este primeiro experimento foi elaborado com dois tipos de controle: o primeiro (grupo controle versus experimental) para controlar o efeito do tempo (idade) ao longo do experimento; o segundo (período controle versus tratamento) para avaliar o efeito da redução da dieta na tenacidade. Como não houveram diferenças no primeiro controle ao longo dos tratamentos, esse tipo de controle foi abandonado no segundo experimento. 
O período controle, condiciona as aranhas para o recebimento de alimento a uma taxa regular, de modo a ocorrer uma quebra de condicionamento quando a alimentação reduz e cessa no período tratamento. É frente a essa quebra de condicionamento, ou efeito da redução e ausência de presas (Nakata et al., 2003), que se espera ver a reação das aranhas.

As medidas das teias foram feitas diariamente, nos 12 últimos dias do período controle, e nos 12 primeiros dias no período tratamento 1, para realizar as comparações. As comparações com as teias no período tratamento 2 não foi possível devido ao reduzido tamanho amostral (quando deste tratamento, a maior parte dos indivíduos já havia morrido ou abandonado sua teia). A medida de tamanho neste experimento é o diâmetro da teia.

\subsubsection{EXPERIMENTO DE REDUÇÃO ABRUPTA DA DIETA}

Este segundo experimento foi planejado para verificar o efeito mais marcado de abandono de microlocal ao expor a aranha a uma situação mais drástica: a ausência de presas logo após um período de alimentação regular. Após o período controle (5 alimentações com um grilo de três semanas a cada quatro dias), interrompeu-se a alimentação e os dados de reconstrução e tenacidade foram acompanhados. Optou-se, neste experimento, por eliminar os grupos controle visto que eles não diferiram entre si no experimento de redução progressiva da dieta (v. resultados abaixo). Dessa forma, foi realizada uma análise pareada em que se compara o período controle com o período de tratamento, procedimento que possibilitou lidar com uma amostra maior $(\mathrm{N}=20$, para cada espécie). As medidas de investimento acumulado em espiral adesiva e dos outros parâmetros da teia foram tomadas diariamente durante todo o período controle (21 dias) e tratamento (21 dias) para que as comparações entre os dois períodos fossem possíveis. A medida de tamanho da teia neste experimento é a área de captura. 


\subsection{Análises estatísticas}

Todas as análises foram realizadas através do pacote estatístico SPSS 15.0 para Windows.

\subsubsection{Tenacidade}

A tenacidade foi analisada através do procedimento de Kaplan-Meier, para obter as curvas de sobrevivência (probabilidade de permanência ao longo do tempo), e o teste de Breslow (Wilcoxon Generalizado - Motulsky, 1995) para saber se as curvas obtidas são significativamente diferentes. Esses testes fazem parte de um grupo de análises usadas principalmente na área médica e criminalística, que lida diretamente com variáveis não recorrentes no tempo e que possuem valores censurados. Valores censurados provêm de indivíduos da amostra que podem ser acompanhados até um dia antes de abandonar o tratamento sem que ocorra o evento estudado, ou provém de indivíduos em que o evento não ocorre durante todo o período de coleta de dados. Como premissa para uso da análise de sobrevivência temos que os valores censurados decorrentes de abandono do tratamento não podem ter ligação direta com o fenômeno estudado (Motulsky, 1995). Apesar do nome do teste, análise de sobrevivência, este pode ser usado para avaliar outras variáveis além de sobrevivência/morte durante determinado tratamento, desde que se sigam os cuidados descritos acima. Aqui é considerada como variável independente o abandono do microlocal pela aranha, e como dado censurado as mortes ou a não ocorrência de fuga até o final do experimento. O teste de Breslow é o mais conservativo e mostrou-se mais adequado do que o Log-Rank (Mantel-Haenszel) e o Tarone-Ware, pois as curvas de sobrevivência não variam proporcionalmente uma em relação à outra (Gross \& Clark, 1975). 


\subsubsection{InVESTIMENTO ACUMULADO EM ESPIRAL ADESIVA E OS OUtRos PARÂMETROS DA TEIA}

A partir das medidas diárias das teias nos dois experimentos obteve-se a média e o desvio-padrão dos parâmetros. Foram usados testes não-paramétricos. As comparações entre os grupos (controle versus experimental) do experimento de redução progressiva da dieta, e todas as comparações entre as espécies foram feitas através do teste de Mann-Whitney. O teste de Wilcoxon foi aplicado na análise dos dados pareados (Wilcoxon Signed Ranks Test), seqüenciais e dependentes (Fowler et al. 1998), representados pela comparação entre períodos controle e tratamento dos dois experimentos. 


\section{Resultados}

\subsection{Experimento de redução progressiva da dieta}

\subsubsection{Tenacidade}

O grupo experimental de $M$. rogenhoferi não muda a taxa de abandono com a redução progressiva e com a ausência de presas $($ Breslow $=0,09, \mathrm{GL}=1, \mathrm{p}=0,766)$, acompanhando a curva de sobrevivência de seu grupo controle (figura 6).
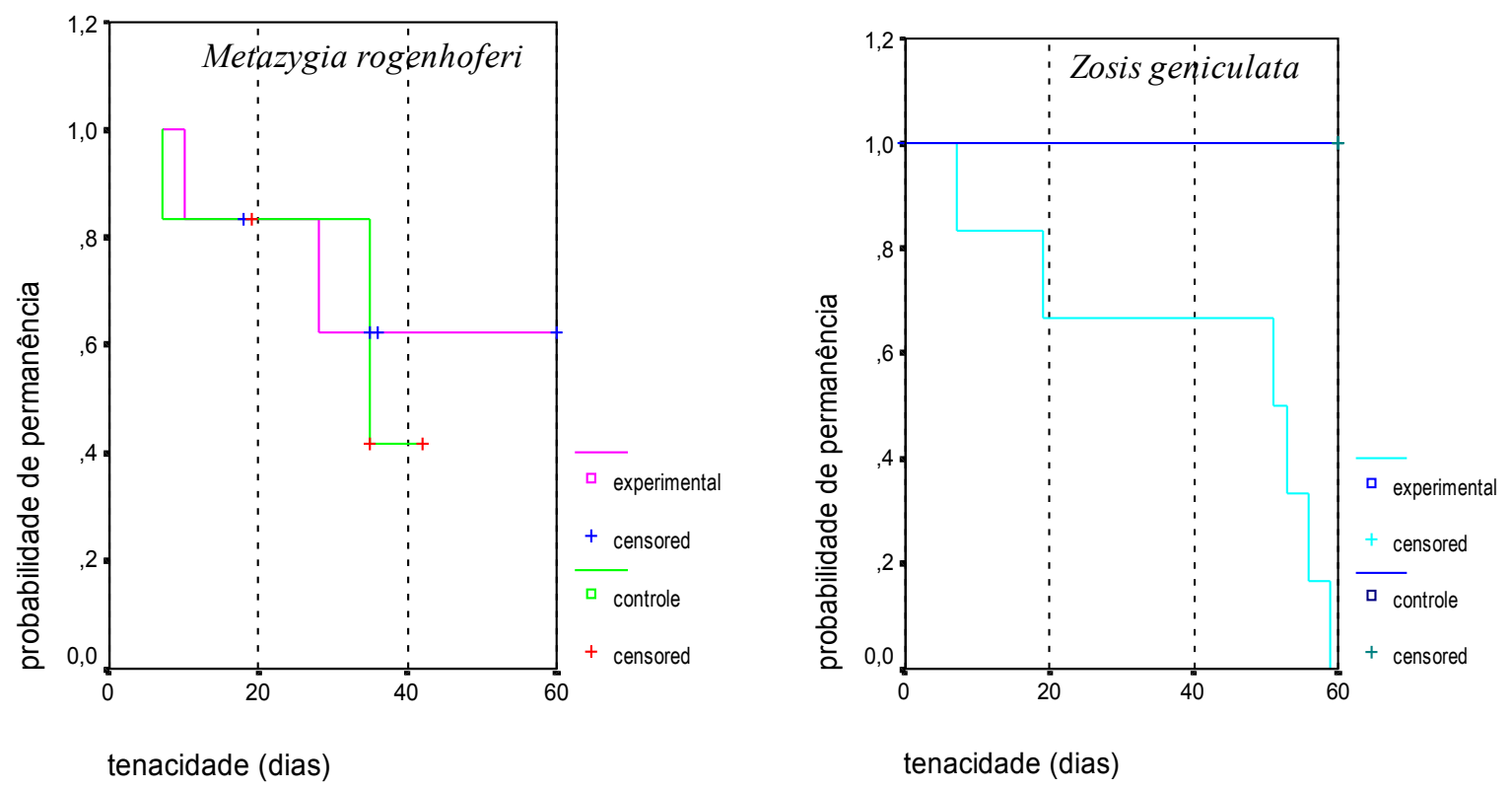

Figura 6. curva de permanência, ou tenacidade, de M. rogenhoferi e Z. geniculata no experimento de redução progressiva da dieta. Foram considerados valores censurados as mortes, e não-fugas após 70 dias experimentais. O primeiro período de 20 dias é o período controle; de 21 a 40 dias é o período de diminuição na oferta de presas; de 41 até 60 dias é o período tratamento (anexo E).

Como primeira reação à diminuição na disponibilidade de presas, Z. geniculata diminui e até cessa por 43 dias (vide anexo E) os abandonos de microlocal, enquanto o grupo controle não abandona o microlocal durante todo o experimento. Assim, o que vemos na figura 6 é um grupo experimental que abandona o microlocal no período controle (um indivíduo), 
pára de abandonar o microlocal no período tratamento 1, e passa a abandonar mais intensamente (4 indivíduos) 19 dias após o início do período tratamento 2. Z. geniculata, difere de $M$. rogenhoferi, pois responde às mudanças no regime alimentar mudando a tenacidade $($ Breslow $=8,570, \mathrm{GL}=1, \mathrm{p}=0,003) . \mathrm{O}$ grupo controle de $Z$. geniculata difere do grupo experimental desde o período controle (figura 6) e o resultado apresentado por esse grupo parece atípico. Entretanto, o pequeno tamanho amostral pede cautela quanto às inferências, do mesmo modo que para M. rogenhoferi.

\subsubsection{INVESTIMENTO EM RECONSTRUÇÃO DE TEIA}

Os resultados (média \pm desvio-padrão) das medições dos parâmetros da teia em cada período do experimento estão sumarizados na tabela a seguir:

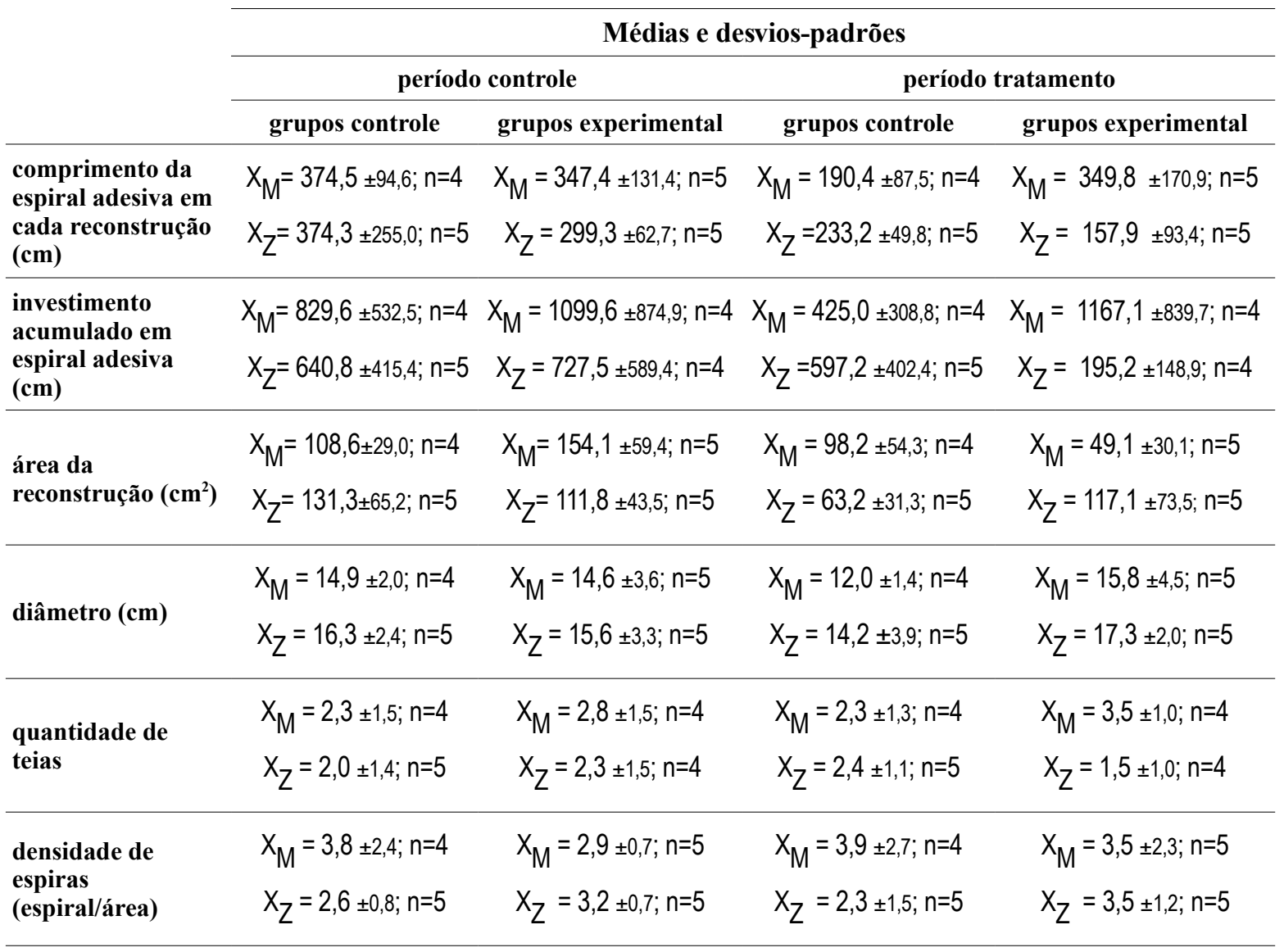

Tabela 3. Médias e desvios-padrões dos grupos no período controle e tratamento. $\mathrm{X}_{\mathrm{M}}$ é a média de M. rogenhoferi e $\mathrm{X}_{\mathrm{Z}}$ é a média de $Z$. geniculata. Cada período possui 12 dias. 
Comparação entre os períodos controle e tratamento. O grupo controle de $M$. rogenhoferi não apresentou nenhuma diferença significativa entre as reconstruções feitas no período controle e no período tratamento 1 , como esperado. $\mathrm{O}$ grupo controle de $Z$. geniculata, apresentou diminuição significativa (tabela 4) da área de teia reconstruída no período tratamento 1 (tabela 3). Esse resultado inesperado no grupo controle pode ser consequência de um grau elevado de saciedade da aranha associado à uma teia que se mantém funcional por um longo tempo: não há necessidade de ampliar a capacidade de captura da teia (p.e. aumentando a densidade de fios, ou aumentando a teia).

\begin{tabular}{|c|c|c|c|}
\hline \multicolumn{4}{|c|}{ Comparação entre as os períodos (controle e tratamento 1) } \\
\hline \multicolumn{2}{|c|}{ M. rogenhoferi } & \multicolumn{2}{|c|}{ Z. geniculata } \\
\hline $\begin{array}{l}\text { grupos controle } \\
(\mathbf{A} / \mathbf{B})\end{array}$ & $\begin{array}{c}\text { grupos experimental } \\
(\mathrm{C} / \mathrm{D})\end{array}$ & $\begin{array}{c}\text { grupos controle } \\
(\mathrm{E} / \mathrm{F})\end{array}$ & $\begin{array}{c}\text { grupos experimental } \\
(\mathbf{G} / \mathbf{H})\end{array}$ \\
\hline$Z=-1,826 ; p=0,068$ & $Z=-0,135 ; p=0,893$ & $Z=-1,214 ; p=0,225$ & $Z=-2,023 ; p=0,043$ \\
\hline$N=4$ & $N=5$ & $N=5$ & $N=5$ \\
\hline$=-1,095 ; p=0,273$ & $Z=0,000 ; p=1,000$ & $Z=-0,405 ; p=0,686$ & $Z=-1,095 ; p=0,273$ \\
\hline$N=4$ & $N=4$ & $N=5$ & $N=5$ \\
\hline
\end{tabular}

\begin{tabular}{|c|c|c|c|c|}
\hline $\begin{array}{l}\text { comprimento da espiral } \\
\text { adesiva em cada } \\
\text { reconstrução }(\mathrm{cm})\end{array}$ & $\begin{array}{c}Z=-1,826 ; p=0,068 \\
N=4\end{array}$ & $\begin{array}{c}Z=-0,135 ; p=0,893 \\
N=5\end{array}$ & $\begin{array}{c}Z=-1,214 ; p=0,225 \\
N=5\end{array}$ & $\begin{array}{c}Z=-2,023 ; p=0,043 \\
N=5\end{array}$ \\
\hline \multirow{2}{*}{$\begin{array}{l}\text { investimento acumulado } \\
\text { em espiral adesiva }(\mathrm{cm})\end{array}$} & $Z=-1,095 ; p=0,273$ & $Z=0,000 ; p=1,000$ & $Z=-0,405 ; p=0,686$ & $Z=-1,095 ; p=0,273$ \\
\hline & $N=4$ & $N=4$ & $N=5$ & $N=5$ \\
\hline \multirow{2}{*}{$\begin{array}{l}\text { área da reconstrução } \\
\left(\mathrm{cm}^{2}\right)\end{array}$} & $Z=-0,365 ; p=0,715$ & $Z=-2,023 ; p=0,043$ & $Z=-2,023 ; p=0,043$ & $Z=-0,135 ; p=0,893$ \\
\hline & $N=4$ & $N=5$ & $N=5$ & $N=5$ \\
\hline \multirow{2}{*}{ diâmetro (cm) } & $Z=-1,826 ; p=0,068$ & $Z=-0,944 ; p=0,345$ & $Z=-0,674 ; p=0,500$ & $Z=-2,023 ; p=0,043$ \\
\hline & $N=4$ & $N=5$ & $N=5$ & $N=5$ \\
\hline \multirow{2}{*}{ quantidade de teias } & $Z=0,000 ; p=1,000$ & $Z=-0,816 ; p=0,414$ & $Z=-1,000 ; p=0,317$ & $Z=-0,816 ; p=0,414$ \\
\hline & $N=4$ & $N=4$ & $N=5$ & $N=4$ \\
\hline \multirow{2}{*}{$\begin{array}{l}\text { densidade de espiras } \\
\text { (espira/área) }\end{array}$} & $Z=-0,365 ; p=0,715$ & $Z=-0,674 ; p=0,500$ & $Z=-0,674 ; p=0,500$ & $Z=-0,405 ; p=0,686$ \\
\hline & $N=4$ & $N=5$ & $N=5$ & $N=5$ \\
\hline
\end{tabular}

Tabela 4. Resultados das comparações dos parâmetros da teia no período controle com o período de diminuição na oferta de presas (Teste de Wilcoxon). Cada período possui 12 dias.

O grupo experimental de $M$. rogenhoferi diminui significativamente (tabela 6) a área de reconstrução frente à redução da dieta. Os demais parâmetros de teia não apresentam diferenças significativas. O grupo experimental de Z. geniculata diminui o comprimento da espiral adesiva de cada reconstrução no período tratamento 1, mas apresenta um aumento no tamanho (diâmetro médio) das teias. 
As poucas mudanças significativas nas teias reconstruídas pelas aranhas dos grupos experimentais no período de tratamento são alterações no sentido de diminuir o gasto em seda, e aumentar a capacidade de captura (aumento no tamanho da teia).

Comparação entre as espécies. No período controle as espécies não mostram diferenças significativas em nenhum dos parâmetros da teia medidos (tabela 3). As comparações entre os grupos controles no período de tratamento também não trazem diferenças significativas entre as espécies (tabela 5). Esse resultado é interessante considerando que se tratam de espécies diferentes, de famílias diferentes, ou seja, teias orbiculares de mesmo tamanho construídas por aranhas de tamanhos semelhantes alimentadas com um bom suprimento de presas investem em comprimento de fio adesivo e nos outros parâmetros da teia de modo semelhante.

\begin{tabular}{|c|c|c|c|c|}
\hline & \multicolumn{4}{|c|}{ Comparação entre as espécies (M. rogenhoferi e $Z$. geniculata) } \\
\hline & \multicolumn{2}{|c|}{ período controle } & \multicolumn{2}{|c|}{ período diminuição da dieta } \\
\hline & $\begin{array}{l}\text { grupos controle } \\
(\mathrm{A} / \mathbf{E})\end{array}$ & $\begin{array}{l}\text { grupos experimental } \\
(\mathbf{C} / \mathbf{G})\end{array}$ & $\begin{array}{c}\text { grupos controle } \\
(\mathrm{B} / \mathrm{F})\end{array}$ & $\begin{array}{l}\text { grupos experimental } \\
(\mathrm{D} / \mathrm{H})\end{array}$ \\
\hline $\begin{array}{l}\text { comprimento da espiral adesiva } \\
\text { em cada reconstrução }(\mathrm{cm})\end{array}$ & $\begin{array}{c}U=8,0 ; p= \\
0,624 \\
N=9\end{array}$ & $\begin{array}{c}U=9,0 ; p=0,465 \\
N=10\end{array}$ & $\begin{array}{c}U=7,0 ; p=0,462 \\
N=9\end{array}$ & $\begin{array}{c}U=3,0 ; p=0,047 \\
N=10\end{array}$ \\
\hline $\begin{array}{l}\text { investimento acumulado em } \\
\text { espiral adesiva }(\mathrm{cm})\end{array}$ & $\begin{array}{c}U=8,0 ; p= \\
0,624 \\
N=9\end{array}$ & $\begin{array}{c}U=6,0 ; p=0,564 \\
N=8\end{array}$ & $\begin{array}{c}U=8,0 ; p=0,624 \\
N=9\end{array}$ & $\begin{array}{c}U<0,0001 ; p=0,021 \\
N=8\end{array}$ \\
\hline área da reconstrução $\left(\mathrm{cm}^{2}\right)$ & $\begin{array}{c}U=9,0 ; p= \\
0,465 \\
N=9\end{array}$ & $\begin{array}{c}U=7,0 ; p=0,251 \\
N=10\end{array}$ & $\begin{array}{c}U=6,0 ; p=0,327 \\
N=9\end{array}$ & $\begin{array}{c}U=6,0 ; p=0,175 \\
N=10\end{array}$ \\
\hline diâmetro (cm) & $\begin{array}{c}U=5,0 ; p= \\
0,221 \\
N=9\end{array}$ & $\begin{array}{c}U=8,0 ; p=0,346 \\
N=10\end{array}$ & $\begin{array}{c}U=4,0 ; p=0,142 \\
N=9\end{array}$ & $\begin{array}{c}U=10,0 ; p=0,602 \\
N=10\end{array}$ \\
\hline quantidade de teias & $\begin{array}{c}U=9,0 ; p= \\
0,786 \\
N=9\end{array}$ & $\begin{array}{c}U=6,5 ; p=0,655 \\
N=8\end{array}$ & $\begin{array}{c}U=9,0 ; p=0,796 \\
N=9\end{array}$ & $\begin{array}{c}U=1,0 ; p=0,034 \\
N=8\end{array}$ \\
\hline $\begin{array}{l}\text { densidade de espiras } \\
\text { (espiral/área) }\end{array}$ & $\begin{array}{c}U=7,0 ; p= \\
0,462 \\
N=9\end{array}$ & $\begin{array}{c}U=9,0 ; p=0,465 \\
N=10\end{array}$ & $\begin{array}{c}U=6,0 ; p=0,327 \\
N=9\end{array}$ & $\begin{array}{c}U=10,0 ; p=0,602 \\
N=10\end{array}$ \\
\hline
\end{tabular}

Tabela 5. Resultados das comparações dos parâmetros da teia entre as espécies. Em negrito estão as diferenças significativas (Teste de Mann-Whitney). Cada período possui 12 dias. 
Quando comparamos os grupos experimentais das duas espécies no período tratamento 1 três variáveis apresentam diferenças significativas (tabelas 5): o comprimento da espiral adesiva em cada reconstrução é maior para M. rogenhoferi do que para Z. geniculata; o investimento acumulado em espiral adesiva de $M$. rogenhoferi é cerca de 3 vezes maior do que o de Z. geniculata; e M. rogenhoferi contrói mais teias. Esse resultado mostra que $M$. rogenhoferi investe mais em espiral adesiva do que $Z$. geniculata no período tratamento 1.

Comparação entre o grupo controle e experimental. Os grupos controle e experimental de ambas as espécies não apresentaram nenhuma diferença significativa (tabela 6).

\begin{tabular}{|c|c|c|c|c|}
\hline & \multicolumn{4}{|c|}{ Comparação entre os grupos (controle e experimental) } \\
\hline & \multicolumn{2}{|c|}{ M. rogenhoferi } & \multicolumn{2}{|c|}{ Z. geniculata } \\
\hline & $\begin{array}{c}\text { período controle } \\
(\mathrm{A} / \mathrm{C})\end{array}$ & $\begin{array}{l}\text { período tratamento } 1 \\
\text { (B/D) }\end{array}$ & $\begin{array}{l}\text { período controle } \\
\text { (E/G) }\end{array}$ & $\begin{array}{l}\text { período tratamento } 1 \\
\qquad(\mathbf{F} / \mathbf{H})\end{array}$ \\
\hline $\begin{array}{l}\text { comprimento da espiral } \\
\text { adesiva em cada reconstrução } \\
\text { (cm) }\end{array}$ & $\begin{array}{c}U=10,0 ; p= \\
1,000 \\
N=9\end{array}$ & $\begin{array}{c}U=4,0 ; p=0,146 \\
N=9\end{array}$ & $\begin{array}{c}U=12,0 ; p=0,917 \\
N=10\end{array}$ & $\begin{array}{c}U=6,0 ; p=0,175 \\
N=10\end{array}$ \\
\hline $\begin{array}{l}\text { investimento acumulado em } \\
\text { espiral adesiva }(\mathrm{cm})\end{array}$ & $\begin{array}{c}U=6,0 ; p=0,564 \\
N=8\end{array}$ & $\begin{array}{c}U=3,0 ; p=0,149 \\
N=8\end{array}$ & $\begin{array}{c}U=9,0 ; p=0,806 \\
N=9\end{array}$ & $\begin{array}{c}U=3,0 ; p=0,086 \\
N=9\end{array}$ \\
\hline área da reconstrução $\left(\mathrm{cm}^{2}\right)$ & $\begin{array}{c}U=4,0 ; p=0,142 \\
N=9\end{array}$ & $\begin{array}{c}U=4,0 ; p=0,142 \\
N=9\end{array}$ & $\begin{array}{c}U=10,0 ; p=0,602 \\
N=10\end{array}$ & $\begin{array}{c}U=7,0 ; p=0,251 \\
N=10\end{array}$ \\
\hline diâmetro (cm) & $\begin{array}{c}U=10,0 ; p= \\
1,000 \\
N=9\end{array}$ & $\begin{array}{c}U=5,0 ; p=0,221 \\
N=9\end{array}$ & $\begin{array}{c}U=11,0 ; p=0,754 \\
N=10\end{array}$ & $\begin{array}{c}U=8,0 ; p=0,347 \\
N=10\end{array}$ \\
\hline quantidade de teias & $\begin{array}{c}U=6,5 ; p=0,655 \\
N=8\end{array}$ & $\begin{array}{c}U=3,5 ; p=0,155 \\
N=8\end{array}$ & $\begin{array}{c}U=9,0 ; p=0,786 \\
N=9\end{array}$ & $\begin{array}{c}U=5,0 ; p=0,197 \\
N=9\end{array}$ \\
\hline $\begin{array}{l}\text { densidade de espiras } \\
\text { (espiral/área) }\end{array}$ & $\begin{array}{c}U=8,0 ; p=0,624 \\
N=9\end{array}$ & $\begin{array}{c}U=8,0 ; p=0,624 \\
N=9\end{array}$ & $\begin{array}{c}U=6,0 ; p=0,175 \\
N=10\end{array}$ & $\begin{array}{c}U=7,0 ; p=0,251 \\
N=10\end{array}$ \\
\hline
\end{tabular}

Tabela 6. Resultados das comparações dos parâmetros da teia entre os grupos (Teste de MannWhitney). Cada período possui 12 dias. 


\subsection{Experimento de redução abrupta da dieta}

\subsubsection{TenACIDADE}

Mortalidade. A diminuição na quantidade de aranhas ao longo do experimento de redução abrupta da dieta deve-se a dois eventos: fugas (abandono de microlocal) e mortes (anexo F). Ao final do experimento observa-se quantidade semelhante de mortalidade e fugas para ambas as espécies: 13 fugas e 7 mortes para M. rogenhoferi, e 14 fugas e 6 mortes para Z. geniculata. Entretanto, uma análise mais detalhada revela que as taxas de mortalidade e fuga, ao longo dos 100 dias de experimento, variam entre as duas espécies. Observando-se a taxa de mortalidade de M. rogenhoferi, a taxa constante e a falta de indício de parasitas (figura 5a e 5b) e de fome (figura 4) indicam que as mortes, para esta aranha, estão desassociadas do tratamento.

A mortalidade de Z. geniculata intensifica-se com o avançar do período sem alimentação, consequência esperada como decorrência da ausência de presas por um período prolongado. As mortes em Z. geniculata começam a ocorrer depois de 11 dias sem alimentação e a taxa intensifica-se no final do experimento a partir de 23 dias sem alimentação (anexo F). O abdômen reduzido em relação ao período controle reforça a idéia de que essas mortes estão associadas à fome (figura 4b) decorrentes do longo período sem alimentação. A última aranha morreu 100 dias após o início do experimento, 79 dias sem ser alimentada e sem fugir do microlocal, mas não estava magra (figura 4d) como seria esperado após tanto tempo sem capturar presas. Provavelmente essa aranha deixou de colocar sua última ooteca e o tamanho do abdômen pode ser reflexo disso.

Fugas. No geral, tanto Z. geniculata quanto M. rogenhoferi abandonaram seus respectivos microlocais em proporções semelhantes (14 e 13 abandonos, respectivamente) ao final do experimento $($ Breslow $=3,370, \mathrm{GL}=1, \mathrm{p}=0,066, \mathrm{~N}=40$ ). A última fuga de Metazygia ocorre no $74^{\circ}$ dia experimental, 57 dias sem alimentação, e a última fuga de Zosis ocorreu no $92^{\circ}$ dia experimental, 75 dias sem alimentação. 
Ao observar a figura 7 percebemos que o perfil de fugas de $M$. rogenhoferi parece indiferente à ausência de capturas no período de tratamento, permanecendo constante até o fim do experimento. Z. geniculata apresenta um perfil de fugas semelhante ao visto no grupo experimental do experimento 1 , mesmo que neste último a redução na dieta tenha sido mais gradual: há uma taxa de fugas no período controle ( 4 fugas, $\mathrm{N}=20$ ) que praticamente cessa por um longo período sem fugas (cerca de 27 dias com somente uma fuga nesse período, $\mathrm{N}=$ 16) seguida por fugas concentradas em 10 dias ( 8 fugas, $\mathrm{N}=12$ ) no período de tratamento. $\mathrm{O}$ teste comparando as curvas de sobrevivência das duas espécies (figura 7), obtida pelo procedimento de Kaplan-Meier, no período tratamento mostra que há diferença significativa (Breslow $=4,956, \mathrm{p}=0,026, \mathrm{~N}=27$ ) entre as espécies no primeiro mês de redução abrupta da dieta (até $49^{\circ}$ dia experimental), mostrando Z. geniculata mais tenaz do que $M$. rogenhoferi

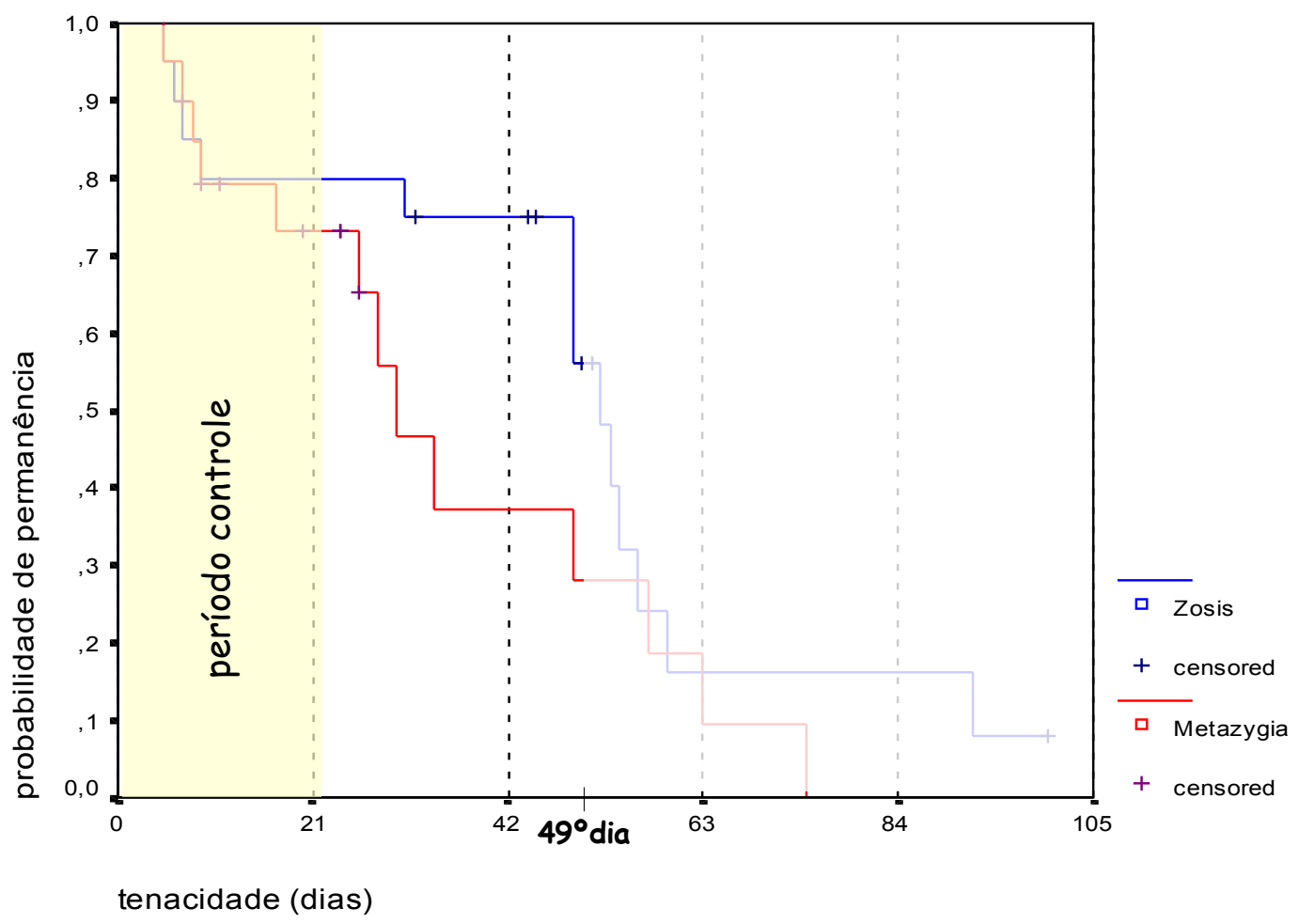

Figura 7. Curva de sobrevivência de $M$. rogenhoferi e $Z$. geniculata no experimento de redução abrupta da dieta. Foram considerados valores censurados os indivíduos que morrem antes do fim do experimento. A área mais clara, a partir do $49^{\circ}$ dia, mostra o período tratamento em que outros fatores não podem ser comparados estatisticamente. 
(figura 7). A possibilidade de efeitos mais marcados da fome a partir do $49^{\circ}$ dia tornam inadequadas as comparações e conclusões no período final do experimento ( $50^{\circ}$ dia até fuga das últimas aranhas no $100^{\circ}$ dia), já que uma das premissas para a análise de sobrevivência (v. métodos) é justamente que os valores censurados (mortes) não podem estar associados ao tratamento (fome) requerido para o estudo do fenômeno (tenacidade) a ser analisado.

Esse resultado corrobora os resultados do experimento de redução progressiva da dieta, com exceção do seu grupo controle que não apresenta fugas. Provavelmente, a ausência de fugas do grupo controle do experimento de redução progressiva da dieta reflete o pequeno tamanho amostral.

\subsubsection{INVESTIMENTO EM RECONSTRUÇÃO DE TEIA}

Os resultados das medições dos parâmetros da teia estão sumarizados na tabela 7:

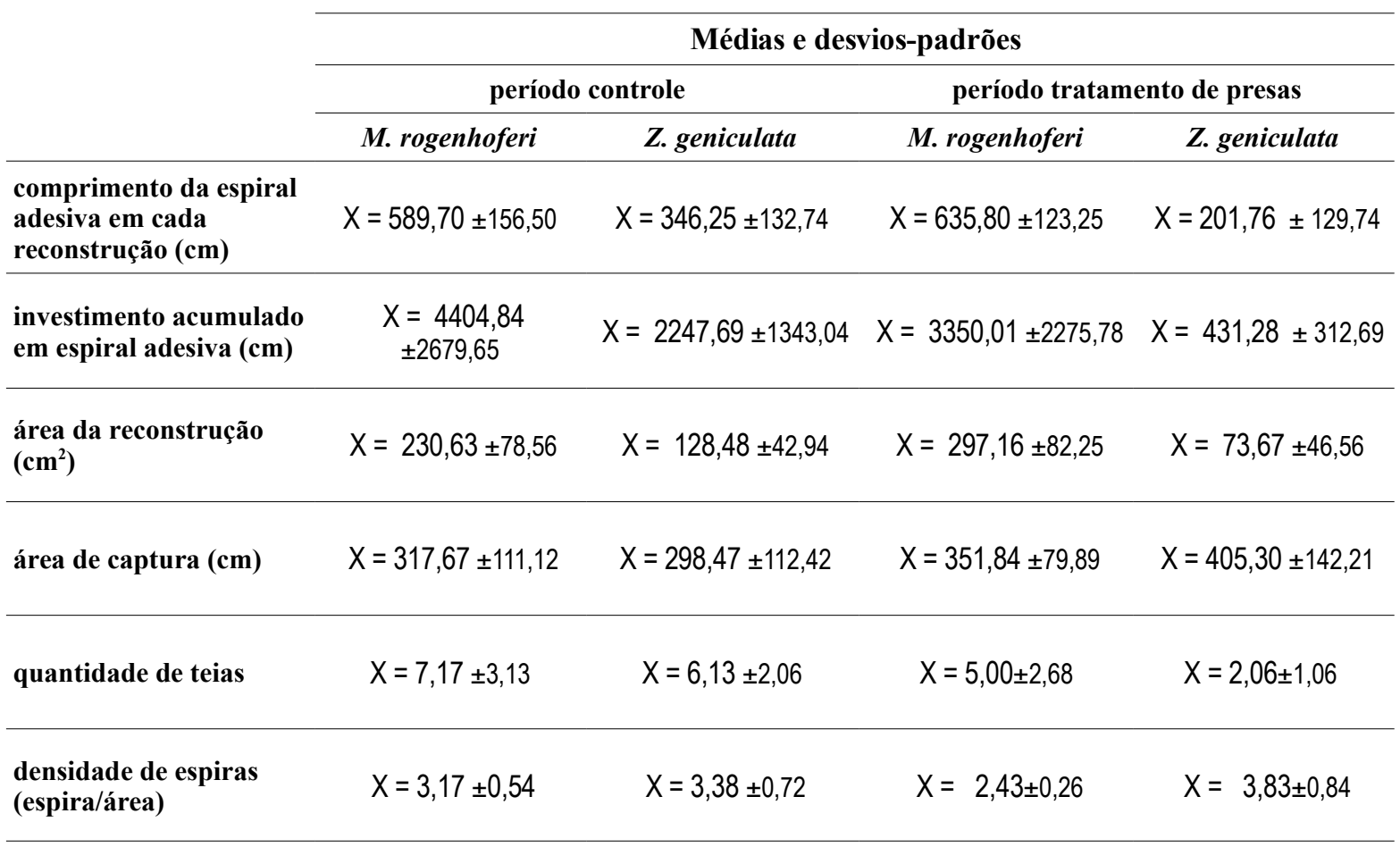

Tabela 7. Médias e desvios-padrões de $M$. rogenhoferi $(\mathrm{n}=6)$ e de $Z$. geniculata $(\mathrm{n}=16)$ no período controle e no período tratamento. Cada período possui 21 dias. 
Comparação entre os períodos controle e tratamento. $M$. rogenhoferi não altera o comprimento da espiral adesiva e a área total de captura de cada reconstrução com a interrupção da alimentação (tabela 8). O investimento acumulado em espiral adesiva, a quantidade de teias e a densidade de espiras das reconstruções diminuem significativamente (tabela 8) no período tratamento. A única variável que aumenta é a área de reconstrução. Estes resultados mostram que $M$. rogenhoferi deixa mais aberta a trama da teia no período de tratamento, aumentando a área renovada com a reconstrução sem construir uma espiral maior. A malha mais aberta da teia pode estar associada à captura de insetos maiores e/ou a uma forma de ampliar a área de captura sem investir em mais espiral adesiva.

\begin{tabular}{|c|c|c|}
\hline & \multicolumn{2}{|c|}{ Comparação entre as os períodos (controle e tratamento) } \\
\hline & M. rogenhoferi $(\mathrm{N}=6)$ & Z. geniculata $(\mathrm{N}=16)$ \\
\hline \multirow{2}{*}{$\begin{array}{l}\text { comprimento da espiral adesiva em cada } \\
\text { reconstrução }(\mathrm{cm})\end{array}$} & $Z=-0,524$ & $Z=-2,534$ \\
\hline & $p=0,600$ & $p=0,011$ \\
\hline \multirow{2}{*}{ investimento acumulado em espiral adesiva (cm) } & $Z=-1,992$ & $Z=-3,464$ \\
\hline & $p=0,046$ & $p=0,001$ \\
\hline \multirow{2}{*}{ área da reconstrução $\left(\mathrm{cm}^{2}\right)$} & $Z=-2,201$ & $Z=-2,689$ \\
\hline & $p=0,028$ & $p=0,007$ \\
\hline \multirow{2}{*}{ área de captura (cm) } & $Z=-1,153$ & $Z=-3,464$ \\
\hline & $p=0,249$ & $p=0,001$ \\
\hline \multirow{2}{*}{ quantidade de teias } & $Z=-2,041$ & $Z=-3,551$ \\
\hline & $p=0,041$ & $p<0,0001$ \\
\hline \multirow{2}{*}{ densidade de espiras (espira/área) } & $Z=-2,201$ & $Z=-1,862$ \\
\hline & $p=0,028$ & $p=0,063$ \\
\hline
\end{tabular}

Tabela 8. Resultados das comparações dos parâmetros da teia entre os períodos (Teste de Wilcoxon Signed Ranks).

Z. geniculata só não altera a densidade de espiras das teias reconstruídas no período tratamento. A área de captura aumenta devido à característica acumulativa das teias de $Z$. geniculata. Todas as demais variáveis diminuem (tabela 7) significativamente (tabela 8), o que reflete uma intensa diminuição no gasto em seda. Diferindo de M. rogenhoferi, Z. geniculata 
opta por diminuir a área e o comprimento da espiral reconstruída, ao invés de diminuir a densidade de fios da reconstrução. A estrutura da teia cribelada (acumulativa com fios cribelados de reconstruções anteriores ainda presentes na teia e que não perdem a adesividade com o tempo, Eberhard, 1980) permite que Z. geniculata adote esse perfil de reconstrução quando a alimentação é interrompida.

Comparação entre as espécies. As diferenças entre as espécies é mais clara nesse experimento devido ao maior tamanho amostral. No geral, M. rogenhoferi apresenta um maior investimento acumulado em espiral adesiva do que Z. geniculata tanto no período controle quanto no período tratamento. A densidade de espiras é a única variável em que $Z$. geniculata apresenta um valor maior do que M. rogenhoferi (tabela 7 e 9).

\begin{tabular}{lcc} 
& Comparação entre as espécies $($ M. rogenhoferi e Z. geniculata) \\
\cline { 2 - 3 } & período controle & período tratamento \\
\hline comprimento da espiral adesiva em cada & $U=10,000$ & $U=1,000$ \\
reconstrução (cm) & $p=0,005$ & $p=0,001$ \\
\hline investimento acumulado em espiral adesiva & $U=19,000$ & $U=1,000$ \\
$(\mathbf{c m})$ & $p=0,033$ & $p=0,001$ \\
\hline área da reconstrução $\left(\mathbf{c m}^{2}\right)$ & $U=9,000$ & $U<0,0001$ \\
& $p=0,004$ & $p<0,0001$ \\
área de captura (cm) & $U=44,000$ & $U=36,000$ \\
& $p=0,768$ & $p=0,376$ \\
quantidade de teias & $U=38,500$ & $U=15,500$ \\
& $p=0,479$ & $p=0,012$ \\
densidade de espiras (espira/área) & $U=38,000$ & $U=4,000$ \\
& $p=0,461$ & $p=0,001$ \\
\hline
\end{tabular}

Tabela 9. Resultados das comparações dos parâmetros da teia entre as espécies (Teste de MannWhitney). $\mathrm{N}=22$ para todos os grupos amostrais.

A frequência das reconstruções (quantidade de teias) e a densidade da malha reconstruída são semelhantes quando a alimentação é regular, mas tornam-se diferentes no período tratamento. A área de captura não apresenta diferença significativa entre as espécies. 


\subsubsection{As OOTECAS de Zosis geNICULATA}

M. rogenhoferi não deposita ootecas regularmente durante os experimentos. A maior parte de suas ootecas foram depositadas no pote de coleta, nas caixas-suporte ainda nos primeiros dias no laboratório, ainda na fase de adaptação, impossibilitando verificar o efeito da variação da taxa de presas sobre esta variável. Z. geniculata, por sua vez, deposita regularmente suas ootecas ao longo do experimento permitindo verificar o efeito de variações na oferta de presas.

No experimento de redução progressiva da dieta, o grupo controle ${ }^{2}$ de $Z$. geniculata deposita cerca de uma ooteca a mais $(U=1,500 ; \mathrm{p}=0,027, \mathrm{~N}=9)$ do que o grupo experimental ${ }^{3}$. As aranhas do grupo controle colocam sua última ooteca cerca de 20 dias depois (dia médio $=45,2 \pm 6,8$ dias depois do início do experimento) que as aranhas que passam por redução na dieta ${ }^{4}$. O resultado mostra que quando a alimentação diminui ou é interrompida a colocação de ootecas pára.

A quantidade de ootecas e o dia em que a última ooteca foi depositada não é diferente entre as $Z$. geniculata que morreram e as que fugiram, no experimento de redução abrupta da dieta, ou seja, a proximidade da morte não altera a taxa que as aranhas colocam suas ootecas.

\footnotetext{
${ }^{2}$. média de ootecas $=3,000 \pm 0,707, \mathrm{~N}=5$

${ }^{3}$. média de ootecas $=1,75 \pm 0,500, \mathrm{~N}=4$

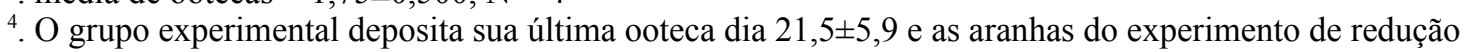
abrupta da dieta deposita sua última ooteca dia $25,8 \pm 5,8$ depois do início do experimento.
} 


\section{DisCuSSÃo}

\subsection{Tenacidade}

Metazygia rogenhoferi apresenta um padrão de fugas constante sem aumentar a quantidade de fugas com a queda progressiva ou abrupta na dieta, diferente de Zosis geniculata que apresenta um aumento de tenacidade seguido de uma redução, disparada pela intensificação da fome atingida no final dos experimentos. Ou seja, Zosis geniculata responde claramente à queda na quantidade de presas, praticamente cessando as fugas em um primeiro momento para, posteriormente, intensificá-las com o aumento da fome. Quando as fugas ocorrem nesta espécie, mesmo com diminuição no investimento em reconstrução, as teias ainda estão funcionais, de modo que a perda da capacidade de captura da teia não é o que motiva o abandono. Esse efeito foi detectado no experimento de redução progressiva da dieta e confirmado no experimento de redução abrupta da dieta. Em comparação com M. rogenhoferi, Z. geniculata apresenta uma estratégia mais conservadora, ajustada às presas, mas ainda assim, diferente do que seria esperado: ao invés de fugir quando percebe uma queda brusca na quantidade de presas disponível e ainda possui um estado fisiológico favorável - saciada, com energia para gastar na exploração de um novo microlocal e na construção de uma nova teia - a aranha opta por ficar até um estado mais intenso de fome. Essa espera estendida é identificada pela ocorrência de fugas e mortes concentradas nos dias finais do experimento (anexo E e F). O padrão de fugas apresentado por Z. geniculata é semelhante ao encontrado em aranhas de teias de alto custo de construção ${ }^{5}$ e identifica-se com a estratégia risco-propensa - se a taxa de capturas está abaixo da demanda nutricional mínima, fixe-se no microlocal - descrita por Gillespie \& Caraco (1987). Dessa forma, não é necessariamente a presença ou ausência de fío viscoso que determina o padrão de tenacidade, mas, talvez, este seja determinado, de maneira

\footnotetext{
${ }^{5}$. Teias de lençol (Janetos, 1982, 1986); teias muito grandes, típicas dos Nephilidae (Vollrath, 1985; Vollrath \& Houston, 1986)
} 
mais geral, por um alto ou baixo custo de construção/manutenção da teia. Em função de apresentar uma teia de alto custo, e uma área de captura que aumenta com o acúmulo de reconstruções novas e antigas, Z. geniculata aproxima-se do padrão de alta tenacidade no comportamento de ocupação de microhabitat, descrito por Janetos (1982) para aranhas de lençol.

Ao construir uma teia de alto custo e que não perde sua funcionalidade, Z. geniculata têm seu comportamento de dispersão moldado para um máximo aproveitamento de suas armadilhas de seda, tornando-se menos lábil na ocupação do habitat. Um dia crítico no processo de ocupação de habitat por Uloboridae deve ser o primeiro em que chega ao microlocal (Janetos, 1982). Seu processo de escolha de microlocal precisa ser mais rigoroso dado a grande dependência da sobrevivência da aranha sobre essa decisão. É possível que a aranha faça pequenas teias de amostragem logo que chega a um microlocal novo, passando a aumentá-la conforme o sucesso de captura de presas se confirme. Gillespie (1981) descreve algo semelhante feito por Amaurobius similis, uma outra espécie de aranha cribelada (não orbitela) e Eberhard (1971) também descreve o aumento da teia de Uloborus diversus devido ao acúmulo de reconstruções sucessivas.

Uma aranha com teia de alto custo pode manter uma elevada taxa de mudança de microlocal, sem ter que investir em construção de teia, usurpando teias de conspecíficos (Bilde et al. 2002) como alternativa. Schuck-Paim (2000) demonstra esse tipo de estratégia para Nephilengys cruentata, uma Nephilidae de teias gigantes e de alto custo. Uma outra forma de avaliar o microlocal antes de estabelecer uma teia de alto custo é usar a presença da teia de conspecíficos como indicador de qualidade (Schuck-Paim \& Alonso, 2001). Porém, esse comportamento não foi registrado no presente experimento.

Já $M$. rogenhoferi, apesar de contrariar o que seria esperado, parece indiferente à dieta, fugindo em uma taxa constante ao longo de todo o experimento. Janetos $(1982,1986)$ sugere que as orbitelas possuem regras simples de abandono de microlocal, e propõe que o 
sucesso de capturas no primeiro dia é decisivo (se houver captura de presas, não há abandono do microlocal e a aranha permanece por mais quatro a cinco dias; se não houver captura de presas no primeiro dia, os abandonos ocorreriam no dia seguinte), porém esse modelo não explica nossos resultados já que não há fuga em massa das caixas-suporte após o quinto dia sem capturar presas $\left(22^{\circ}\right.$ dia experimental). O padrão de abandono observado em $M$. rogenhoferi assemelha-se ao descrito por Gillespie (1987) e Gillespie \& Caraco (1987) para uma outra espécie de aranha de teia orbicular viscosa (Tetragnathidae), que habita ambiente próximo à água e por isso ricos em presas: locais ricos promovem abandono freqüente. $\mathrm{O}$ comportamento de $M$. rogenhoferi seria, então, compatível com um ambiente de grande disponibilidade de presas, o que pode ser realmente o caso na população de origem dessas aranhas, dado elas viverem também próximas a corpos de água.

A redução ou eliminação da oferta de presas nos dois experimentos tem conseqüências diferentes para as duas espécies. A teia de alto custo de Z. geniculata faz com que esta mantenha uma tenacidade alta como reação a uma grande redução na oferta de presas, uma estratégia de máximo aproveitamento do investimento acumulado na teia até aquele momento, enquanto $M$. rogenhoferi, tendo uma teia menos custosa, não altera sua tenacidade com a redução na dieta. Segundo Gillespie \& Caraco (1987), uma estratégia de baixa tenacidade, por isso mais lábil na ocupação de microlocal (estratégia risco-aversa), confere mais vantagem adaptativa do que a estratégia de ocupação mais fixa de microlocal (estratégia risco-propensa).

\subsection{Investimento em reconstrução de teia}

No geral, M. rogenhoferi constrói mais e com maior frequência a espiral adesiva do que Z. geniculata, tanto no período controle quanto no tratamento. Este resultado reflete as diferenças estruturais das duas teias: $Z$. geniculata não precisa renovar a teia pois o fio 
cribelado não perde adesividade, enquanto o fio viscoso perde adesividade progressivamente ao longo do dia em que foi construída. Ou seja, M. rogenhoferi precisa investir mais em reconstruções para manter sua teia funcional. Por outro lado, a teia de baixo custo (v. Introdução) de $M$. rogenhoferi permite que a aranha mantenha uma atividade mais intensa de reconstrução necessária para a manutenção da adesividade dos fios de captura.

Frente à redução progressiva ou abrupta da dieta, a reação de $M$. rogenhoferi é diminuir gasto em seda mantendo a área de captura. Ela faz isso reconstruindo menos teias no período tratamento (aumentando o intervalo entre as reconstruções), diminuindo o comprimento de espiral adesiva, mas aumentando a área de reconstrução (o que resulta em uma densidade menor de espiras adesivas). Os resultados do presente trabalho corroboram parcialmente com os obtidos por Sherman (1994) com Larinioides cornutus, Araneidae. Apesar do autor realizar seus experimentos com a situação inversa do presente trabalho (efeito da suplementação da alimentação), temos como resultados semelhantes a maior área reconstruída no período de menor alimentação. Vollrath \& Samu (1997) também descrevem alterações em parâmetros da teia de uma Araneidae (Araneus diadematus, o aumento das reconstruções com a diminuição na oferta de presas), mas seus resultados precisam ser interpretados dentro de um contexto de desenvolvimento já que trabalham com indivíduos juvenis, requerendo cautela ao serem extrapoladas para aranhas adultas. Mudanças na densidade de fios decorrentes de alterações na dieta das aranhas já foram descritas na literatura (Sandoval, 1994) e a malha de fios mais aberta pode repercutir, também, no tipo de presa que será interceptada pela teia.

Z. geniculata reduz intensamente o gasto em seda em função da redução na dieta, diminuindo tanto o comprimento da espiral adesiva, a área de reconstrução e a quantidade de teias (aumentando o intervalo entre as reconstruções), mas mantendo a densidade de fios e aumentando a área de captura por acúmulo de fragmentos de teias anteriores que permanecem acopladas funcionalmente à estrutura da teia. A teia de alto custo de Z. geniculata apresenta 
um efeito acumulativo de reconstruções que permite que ela aumente a área de captura sem ter que aumentar a quantidade e o tamanho das reconstruções. Este efeito acumulativo também foi observado em Uloborus diversus (Uloboridae) por Eberhard (1971). Parar de reconstruir não parece ser tão crítico para Uloboridae quanto é para Araneidae, dado que o fio de captura cribelado possui uma adesividade que perdura por um longo tempo, o que não ocorre com o fio viscoso (Eberhard, 1980; Peters, 1987). Assim, manter-se no mesmo microlocal representa uma economia de energia em um primeiro momento: Z. geniculata pode diminuir o gasto em reconstrução de teias, pois a teia em que ela investira durante o período em que recebia alimentação regular ainda está funcional. Já a teia viscosa de perde funcionalidade em um curto espaço de tempo, e essas aranhas não podem deixar de reconstruir se quiserem manter a capacidade de retenção de presas (Peters, 1987; Sherman, 1994). As fugas tardias de $Z$. geniculata e as mortes que ocorrem no mesmo período indicam o limite de fome que $Z$. geniculata chega para, aí sim, abandonar sua teia. Essa fuga diparada pela fome ocorre não apenas em uloborídeos, mas também em outras famílias construtoras de teia cribelada, como por exemplo em Stegodyphus lineatus (Eresidae) que nesta situação busca invadir teias de conspecíficos (Bilde et al. 2002).

Uma exceção ocorreu com um único exemplar de $M$. rogenhoferi que não fugiu no experimento de redução progressiva da dieta, apresentando um comportamento parecido ao de Z. geniculata: reconstruções sucessivas cada vez menores (figura 8). Fugindo ao padrão comumente encontrado nas teias das Araneidae, essa aranha deixa restos da teia anterior enquanto reconstrói teias cada vez menores na região central, assemelhando-se às reconstruções de Uloboridae. Entretanto, as reconstruções de Uloboridae não mantém necessariamente o padrão tipicamente orbicular. Esse caso demonstra que até Araneidae, com sua teia de baixo custo, chega em um limite energético em que precisa diminuir sistematicamente sua teia, e que fugir pode ter um custo mais elevado do que ficar (Sherman, 1994). 


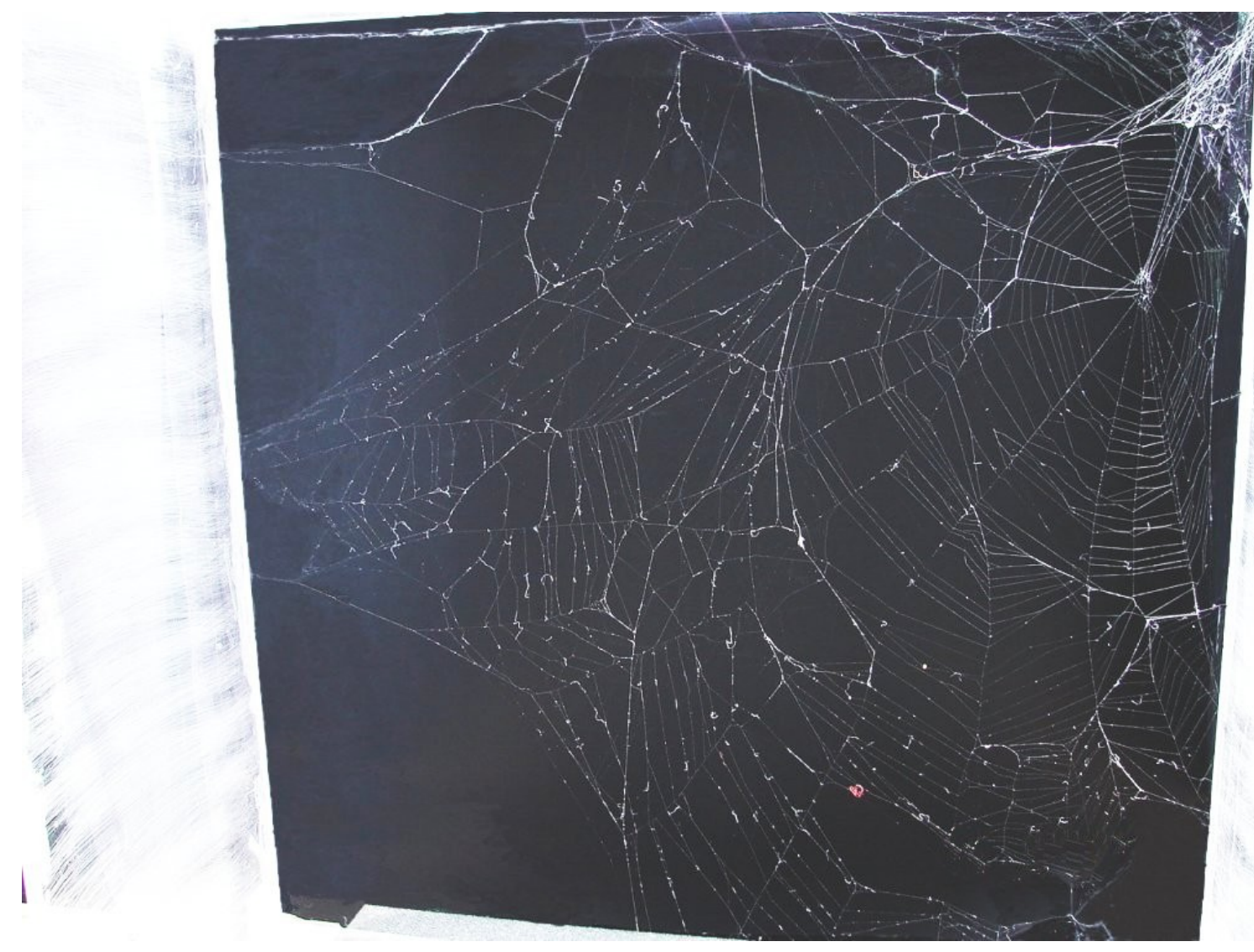

Figura 8. Foto da teia da única $M$. rogenhoferi que não abandonou a caixa-suporte no experimento de redução progressiva da dieta, mostrando reconstruções concêntricas.

\subsection{Ootecas}

Um dos efeitos imediatos da mudança na taxa de presas é a alteração da disponibilidade energética para produzir ootecas (Eberhard, 1979; Sherman, 1994; Wise, 1993). O primeiro parâmetro afetado pela ausência ou diminuição de recurso alimentar é a produção de ootecas por Z. geniculata. As aranhas deixam de colocar ootecas procurando, assim, resguardar a energia que seria gasta na produção de mais ovos para optar, momentaneamente, por sua própria sobrevivência e reconstrução da armadilha responsável pela aquisição de mais alimento. Um exemplo extremo disso ocorreu com os dois últimos exemplares de $Z$. geniculata que sobreviveram ao término do experimento de redução abrupta da dieta (uma fugiu após 71 dias e outra morreu após 79 dias sem alimentação). 


\section{CONSIDERaÇões FINAIS}

A maior parte da literatura sobre orbitelas lida com dados obtidos com espécies de Araneidae, Tetragnathidae e Nephilidae (Craig, 1989; Craig \& Freeman, 1991; Eberhard, 1989; Enders, 1975; Gillespie, 1987; Gillespie \& Caraco, 1987; Greenstone \& Bennett, 1980; Higgins, 1995; Janetos, 1982; Nakata et al., 2003; Pasquet et al., 1994; Post \& Riechert, 1977; Sherman, 1994; Vollrath, 1985; Vollrath \& Samu, 1997; Wise, 1979) que constróem teias de fio viscoso. Nossos resultados apontam para uma diferença na resposta à redução de presas entre orbitelas de fio viscoso e cribelado. Dessa forma, os dados abundantes na literatura citada acima não devem ser considerados como boas estimativas do comportamento de orbitelas em geral. Dados e generalizações com orbitelas de fios cribelados estão presentes em menor quantidade na literatura (Eberhard, 1971; Herberstein et al. 2000; Köhler \& Vollrath, 1995; Opell, 1998a; Uetz et al., 1999), e muitas vezes não são distinguidos de considerações gerais acerca do forrageamento de orbitelas.

A diminuição na quantidade de presas ocorre na natureza, seja por uma sazonalidade, ou por um esgotamento local, reforçando a importância das respostas descritas frente à flutuação da quantidade de presas. O perfil de manutenção da teia de M. rogenhoferi, com fios de pouca duração, com renovações mais freqüentes, leva a uma tenacidade mais baixa do que a mostrada por Z. geniculata, com fios cribelados mais caros e de longa duração. A resposta clara de Z. geniculata - demora para o início das fugas e diminuição intensiva no gasto em seda adesiva - é decorrência de um alto investimento na construção da espiral adesiva, principal diferença estrutural entre as teias orbiculares de fio cribelado e viscoso (Lubin, 1986; Zschokke \& Vollrath, 1995a,b). Esse alto investimento na construção da seda cribelada (v. Capítulo 2) estreita a amplitude das respostas da aranha, que tem de lidar com um comprometimento energético maior e mais intenso. Já M. rogenhoferi apresenta um menor 
comprometimento energético com a armadilha de seda, resultado da reciclagem da teia e da construção de um fio mais econômico (Opell, 1998b). Entretanto, esta espécie também diminui o gasto em seda frente à interrupção da alimentação. A baixa tenacidade observada em $M$. rogenhoferi é característica de um predador menos limitado energeticamente conferida por uma armadilha mais econômica e que pode ser realocada com facilidade (Gillespie \& Caraco, 1987).

A alta tenacidade de $Z$. geniculata não significa uma limitação terminal à dispersão. Em diferentes momentos do processo de seleção de habitat pode haver uma maior facilidade para a dispersão. Filhotes e juvenis apresentam grande potencial dispersivo por serem pequenos e leves. Em muitas espécies de aranhas é nesta fase de desenvolvimento que a dispersão ocorre com mais intensidade (balonismo, Bell et al., 2005; uso de outros animais para a dispersão, Ichinose et al., 2004). Outro fator que reduz a tenacidade em aranhas com teia de alto custo são os danos sofridos naturalmente pela teia. Eberhard (1971) descreve o abandono de microlocais a partir de danos ocasionados por vento às teias de Uloborus diversus.

O surgimento de uma teia mais econômica em Araneoidea (v. Capítulo 2 para dados de gasto energético, Opell, 1996, para informações acerca de reciclagem diferencial das teias, e Peters, 1987, para dados sobre o material que compõe a seda) parece estar associado a uma redução na tenacidade, o que implica em um aumento no potencial exploratório do ambiente nestas aranhas. Esse comportamento exploratório aumentado poderia ser um importante fator na grande diversificação do grupo Araneoidea. Tal diversificação estaria ligada, então, não a um maior sucesso de captura da armadilha viscosa, como sugerem Köhler \& Vollrath (1995, questionado por Opell \& Bond, 2000), mas associado a uma economia energética proporcionada por esta teia. Outros pontos da filogenia também mostram perdas do cribelo associadas a um aumento de diversidade de espécies e nestes outros casos não ocorre o surgimento de uma armadilha considerada mais eficiente na captura de presas. Dessa forma, 
parece haver um fator mais geral atuando que poderia estar associado à perda de um fio cribelado de custo elevado. Esse tema será melhor explorado no Capítulo 3 do presente trabalho. 
Capítulo 2

Metabolismo Energético e a Construção da Teia Orbicular 


\section{INTRODUÇÃo}

As aranhas são conhecidas pela sua adaptação à escassez de recursos alimentares. Wise (1993) defende que as aranhas, mesmo hoje, estão sempre aquém de seu potencial máximo de reprodução, limitadas por uma quantidade insuficiente de recursos alimentares. Entre os indícios dessa condição estão o aumento na produção de ootecas quando as aranhas recebem suplemento de presas em suas teias, o baixo metabolismo em relação a outros artrópodes de mesmo tamanho e a presença de um sistema fisiológico adaptado (Greenstone \& Bennett, 1980) para resistir muito tempo sem alimentação. Essa afirmação, decorrência do metabolismo padrão estabelecido por Anderson (1970), mostra que as taxa metabólicas obtidas com as aranhas estão abaixo dos valores esperados para os artrópodes terrestres. Recentemente esta afirmação foi questionada: Lighton et al. (2001) afirmam que essa menor taxa metabólica apresentada pelos aracnídeos deve-se a medidas mais precisas nesses organismos, devido à sua estratégia senta-espera, enquanto as medidas dos demais artrópodes apresenta-se “contaminada" por possíveis surtos de atividade não detectáveis pelas técnicas empregadas por Anderson (1970). Para que se confirme essa nova interpretação das informações da literatura, mais medidas com equipamentos que permitam maior precisão precisam ser realizadas. Mesmo com um dos principais argumentos fortemente questionado, os demais aspectos levantados por Wise (1993) ainda sustentam sua afirmação de que as aranhas são altamente adaptadas à escassez de alimento.

Tendo em vista essa constante necessidade por recursos alimentares, as aranhas são especialmente dependentes de suas estratégias de forrageamento. Essencialmente, dois estilos de forrageamento estão presentes nas aranhas: o forrageamento ativo representado pelas aranhas andarilhas, e a captura de presas intermediada por uma armadilha de seda, presente nas aranhas de teia. Dentre as aranhas de teia, as do grupo Orbiculariae, construtoras de teia 
orbicular, são as que possuem as relações filogenéticas melhor estabelecidas no momento (Coddington \& Levi, 1991; Griswold et al., 1998, 1999). Como muitos outros grupos taxonômicos de aranhas, elas possuem em sua base um táxon de aranhas cribeladas (Deinopoidea) associado a um grupo irmão não cribelado mais diverso (Araneoidea, Coddington \& Levi, 1991).

Muitos autores atribuem a grande diversificação de Araneoidea à maior eficiência nas capturas da teia orbicular viscosa em comparação com sua correspondente cribelada (Craig et al., 1994; Eberhard, 1989; Köhler \& Vollrath, 1995), argumento que é contraposto por outros autores (Opell \& Bond, 2000, Capítulo1). O fio cribelado possui algumas vantagens estruturais com relação ao fio viscoso que podem surgir em alguns contextos de forrageamento: sua capacidade adesiva não depende de condições abióticas (como o fio viscoso, que depende de uma elevada umidade relativa do ar), e a sua longa durabilidade permite uma diminuição na área de teia reconstruída sem que se perca área de captura, mesmo quando a aranha passa por uma grande restrição alimentar (v. citações e discussão no Capítulo 1). Assim, a atribuição de uma superioridade de eficiência de captura absoluta à teia orbicular construída com espiral de captura viscosa não explica completamente sua grande diversificação em relação ao seu grupoirmão basal cribelado. Uma característica vantajosa e pouco explorada do fio viscoso é o seu baixo custo de produção (Lubin, 1986; Opel1, 1998b). O baixo custo da teia orbicular viscosa resulta de: uma atividade de construção barata em que a aranha simplesmente locomove-se depositando o fio entre um raio e outro; um fio de mesma capacidade adesiva combinado a uma economia de proteínas, já que as gotículas adesivas apresentam-se espalhadas e espaçadas ao longo do fio axial e constituem-se de $80 \%$ de água; e finalmente, resulta também da reciclagem de cerca de 92\% da teia (Opell, 1998b). Em contraposição, o fio cribelado possui um alto custo de produção dado: pela intensa atividade das pernas IV durante a produção do fio cribelado; pela grande quantidade de proteínas presente nos tufos contínuos e espessos depositados nos fios axiais; e finalmente, pela pouca ou inexistente reciclagem da teia (Lubin, 
1986; Opell, 1998b). Além do evidente gasto em material, o gasto energético da atividade de produção do fio cribelado, embora nunca explicitamente medido, é considerado implicitamente elevado em função do tempo gasto na construção da espiral de captura cribelada, que é muito maior do que aquele gasto na produção da espiral viscosa (Zschokke \& Vollrath, 1995a,b).

O custo de construção da teia provavelmente tem seu papel na determinação de estilos de forrageamento (Gillespie, 1981; Janetos, 1982; Schuck-Paim, 2000) e também nos padrões fisiológicos das aranhas (Greenstone \& Bennett, 1980; Prestwich, 1977). Tentativas de medidas e de estimativas do gasto energético da construção da teia orbicular viscosa já foram feitas, mas estão associadas a uma série de problemas metodológicos. Peakall \& Witt (1976) mediram o consumo de oxigênio associado à construção da teia de Araneus diadematus (Araneidae) tentando associar um sistema de "passos" como unidades de locomoção na análise de gravações em vídeo de construções de teia. Ao final da construção da teia, a aranha era colocada em um sistema respirométrico e o consumo de oxigênio medido. A justificativa para não realizar as medidas simultaneamente com a atividade de reconstrução vinha da descrição do funcionamento do sistema respiratório das aranhas: esse só realizaria trocas gasosas após a atividade, pois haveria um comprometimento entre locomoção e trocas gasosas nas aranhas, já que os dois sistemas fazem uso da hemolinfa: a locomoção nas aranhas é resultado da ação de músculos de contração e de um sistema hidráulico (baseado no fluxo de hemolinfa) para a extensão das pernas (Anderson \& Prestwich, 1975). Assim, momentos de grande atividade fazem com que a comunicação entre cefalotórax e opistossoma fique interrompida para manter a alta pressão hidráulica no cefalotórax, necessária para a extensão das pernas durante a locomoção. Como resultado, as trocas gasosas ficam limitadas ao opistossoma, onde estão os pulmões foliáceos, de modo que há no cefalotórax um rápido consumo das reservas oxidativas, bem como o uso intenso de metabolismo anaeróbico, o qual também se esgota rapidamente (Anderson \& Prestwich, 1975). Porém, percebe-se claramente que as aranhas orbitelas não 
estão limitadas a uma atividade intensa de dois minutos (Zschokke \& Vollrath, 1995a,b), como seria esperado a partir do modelo acima, pois mantêm atividade contínua por muito mais tempo durante a construção da teia. Essas diferenças de capacidade locomotora provavelmente refletem diferenças de sistema respiratório (a presença de traquéias no cefalotórax permitiria a oxigenação do cefalotórax sem necessitar do intermédio da hemolinfa) e de metabolismo ou, como sugere Opell (1979), a interrupção entre o fluxo de hemolinfa não dura longos períodos durante a atividade. Essas constatações fazem com que as medidas de Peakall \& Witt (1976) representem valores subestimados. De qualquer modo, tais medidas realizadas em orbitelas de fio viscoso não podem ser extrapoladas para orbitelas cribelada, dadas as diferenças marcadas no tempo, no comportamento e no material utilizados na construção dos dois tipos de armadilha.

Outra tentativa de medir o custo de construção de teia foi realizada por Prestwich (1977) com Sosippus janus, uma aranha construtora de teia em lençol. A dificuldade metodológica aqui encontrada estava em realizar a medida precisa somente no momento de atividade de construção. Dessa forma, as medidas eram realizadas e, posteriormente a atividade de construção era constatada através da presença de fios no recipiente respirométrico. Da mesma forma que Peakall \& Witt (1976), Prestwich (1977) considera a atividade de construção energeticamente equivalente à simples locomoção das aranhas, embora admita que o comportamento de construção não é o mesmo que simplesmente depositar fios no substrato.

Assim, os estudos que tentam dar conta do gasto energético que a aranha demanda na construção de sua armadilha de seda se mostram, até agora, imprecisos, mas nos instigam a entender melhor a atividade de construção da teia. Através do refinamento e do aumento da precisão das técnicas respirométricas de medida de consumo de oxigênio e liberação de gás carbônico, tem havido, nos últimos anos, uma ampliação de possibilidades de medição a organismos cada vez menores, o que já culminou na proposta de Lighton et al. (2001) de que 
os aracnídeos teriam a mesma taxa metabólica de outros artrópodes terrestres, como os insetos. Medidas comparáveis de gasto energético em aranhas de teia orbicular com estratégias de forrageamento diferenciadas, tais como o são as orbitelas cribeladas e ecribeladas, podem ajudar na compreensão acerca da evolução destas próprias estratégias, a partir de possíveis restrições energéticas impostas a um e não a outro destes dois sistemas biológicos. Para tanto, no presente trabalho realizamos medidas em duas espécies de aranhas orbitelas que diferem quanto ao fio de captura que tecem: a aranha cribelada Zosis geniculata (Olivier, 1789) e a ecribelada (fio viscoso) Metazygia rogenhoferi (Keyserling, 1878). 


\section{Material \& Métodos}

As aranhas foram mantidas em caixas-suporte de acrílico (dimensões 30x30x12) com tampas de vidro, em sala com pouca variabilidade de temperatura $\left(25 \pm 1^{\circ} \mathrm{C}\right)$ e ciclo normal de claro/escuro. As medidas foram realizadas entre três e sete dias após a última alimentação para evitar possíveis alterações metabólicas decorrentes da ingestão recente de presas. A técnica usada foi a respirometria fechada intermitente, o equipamento de registro das variações na pressão parcial de oxigênio foi o PA-1 $\mathrm{O}_{2}$ Analyzer, e os dados foram processados pelo programa Datacan V, ambos da Sable Systems ${ }^{\circledR}$.

A respirometria fechada intermitente mede os diferentes consumos de oxigênio, ou de liberação de gás carbônico, após um período conhecido de reclusão do animal dentro de um recipiente de volume também conhecido. A medição se dá no final desse período com a retomada controlada do fluxo de ar ( $150 \mathrm{ml} /$ minuto) que passa, antes de entrar no equipamento de registro, por um tubo contendo sílica, para retirar a umidade, e ascarite, para retirar o $\mathrm{CO}_{2}$ do ar (figura 1), por um período previamente determinado (p.e. 4 minutos para cada câmara).

O consumo de oxigênio foi acompanhado através de uma curva de diminuição de pressão parcial de $\mathrm{O}_{2}$ contido na mistura de gases que entra no aparelho até a recuperação das medidas aos níveis atmosféricos (cerca de 21\%, figura 2). O consumo de oxigênio total foi calculado a partir da área do gráfico correspondente à queda da pressão parcial de oxigênio (figura 2) pelo programa DatacanV. 


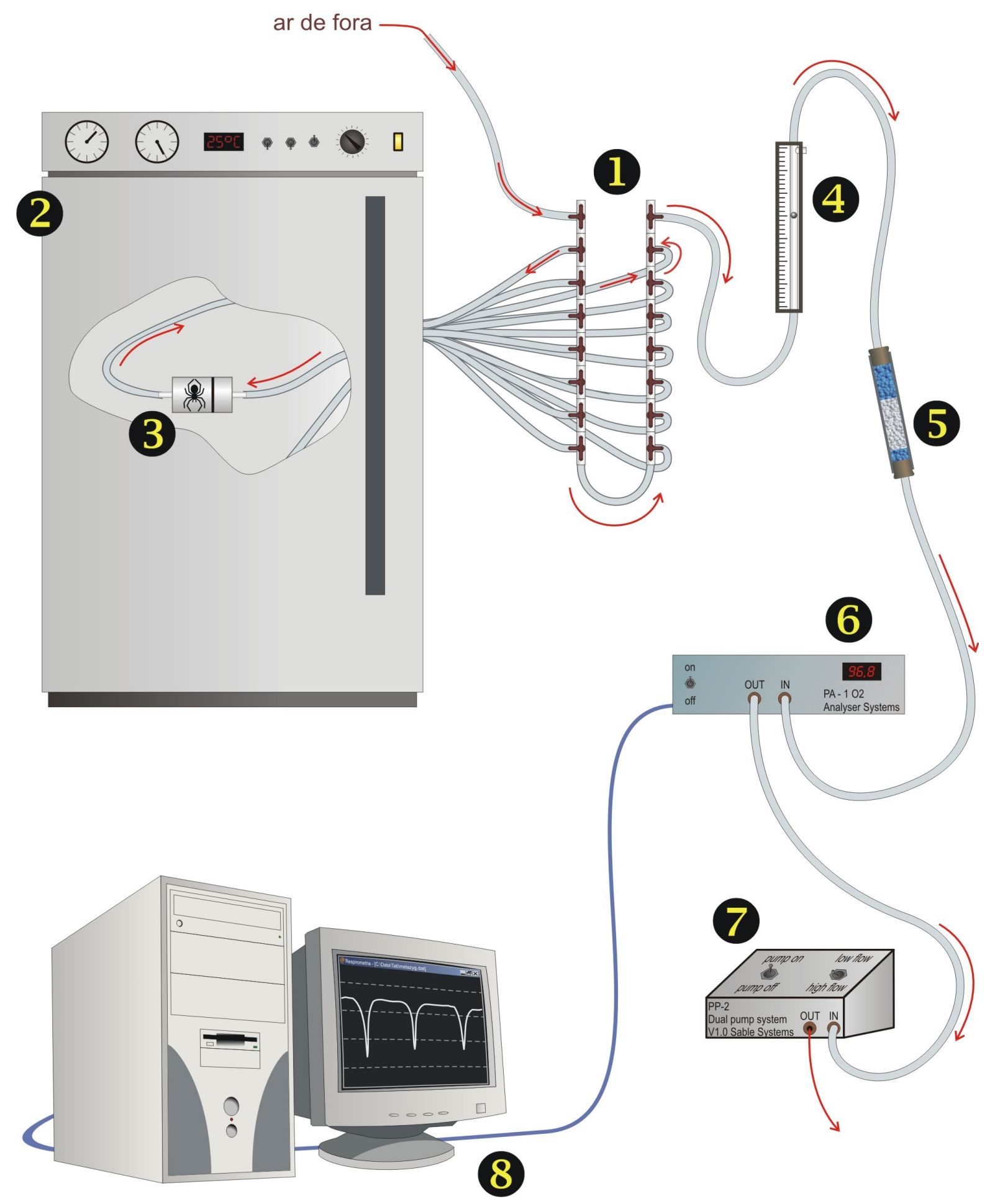

Figura 1. Esquema do equipamento usado para realizar as medidas de consumo de $\mathrm{O}_{2}$. 1. sistema de mangueiras adaptadas para realizar medidas seqüenciais; 2. câmera climática com temperatura e umidade constantes; 3. recipientes contendo as aranhas; 4. fluxômetro (ajustado em 150ml/min); 5. tubo contendo sílica, para eliminar a umidade, e ascarite, para eliminar o gás carbônico; 6 . aparelho que realiza as medidas de concentração de oxigênio (PA-1 O2 Analyzer da Sable Systems ${ }^{\circledR}$ ); 7. bomba de ar que mantém o fluxo; 8. dados vindos de uma saída analógica foram decodificados com o programa DatacanV da Sable Systems ${ }^{\circledR}$. As setas vermelhas indicam o fluxo do ar. 


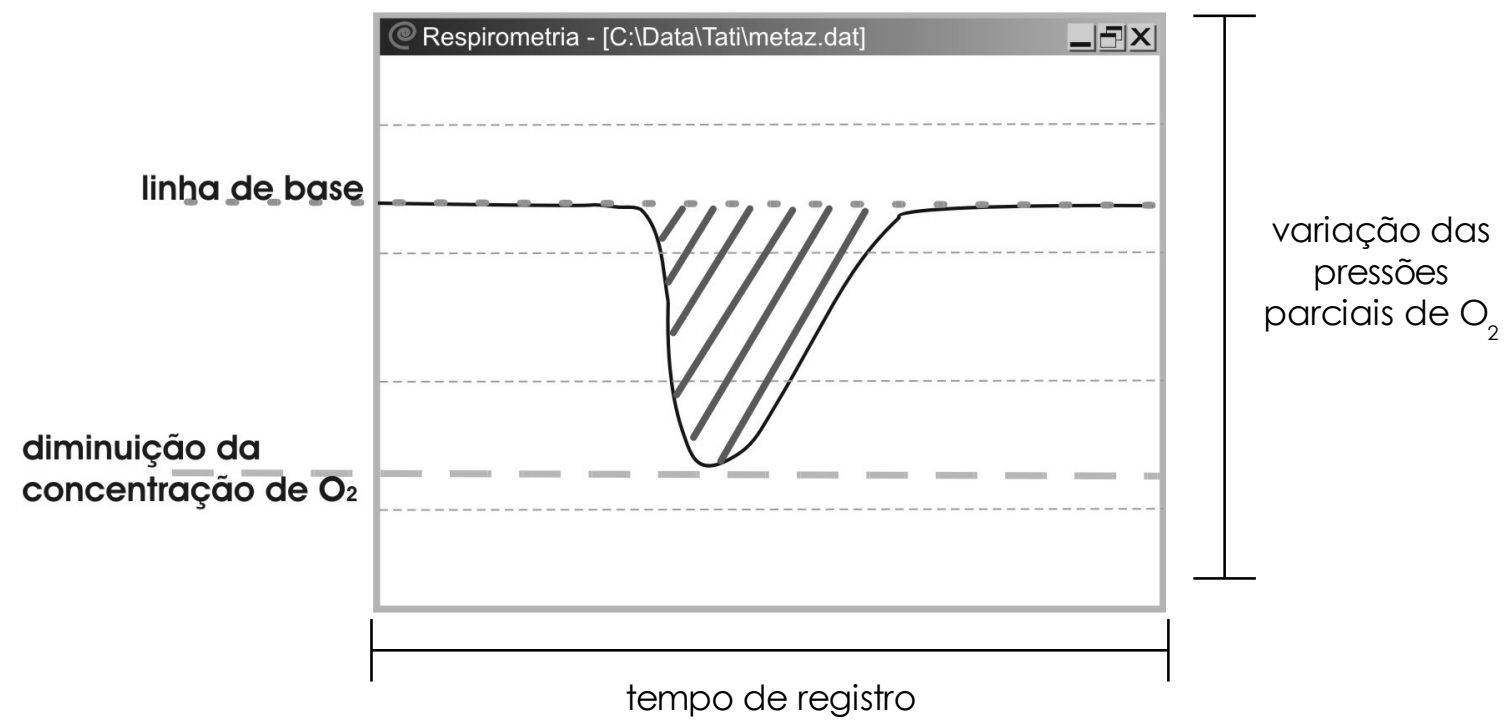

Figura 2. Registro do experimento mostrando a área correspondente ao consumo de $\mathrm{O}_{2}$. $\mathrm{O}$ pontinhado mostra a linha de base, onde o oxigênio apresenta os níveis atmosféricos, o tracejado mostra o nível mais baixo de pressão parcial de $\mathrm{O}_{2}$ atingido durante o registro, e as linhas diagonais marcam a área correspondente ao consumo de $\mathrm{O}_{2}$ calculada pelo programa DatacanV.

Alguns cuidados precisaram ser tomados durante as medições. A calibragem e estabilização do equipamento de registro foram feitas com gás de nitrogênio como referência para $0 \%$ de pressão parcial de oxigênio. O tempo de 4 minutos de duração do registro foi estabelecido de modo que fosse suficiente para que os níveis de pressão parcial de oxigênio pudessem retornar à linha de base. O fluxo de ar de $150 \mathrm{ml} /$ minuto que passa pelo sistema deve gerar um sinal que se afaste da linha de base e permita a medição do consumo de oxigênio sem que esse se perca no sinal de ruído do aparelho. O tempo de fechamento de cada câmara respirométrica precisa resultar de um ajuste entre o tempo necessário para obter um consumo de oxigênio detectável pelo aparelho e o tempo limite dado por um nível de concentração de oxigênio intolerável pelo animal (hipóxia). Com o procedimento descrito acima foram realizadas, para cada espécie, as medidas da taxa de consumo específico de oxigênio das aranhas em repouso (taxa metabólica de repouso), e a taxa de consumo de oxigênio durante a atividade de construção de uma teia (taxa metabólica de atividade). 


\subsection{Taxa metabólica de repouso}

A taxa metabólica de repouso é definida como o menor consumo de oxigênio, por grama do animal estudado e por tempo $\left(\mathrm{mlO}_{2} \mathrm{~h}^{-1} \mathrm{~g}^{-1}\right)$ do mesmo em repouso (Withers, 1992). Esse valor é obtido pelo registro do consumo de oxigênio dos organismos em repouso, tomando o cuidado para que outros processos metabólicos, como a digestão, não estejam ocorrendo. Através de uma grande quantidade de medidas escolhe-se sempre os menores valores obtidos para cada massa correspondente.

Foram usados 10 indivíduos da espécie $M$. rogenhoferi e 20 indivíduos da espécie $Z$. geniculata para obtermos os valores correspondentes ao metabolismo de repouso. As medidas foram realizadas a $25 \pm 1^{\circ} \mathrm{C}$ durante o claro, período de menor atividade das aranhas. Foram usadas 12 câmaras ( 2 controles) cilíndricas de acrílico de $80 \mathrm{ml}$ hermeticamente fechados (figura 3a). Calculamos ${ }^{6}$ o volume inicial de oxigênio contido nesta câmara como $16,8 \mathrm{mlO}_{2}$. Nenhuma aranha consumiu mais do que $0,01 \%$ do oxigênio contido inicialmente nesse recipiente respirométrico. A superfície interna do recipiente foi recoberta por papel filtro úmido que, além de manter a umidade durante a medida, provinha um suporte onde a aranha podia subir e ficar em repouso, o que seria mais difícil na superfície lisa do acrílico.

As aranhas foram pesadas em uma balança de precisão, colocadas nas câmaras e estas últimas ligadas ao equipamento (figura 1) com a bomba de ar ligada no máximo para que o ar atravessasse todas as câmaras. Antes de iniciar as medidas aguardou-se entre uma e duas horas, tempo suficiente para que as aranhas explorassem o recipiente e ficassem em posição de repouso, e para que o fluxo de ar eliminasse o consumo decorrente do estresse durante a pesagem. No momento das medidas, o fluxo de ar era ajustado para $150 \mathrm{ml} / \mathrm{min}$ (fluxômetro) e as câmaras fechadas seqüencialmente, a intervalos de 4 minutos, tempo suficiente para trocar totalmente o ar dentro das câmaras durante o registro de consumo de oxigênio. As câmaras ficaram fechadas durante 4 horas, tempo necessário para detectar o metabolismo de repouso de

\footnotetext{
${ }^{6}$ Considerando a concentração atmosférica de $\mathrm{O}_{2}$ como $21 \%$.
} 
aranhas pequenas e que possivelmente possuem um metabolismo baixo.

Metazygia rogenhoferi é uma aranha intensamente parasitada e precisa ser coletada em grandes quantidades para que se consiga uma amostra que sobreviva até o final dos experimentos (v. Capítulo 1). De todos os indivíduos que foram coletados, conseguimos com que o consumo de oxigênio em repouso de 10 aranhas fossem registrados. Com o intuito de garantir o registro do menor consumo de oxigênio correspondente ao metabolismo de repouso, foram realizadas medidas de consumo de oxigênio por três dias consecutivos, selecionando-se sempre o menor dentre os valores obtidos para cada aranha nos três dias. Esse procedimento mostrou-se apropriado devido à grande variabilidade de resposta individual das medidas respirométricas encontrada para essa aranha já nos primeiros testes. A medida em três dias diferentes mostrou, também, que não havia um possível efeito do dia da medição nos registros obtidos.

Zosis geniculata é uma espécie sinantrópica fácil de coletar em grande quantidade e suas medidas apresentam coerência e pouca variabilidade entre os indivíduos. Desse modo, pudemos optar por medir uma aranha de cada vez, provindas de uma grande amostra $(\mathrm{N}=30)$, eliminando os valores caracterizados como outliers (indicados no Boxplot, SPSS 11.0) e que excederam o valor mínimo obtido para cada massa correspondente. 


\subsection{Consumo de $\mathrm{O}_{2}$ durante a construção da teia}

A câmara cilíndrica usada nas medidas de metabolismo de repouso constitui o melhor formato para facilitar o fluxo e troca do ar dentro da câmara em que o animal está durante as medidas, e por isso é amplamente usada. Contudo, a necessidade de suportes adequados para que a aranha possa construir sua teia já foi amplamente descrita na literatura (Colebourn, 1974; Gunnarsson, 1992; Janetos, 1986; Jocqué, 1981; Robinson, 1981) e, no caso das orbitelas, significa a existência de descontinuidades e cantos (Japyassú, 1998). Para que a medida de consumo de oxigênio durante a construção da teia fosse possível, os recipientes precisaram ser construídos segundo uma série de requisitos:

1) com cantos, usados pelas aranhas para a orientação e detecção dos pontos de suporte da teia;

2) não ultrapassando o volume de $180 \mathrm{ml}$, para que o equipamento pudesse detectar o consumo de oxigênio das aranhas;

3) transparente, para que se pudesse observar diretamente a atividade de construção de teia e marcar, assim, o tempo exato de atividade de cada uma.

Seguindo esses requisitos chegamos aos recipientes com volume interno de $116,9 \mathrm{ml}$ construídos especialmente para essa medida (figura 3b, anexo G) e obtivemos a taxa metabólica durante a construção de uma teia cribelada e de uma teia ecribelada. O volume inicial de oxigênio contido na câmara respirométrica do experimento de atividade (figura 3b) é de 24,6 $\mathrm{mlO}_{2}$. Nenhuma aranha consumiu mais do que $0,17 \%$ do oxigênio contido inicialmente nesse recipiente respirométrico.

Para obter a medida de consumo de oxigênio exata durante a construção da teia, sem que esta se diluísse muito em um extenso período de fechamento da câmara, optou-se por fechar a câmara tão logo a atividade de construção fosse detectada visualmente pelo experimentador. As fases e seus respectivos tempos de construção foram anotados através de 
observação direta, e um prazo de uma hora com o recipiente fechado foi acrescido ao final da construção da teia, para garantir o registro do consumo de oxigênio decorrente da atividade (possivelmente, as aranhas realizam a maior parte das trocas gasosas decorrente de atividade intensa 40 minutos após esta cessar, segundo Peakall \& Witt, 1976). Uma segunda medida de consumo de oxigênio ${ }^{7}$ foi realizada logo depois para confirmar que o tempo de uma hora a mais depois do término na construção da teia era suficiente para obter-se o registro integral do consumo de oxigênio referente à atividade de construção. Essa segunda medida sempre apresentou valores compatíveis com a taxa metabólica de repouso, ou mesmo abaixo.

Ao final da construção, fotos digitais das teias foram feitas com uma câmera Sony DSC-H1 (5.1 mega pixels) e o comprimento da espiral adesiva correspondente à medida de oxigênio foi obtida com o programa gratuito UTHSCSA Image Tool 3.0 para Windows ${ }^{8}$.
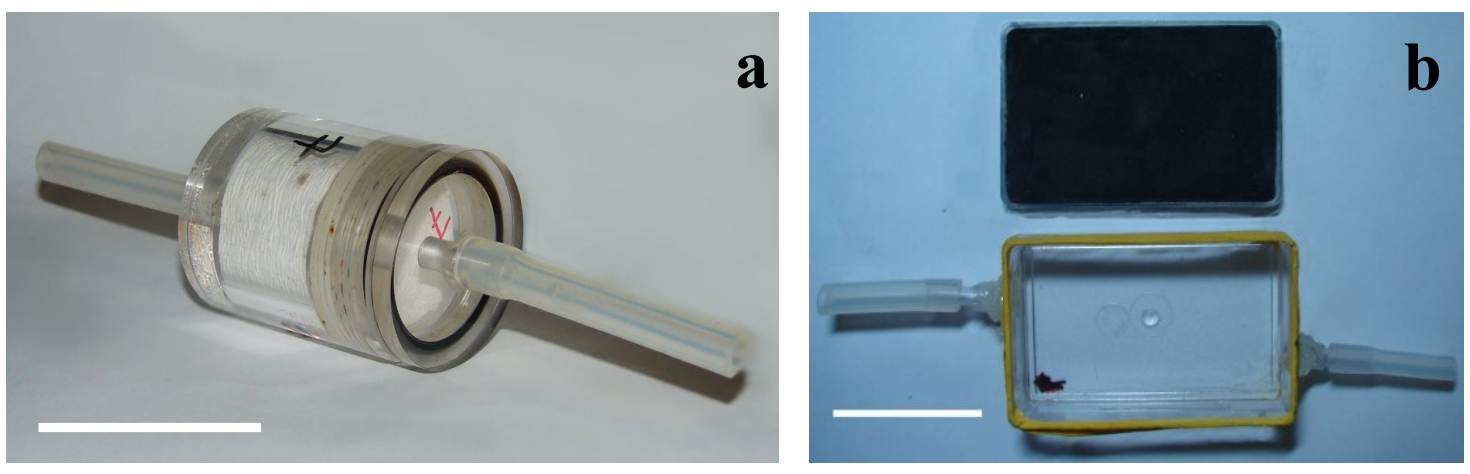

Figura 3. Foto dos recipientes respirométricos: a) usado na medida do metabolismo de repouso; e b) construído para realizar as medidas respirométricas durante a construção da teia orbicular. Caixa de plástico com vedação de borracha (amarela) e tampa com fundo preto para facilitar a visualização da teia. Escala $5,0 \mathrm{~cm}$.

\footnotetext{
${ }^{7}$ Fechou-se a câmara, aguardou-se mais uma hora e obteve-se o registro do consumo de oxigênio

${ }^{8}$ Disponível no endereço eletrônico http://ddsdx.uthscsa.edu/dig/itdesc.html
} 


\subsection{Cálculo do consumo de $\mathrm{O}_{2}$ durante a construção da teia}

Para obtermos o consumo específico durante a atividade de construção da teia calculamos o consumo específico em repouso $\left(\mathrm{Mr}_{\mathrm{a}}\right)$ correspondente ao período em que o recipiente permaneceu fechado durante o registro $\left(\Sigma \mathrm{t}_{\mathrm{a}}\right)$, e ao peso $(\mathrm{p})$ da aranha construtora.

$$
\mathrm{Mr}_{\mathrm{a}}=\mathrm{Mr} \cdot \mathrm{p} \cdot \Sigma \mathrm{t}_{\mathrm{a}}
$$

Subtraímos esse consumo metabólico de repouso $\left(\mathrm{Mr}_{\mathrm{a}}\right)$ do volume total de oxigênio consumido durante a atividade de construção da teia $\left(\mathrm{V}_{\mathrm{a}}\right)$, obtendo-se o volume de oxigênio correspondente à atividade (At).

$$
\mathrm{At}=\mathrm{V}_{\mathrm{a}}-\mathrm{Mr}_{\mathrm{a}}
$$

Dividimos o valor de atividade (At) pelo tempo gasto somente em atividade de construção da teia $\left(t_{a}\right)$ e corrigimos o valor pelo peso da aranha construtora $(p)$, obtendo o consumo específico de oxigênio durante a construção da teia (Co) em $\mathrm{ml} \mathrm{O}_{2} \mathrm{~h}^{-1} \mathrm{~g}^{-1}$;

$$
\mathrm{Co}=\frac{\mathrm{At}}{\mathrm{t}_{\mathrm{a}} \cdot \mathrm{p}}
$$

Para obtermos o valor da taxa metabólica correspondente ao comprimento da espiral de captura (Es) construída repetimos o procedimento descrito no item anterior substituindo o tempo pelo comprimento do fio construído (f). Corrigindo o valor pelo peso da aranha construtora (p), obtemos o consumo de oxigênio por centímetro de espiral adesiva em $\mathrm{mlO}_{2} \mathrm{~cm}^{-}$ ${ }^{1} \mathrm{~g}^{-1}$.

$$
\mathrm{Es}=\frac{\mathrm{At}}{\mathrm{f} \cdot \mathrm{p}}
$$


Onde:

$\mathrm{Mr}=$ metabolismo de repouso (consumo específico de repouso),

$\mathrm{Mr}_{\mathrm{a}}=$ volume total de $\mathrm{O}_{2}$ correspondente ao metabolismo de repouso durante o tempo de fechamento da câmara,

$\mathrm{V}_{\mathrm{a}}=$ volume total de $\mathrm{O}_{2}$ medido durante a construção da teia,

At $=$ volume $\mathrm{O}_{2}$ referente somente à atividade de construção da teia,

$\mathrm{Co}=$ consumo específico de $\mathrm{O}_{2}$ da atividade de construção da teia,

Es $=$ consumo de $\mathrm{O}_{2}$ correspondente à construção de cada centímetro de espiral adesiva,

$\mathrm{t}_{\mathrm{a}}=$ tempo de atividade das aranhas,

$\mathrm{f}=$ comprimento de fio adesivo construído,

$p=$ peso da aranha que construiu a teia. 


\section{Resultados}

\subsection{Taxa metabólica de repouso}

Metazygia rogenhoferi apresentou taxa metabólica padrão $\left(0,78 \pm 0,12 \mathrm{ml} \mathrm{O}_{2} \mathrm{~h}^{-1} \mathrm{~g}^{-1}\right)$, significativamente diferente $(U<0,0001, \mathrm{p}<0,0001, \mathrm{~N}=30)$ de Zosis geniculata $(0,36 \pm 0,08$ $\left.\mathrm{mlO}_{2} \mathrm{~h}^{-1} \mathrm{~g}^{-1}\right)$. O próprio metabolismo de repouso é um resultado interessante, e mostra que $M$. rogenhoferi mantém um nível de gasto energético quase duas vezes maior do que $Z$. geniculata.

\subsection{Consumo de $\mathrm{O}_{2}$ durante a construção da teia}

Apesar do esforço de coleta de dados, só foi possível obter uma medida de construção de teia para cada espécie estudada. M. rogenhoferi consumiu mais oxigênio para construir uma teia com espiral viscosa cerca de quatro vezes mais extensa do que Z. geniculata (tabela 1). Quando fazemos o cálculo de consumo de oxigênio para a quantidade de fio adesivo construído, e não pelo tempo de construção da teia, essa relação inverte-se: o custo de cada centímetro de fio cribelado mostra-se três vezes maior do que o custo de produção do fio viscoso.

\begin{tabular}{lcccccccc}
\hline & $\begin{array}{l}\text { peso } \\
(\mathbf{m g})\end{array}$ & $\begin{array}{c}\text { tempo } \\
\text { total } \\
(\mathbf{m i n})\end{array}$ & $\begin{array}{c}\text { construção } \\
\text { da teia }(\mathbf{m i n})\end{array}$ & $\begin{array}{c}\text { construção } \\
\text { da espiral } \\
\text { adesiva (min) }\end{array}$ & $\begin{array}{c}\text { espiral } \\
\text { adesiva } \\
(\mathbf{c m})\end{array}$ & $\begin{array}{c}\text { repouso } \\
\left(\mathbf{m l O} \mathbf{O}_{2} \mathbf{h}^{-1} \mathbf{g}^{-1}\right)\end{array}$ & $\begin{array}{c}\text { construção } \\
\mathbf{d a} \text { teia } \\
\left(\mathbf{m l O}_{2} \mathbf{h}^{-1} \mathbf{g}^{-1}\right)\end{array}$ & $\begin{array}{c}\text { consumo por } \\
\mathbf{c m} \mathbf{d e} \mathbf{~ e s p i r a ~} \\
\left(\mathbf{m l O}_{2} \mathbf{g}^{-1} \mathbf{c m}^{-1}\right)\end{array}$ \\
\hline \hline $\begin{array}{l}\text { Metazygia } \\
\text { rogenhoferi }\end{array}$ & 8,1 & 83 & 25 & 5 & 177,7 & $0,78 \pm 0,12$ & $\mathbf{9 , 4 3}$ & $\mathbf{0 , 0 2}$ \\
\hline $\begin{array}{l}\text { Zosis } \\
\text { geniculata }\end{array}$ & 12,6 & 97 & 27 & 13 & 41,2 & $0,36 \pm 0,08$ & $\mathbf{5 , 8 9}$ & $\mathbf{0 , 0 6}$ \\
\hline \hline
\end{tabular}

Tabela 1. Valores obtidos durante a construção da teia orbicular. Valores em negrito referem-se ao consumo de oxigênio a mais, resultado da atividade. O metabolismo de repouso está apresentado como média \pm desvio padrão. 


\section{DisCuSSÃo}

Os valores de metabolismo de repouso obtidos para Metazygia rogenhoferi e para Zosis geniculata estão acima do esperado pela estimativa feita por Lighton et al. (2001) para as aranhas (figura 4).

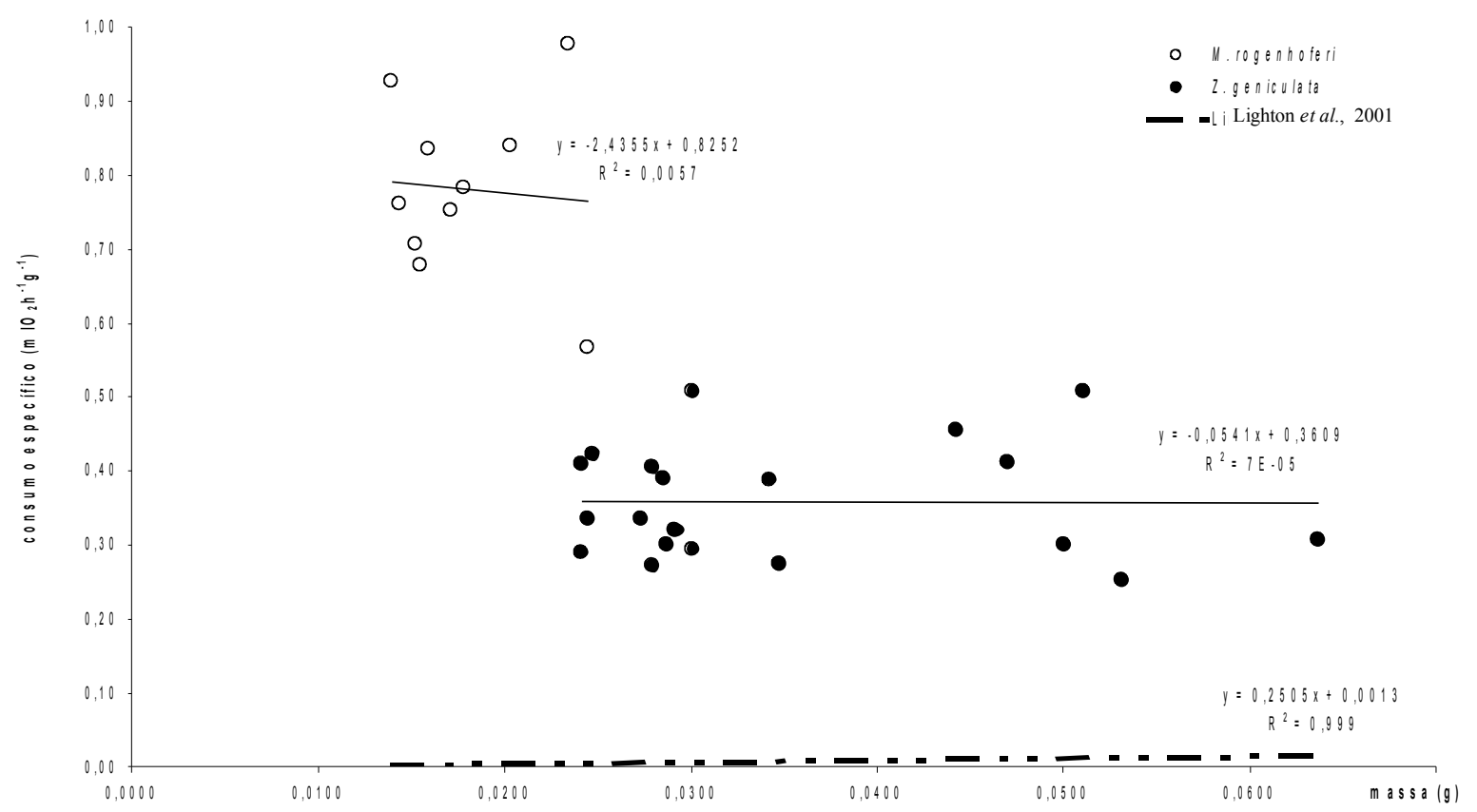

Figura 4. Consumo específico durante as medidas de metabolismo de repouso obtidos para $M$. rogenhoferi $(\mathrm{N}=10)$ e $Z$. geniculata $(\mathrm{N}=20)$ no presente experimento. A linha tracejada representa a estimativa de Lighton et al. (2001) para o metabolismo de repouso das aranhas.

Uma possível explicação para a obtenção de um metabolismo de repouso mais elevado em nossas medidas pode residir no longo período de quatro horas necessário para o registro do consumo de oxigênio de animais pequenos e que metabolizam principalmente lipídios (Prestwich, 1977). Quanto mais longo o período usado para registrar o consumo de oxigênio, maior a possibilidade do animal apresentar surtos de atividade durante as medidas. Esses surtos de atividade podem aumentar o volume de oxigênio consumido, como argumenta Lighton et al. (2001) quando defende taxas metabólicas de repouso equivalentes entre aracnídeos e insetos. 
Outra explicação é a possibilidade de que mesmo em repouso o animal observado pode estar mantendo atividade fisiológica (p.e. produção dos ovos, digestão, síntese de proteínas entre outras) que aparece como consumo de oxigênio. O metabolismo de repouso do presente estudo precisa ser repetido, e outras estratégias de medidas apropriadas para animais pequenos e de baixo consumo de oxigênio realizadas, para que esse resultado se confirme ou seja corrigido para patamares mais baixos. Entretanto, as medidas não perdem seu valor comparativo já que as aranhas do presente trabalho estão sendo afetadas da mesma forma pelo desenho experimental. As medidas foram realizadas em dias diferentes, mas ainda mostram-se consistentes entre si, ou seja, não verificamos uma possível tendência ou efeito dos diferentes dias em que as aranhas foram medidas.

Os dados de consumo de $\mathrm{O}_{2}$ durante a construção de teia representam uma primeira exploração desse balanço energético que deve ser tomada com cautela dada a amostragem pequena obtida no presente experimento. $\mathrm{O}$ consumo de $\mathrm{O}_{2}$ durante a construção de teia elevou-se em cerca de 10 vezes, como esperado para atividade intensa (Lighton et al., 2001).

A taxa metabólica de repouso de $M$. rogenhoferi, mais alta do que a apresentada por Z. geniculata, indica uma maior prontidão desta primeira para a atividade devido ao acoplamento do metabolismo de repouso e de atividade (Reinhold, 1999), ou seja, se a aranha possui um padrão de atividade mais elevado, seu metabolismo de repouso também será mais elevado, efeito que pode ser visto em nossos resultados. Reinhold (1999) mostra também, através da análise de comportamentos energeticamente custosos ${ }^{9}$, que insetos que possuem um comprometimento energético diário mais baixo têm maior probabilidade, no tempo evolutivo, de aumentar seu metabolismo de atividade, o que possibilitaria a aquisição destes comportamentos mais custosos. Este parece ser o caso de $M$. rogenhoferi com sua teia de baixo custo associada a uma estratégia relativamente ativa de forrageamento (baixa tenacidade pelo microlocal, capítulo 1). Já Z. geniculata, construtora de teia cribelada, apresenta um

\footnotetext{
9. O locomoção por vôo e a comunicação acústica de aviso foram analisados pelo autor como comportamentos energeticamente custosos.
} 
metabolismo de repouso e de atividade que refletem um maior comprometimento energético diário, dado pela manutenção de sua teia de alto custo, associada a uma estratégia de forrageamento relativamente mais sedentária (alta tenacidade pelo microlocal, capítulo 1).

A construção de cada centímetro do fio viscoso apresentou um custo três vezes menor do que o fio cribelado. A diferença entre a taxa metabólica de atividade e a taxa metabólica por comprimento de fio adesivo construído pode ser explicada facilmente pela maior atividade de M. rogenhoferi, traduzida em rápido deslocamento durante a construção de sua teia, que resultou em uma espiral de captura mais comprida. Já Z. geniculata mantém uma taxa metabólica de atividade que não se traduz em deslocamento durante a construção da teia, mas sim na produção do fio cribelado com a intensa movimentação das pernas IV ("raspando" repetidamente o calamistro da perna IV sobre o cribelo), concluindo na construção de uma teia menor e com menos fio de captura.

Ao cruzarmos os dados obtidos no Capítulo 1 (período controle, experimento 2) com o consumo de $\mathrm{O}_{2}$ por centímetro de fio adesivo construído, percebemos que o custo médio de cada teia orbicular com fio viscoso $(0,057 \mathrm{Kcal} / \mathrm{g}$ por teia $)$ é cerca de duas vezes menor que o custo de uma teia orbicular com fio cribelado $(0,100 \mathrm{Kcal} / \mathrm{g}$ por teia). Entretanto, essas duas aranhas poderiam apresentar o mesmo investimento acumulado após algum tempo, já que $M$. rogenhoferi reconstrói com frequência maior suas teias e o investimento acumulado em 21 dias de reconstruções resulta no dobro de espiral de captura construído por $M$. rogenhoferi em comparação com Z. geniculata (figura 5a). Mesmo assim, o que vemos é que o consumo de $\mathrm{O}_{2}$ por centímetro de fio adesivo de $M$. rogenhoferi, ao final de 21 dias de reconstrução é menor do que o investimento de Z. geniculata (figura 5b). Se acrescentamos a isto o fato de que a teia com fio viscoso é em boa parte reciclada, enquanto que a teia com fio cribelado não o é (Opell, 1998b), veremos que o custo de manutenção de $M$. rogenhoferi, em relação a $Z$. geniculata, é proporcionalmente ainda menor. Finalmente, se somarmos o menor custo em proteínas que apresenta o fio viscoso quando comparado ao cribelado (Peters, 1987), parece 
que temos um conjunto sólido de evidências no sentido de que a teia orbicular viscosa é efetivamente mais econômica do que a cribelada.
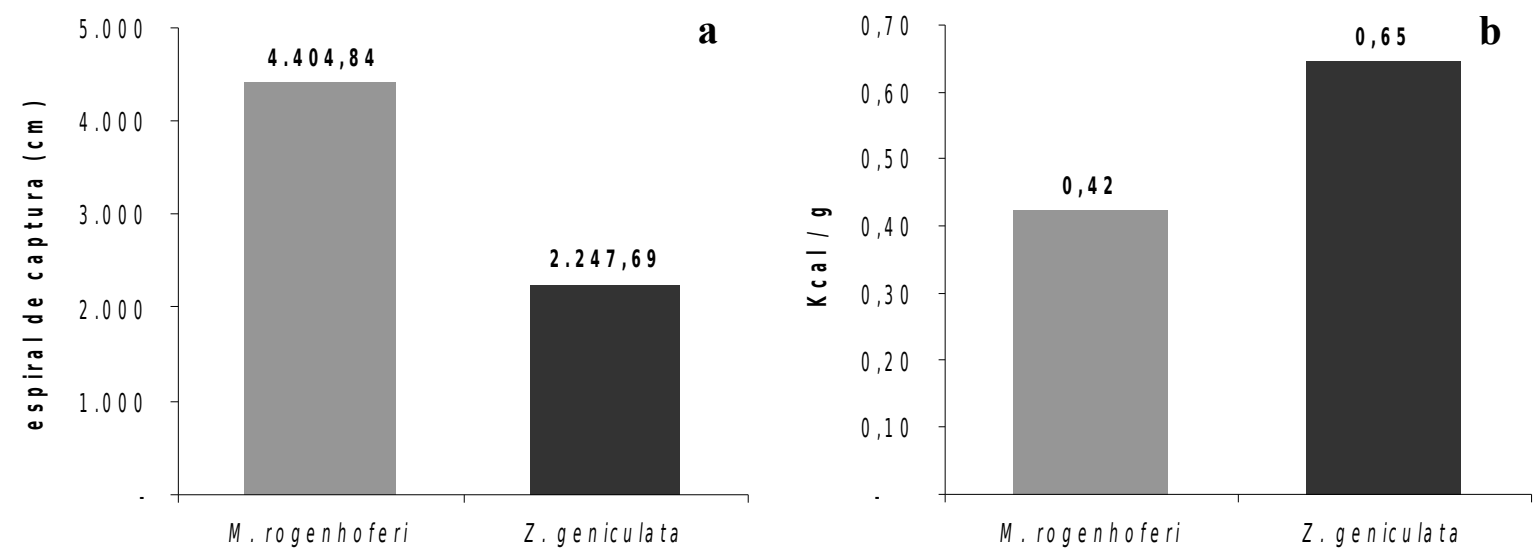

Figura 5. Investimento em seda de captura (a) e em atividade de construção (b) acumulado em um período de 21 dias com alimentação regular (período controle). Dados de investimento acumulado médio obtidos no experimento de redução abrupta da dieta, Capítulo 1.
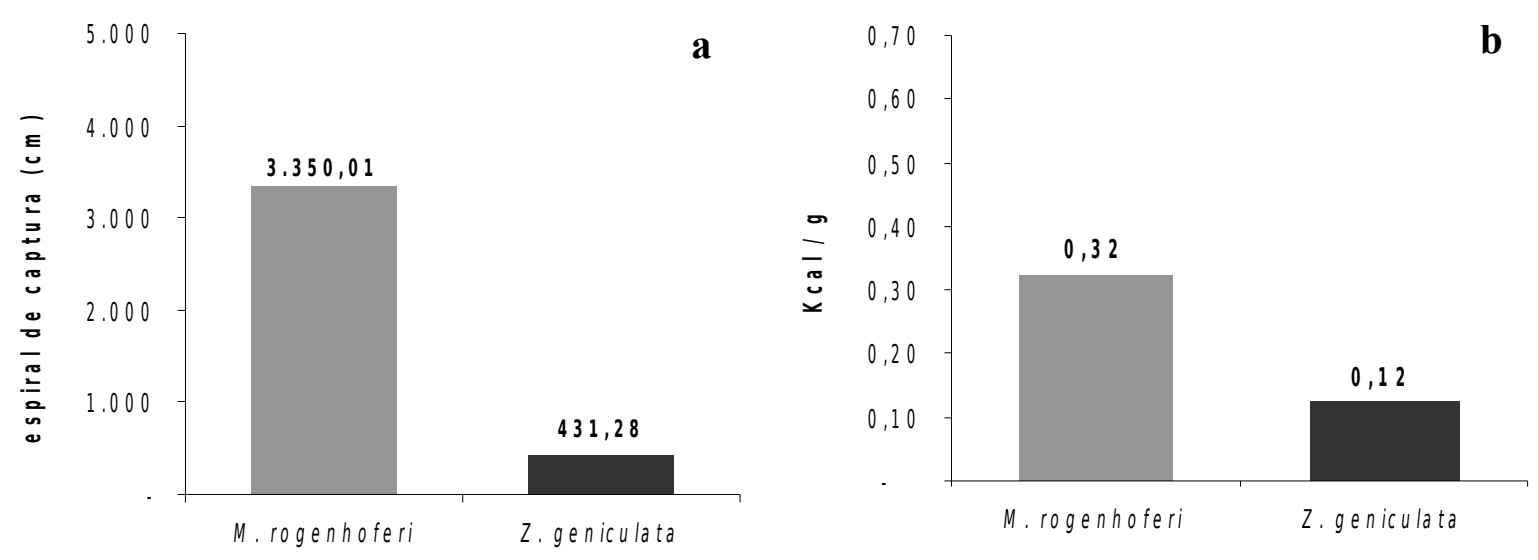

Figura 6. Investimento em seda de captura (a) e em atividade de construção (b) acumulado em um período de 21 dias sem alimentação (período tratamento). Dados de investimento acumulado médio obtidos no experimento de redução abrupta da dieta, Capítulo 1. 
Dentro deste panorama em que a teia de $M$. rogenhoferi é mais econômica que a de $Z$. geniculata, a questão agora é qual a resposta comportamental de cada uma delas frente a uma redução na oferta de presas. O que vemos é que, nesta situação, ambas reduzem o investimento em espiral de captura, mas que $M$. rogenhoferi o faz com menor intensidade (figuras 5 e 6). É provável que, justamente por ter uma teia de baixo custo, $M$. rogenhoferi possa, nesta situação de baixa disponibilidade de presas, investir mais em teia do que Z. geniculata. Além disso, a intensa diminuição nas reconstruções de espiral cribelada por Z. geniculata só é possível devido à longa duração da adesividade deste fio (Eberhard, 1980), possibilitando que esta aranha use por mais tempo as reconstruções anteriores sem necessitar de novas reconstruções. Porém, esta estratégia de diminuição de gasto energético frente a uma queda abrupta na oferta de presas apresentada por Z. geniculata tem como consequência a permanência em microlocais em que a teia está menos sujeita a danos e, consequentemente, uma estratégia de forrageamento menos ativa do que a de $M$. rogenhoferi. 


\section{Considerações Finais}

Mesmo com a possibilidade de comparação entre as espécies através do metabolismo de repouso e de atividade, é desejável a obtenção da taxa de metabolismo padrão ${ }^{10}$ das espécies estudadas, na medida que é um valor que possibilita mais generalizações e comparações com os dados já presentes na literatura.

O fato da teia orbicular ecribelada ser mais econômica pode ajudar a entender a maior diversidade que este grupo apresenta em relação ao ancestral de teia orbicular cribelado. Ao possuir uma teia mais econômica, tanto em material gasto quanto em atividade de construção, as orbitelas de fio viscoso puderam aumentar o seu nível geral de atividade, deslocando-se mais freqüentemente pelo ambiente, de modo a utilizar uma estratégia menos sedentária de forrageamento, conforme já observado por Janetos (1982). Ao ter uma estratégia de forrageamento mais móvel, abandonando mais freqüentemente seus microlocais, as orbitelas de fio viscoso, além de evitarem mais facilmente situações de escassez de alimento (Gillespie \& Caraco, 1987), expõem-se a uma maior diversidade de ambientes o que, no longo prazo, poderia ser a chave para o aumento na diversidade em espécies neste grupo.

Entretanto, o surgimento de uma teia de baixo custo não é a única sinapomorfia de Araneoidea, visto que, na base deste grupo surgem também várias outras características, tais como uma maior verticalização da armadilha ou mesmo a viscosidade no fio de captura, associada à perda do cribelo (Bond \& Opell, 1998). Dessa forma, qualquer destas características poderia ser responsável pela maior diversificação de Araneoidea. No Capítulo 3 procuramos verificar se este aumento de diversidade está de fato associado à perda do cribelo.

\footnotetext{
${ }^{10}$. Definida como o menor consumo de oxigênio, por grama do animal estudado e por tempo $\left(\mathrm{mlO}_{2} \mathrm{~h}^{-1} \mathrm{~g}^{-1}\right)$ dado apenas pela manutenção dos processos fisiológicos mínimos (Withers, 1992)
} 


\section{Capítulo 3}

Diversificação das aranhas e a perda do cribelo 


\section{EvoluÇão \& DiversificaÇão em Araneomorphae}

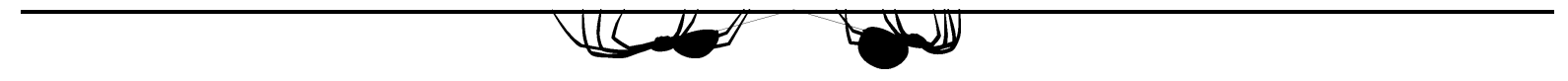

A teia orbicular sempre fascinou a humanidade devido à sua regularidade e forma geométrica. Percebe-se este fascínio através da mitologia e crenças de muitos povos. Na Grécia antiga foi fruto de inveja para a deusa Atenas ${ }^{11}$. Para muitos nativos norte-americanos é a deusa da criação e responsável pela harmonia do mundo ${ }^{12}$. Quando procuramos os aspectos positivos das aranhas sempre recaímos na beleza translúcida e harmonia das teias, enquanto o aspecto negativo sempre está ligado à aparência do animal que a construiu.

A idéia de uma teia perfeita e superior não se limitou aos mitos e lendas e permeou, até recentemente, os estudos de evolução das armadilhas de seda construídas por aranhas. As primeiras tentativas de explicar a evolução das teias propunham séries de transformação que partiam de teias irregulares e atingiam o auge com a teia geométrica (figura 1): sua perfeição, não poderia ser perdida, nem superada.
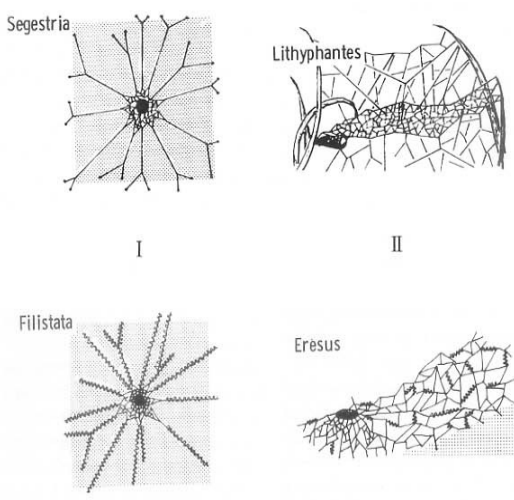

II

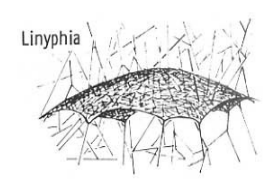

III
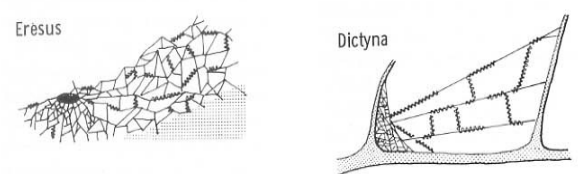
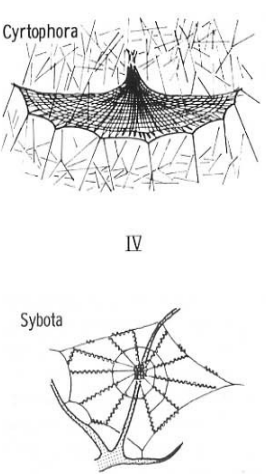
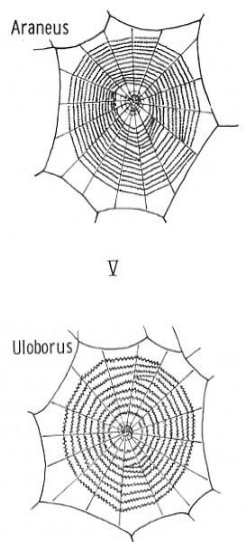

Figura 1. Convergência da teia orbicular. Série de transformação de teias irregulares para as regulares. Acima: transição que culmina em Araneidae; abaixo: transição que culmina em Uloboridae. Modificado de Foelix, 1996.

\footnotetext{
11. Segundo a mitologia grega, Aracne teceu um tapete mais belo e original do que Atenas, deusa da sabedoria. Atenas, humilhada, transforma Aracne em uma aranha orbitela: condenada a tecer por toda a existência.

${ }^{12}$. Muitas tribos nativas norte-americanas possuem no papel principal da criação e manutenção da harmonia no mundo a Mulher-Aranha, ou velha Mulher-Aranha
} 
Como reação a esse modelo de progressão continuada em direção à perfeição, e acompanhando as tendências dos anatomistas do final do século XIX, Bertkau solidificou o uso de características morfológicas como base para entender a filogenia das aranhas, inclusive as construtoras de teia (Coddington, 1986; Shear, 1986). Surge, assim, o táxon Cribellatae, grupo monofilético justificado pela presença de cribelo em todas as suas espécies. O táxon Cribellatae reunia as famílias: Zoropsidae, Miagrammopidae, Filistatidae, Oecobiidae, Dinopidae, Uloboridae, Dictynidae, Eresidae e Amaurobiidae (Coddington, 1986). Mesmo com a predominância de estudos filogenéticos com base em dados morfológicos a idéia de superioridade da teia geométrica não foi superada, pelo contrário, enfatizou-se ainda mais a perfeição da teia orbicular, interpretada agora como a melhor estratégia para "um animal séssil, míope e insetívoro" (Coddington, 1986). Agora, carregada da idéia de ajuste, qualquer característica relacionada à teia geométrica passa a significar baixo sinal filogenético e, sua estrutura, fruto de convergência. Porém, estudos mais aprofundados da estrutura da teia, inspirados em interesses no uso tecnológico do fio de seda e bioengenharia, e do comportamento fino da aranha, amparados pelo conceito etológico de instinto, construíram os argumentos que justificaram a origem única da estrutura orbicular devido à sua complexidade.

\subsection{Por que a monofilia de Cribellatae é incompatível com a monofilia de Orbiculariae?}

A relação filogenética entre esses dois grupos de aranhas de teia orbicular fomentou uma controvérsia de mais de 100 anos (Eberhard, 1988). O principal fator de confronto foi a incompatibilidade entre a mudança morfológica, representada pela presença/ausência do par cribelo/calamistro $^{13}$, e a mudança comportamental complexa ${ }^{14}$ representada pelo surgimento da

\footnotetext{
13. O cribelo é uma placa achatada, homóloga à fiandeira anterior mediana das aranhas não-cribeladas, repleta de fúsulas que fiam os minúsculos fios; já o calamistro é uma peça em forma de pente presente no metatarso das pernas IV.

${ }^{14}$. A teia orbicular é considerada complexa devido à hierarquia no comportamento de construção e alto grau de organização funcional de suas partes (amarras, fios de quadro, raios, espiral auxiliar, espiral de captura).
} 
teia orbicular (Coddington, 1986; Shear, 1986; Eberhard, 1987). O conflito surgiu devido à existência de uma família de aranhas (Uloboridae) com ambas as características: cribelo e teia orbicular. Quando se aceitava a monofilia de Cribellatae, a teia orbicular apresentava duas origens (figura 1): uma origem independente para Uloboridae e outra para Araneidae; quando se aceitava a monofilia de Orbiculariae, os grupos de aranhas com cribelo espalhavam-se pela filogenia sem nenhum padrão compreensível. O surgimento de aranhas cribeladas com características plesiomórficas das araneomorfas e o crescente acúmulo de informações sobre as aranhas cribeladas da Austrália e Nova Zelândia culminaram na estrutura filogenética básica proposta por Lehtinen (1967) e que prevalece hoje: o cribelo surgiu na base de todas as Araneomorphae, ou "verdadeiras aranhas", e foi perdido diversas vezes ao longo da filogenia, enquanto a teia orbicular surgiu uma vez em um ancestral cribelado surgindo, logo após, o fio viscoso característico do restante do grupo (Araneoidea). O colapso de Cribellatae abriu caminho para a monofilia das aranhas de teia orbicular. Em 1991, Coddington \& Levi finalmente reúnem argumentos suficientes, tanto morfológicos quanto comportamentais, para estabelecer filogenia de Orbiculariae (figura 2), e propor a perda do padrão orbicular nos grupos mais derivados. Ou seja, a teia orbicular perde, também, o status de auge evolutivo. A filogenia de orbiculariae mais aceita hoje foi consolidada com os estudos cladísticos de Griswold e colaboradores de 1998 e 1999. 


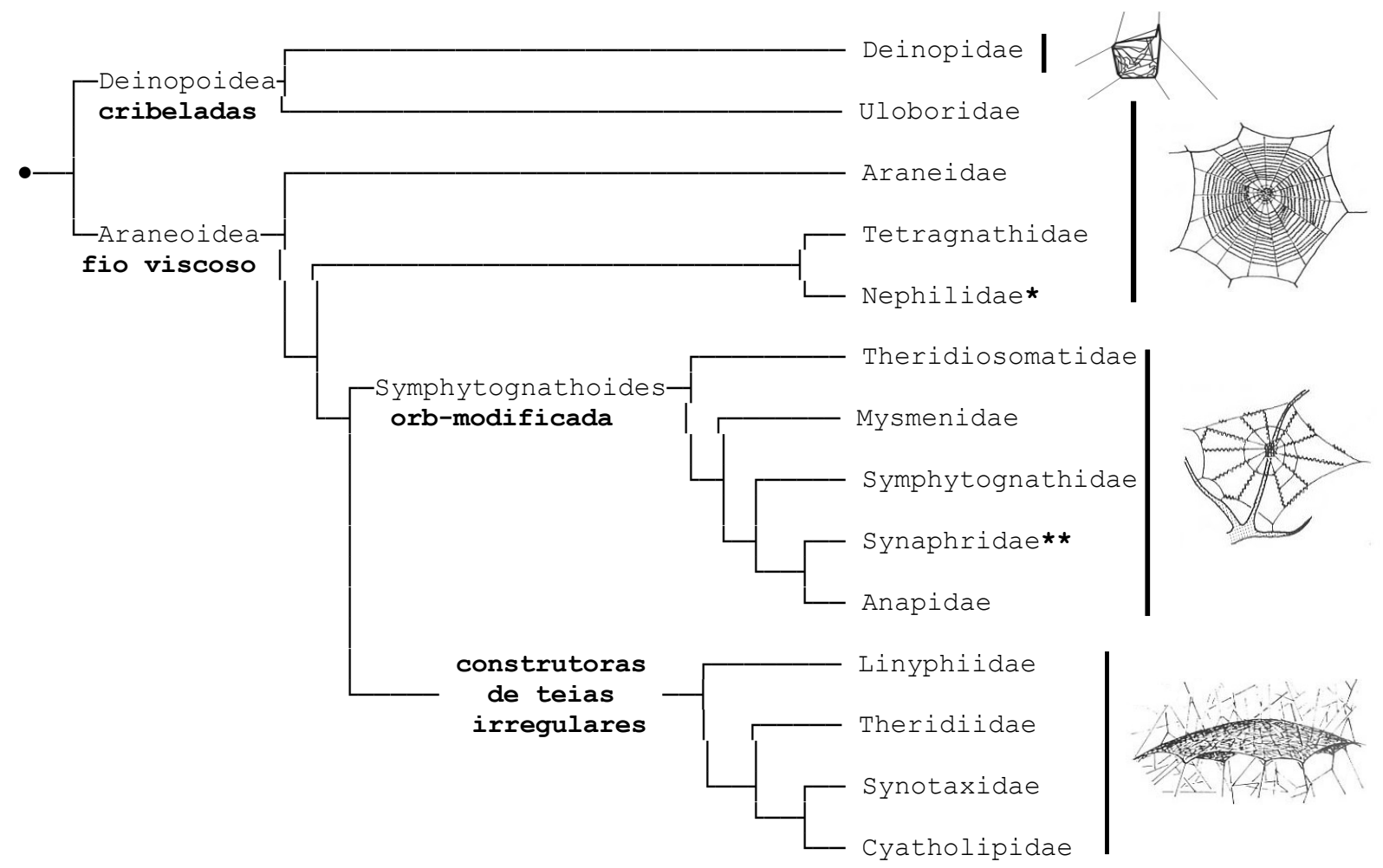

Figura 2. Cladograma das Orbiculariae: grupo de aranhas construtoras de teia orbicular. A teia orbicular é basal e surge entre as aranhas cribeladas. A perda do cribelo ocorre simultaneamente ao surgimento do fio viscoso. Dentro de Araneoidea há ainda a perda do padrão de teia orbicular, parcialmente em Symphytognathoides e, totalmente, nas aranhas construtoras de teias irregulares. Filogenia adaptada de Griswold et al. (1998) e as figuras das teias de Foelix (1996).* atualizado segundo Kuntner (2006). ** atualizado segundo Marusik \& Lehtinen (2003).

A partir desses trabalhos as famílias de aranhas cribeladas, que anteriormente faziam parte de um único táxon chamado Cribellatae (em contraposição ao grupo das aranhas nãocribeladas, Ecribellatae), além de espalhadas na filogenia, surgem como grupo irmão menos diverso de vários clados de aranhas (figura 3). Mesmo aparecendo como grupo menos especioso em vários ramos da filogenia, a presença de aranhas cribeladas em quase todas as famílias de Araneomorphae mostra a importância do cribelo em sua grande diversificação quando comparado a Mygalomorphae (Coddington \& Levi, 1991). 


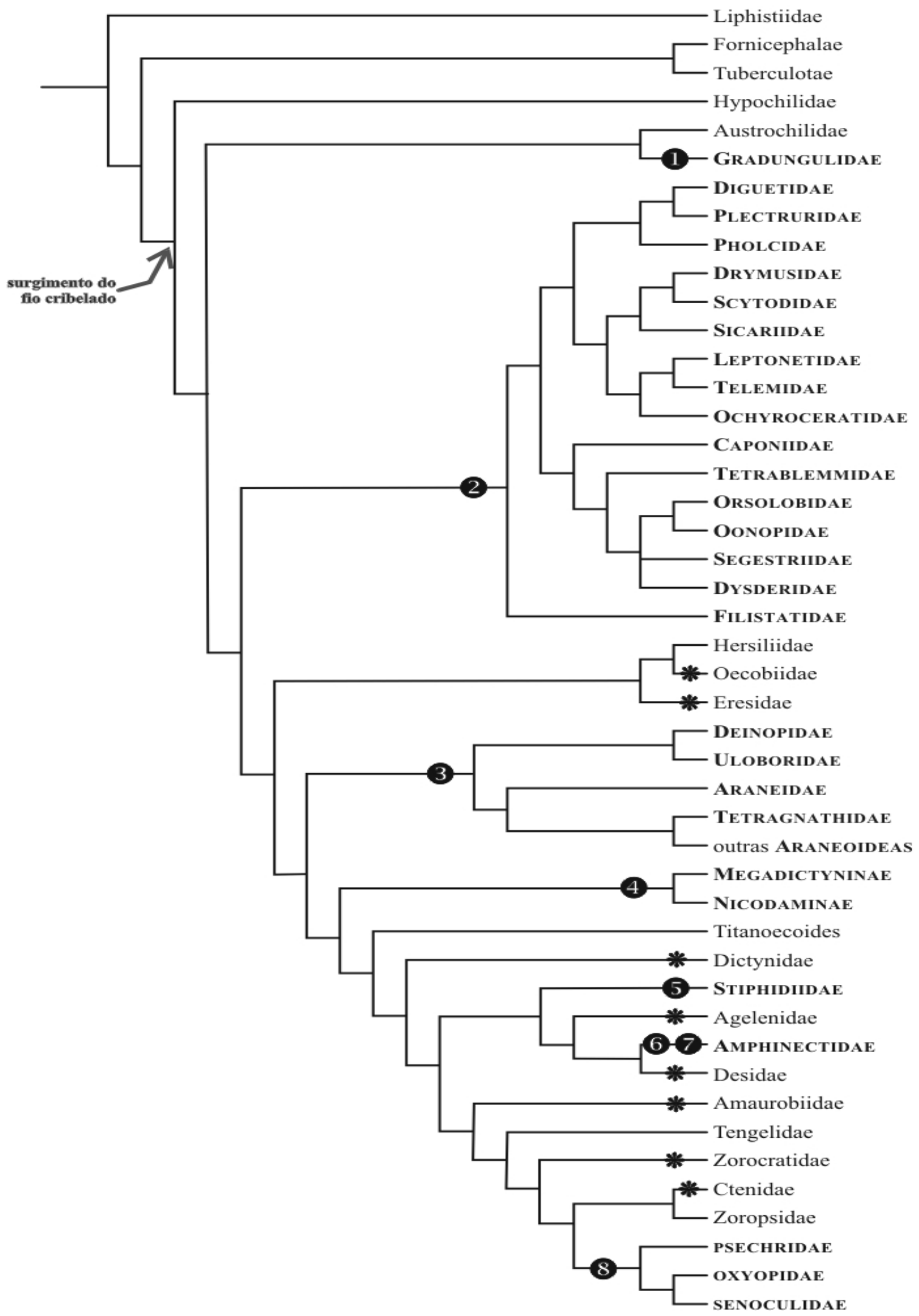

Figura 3. Filogenia atual das Araneomorphae. Os clados usados na análise estão numerados. Outros pontos em que há pares de aranhas ecribeladas/cribeladas estão marcados com asterisco. Os demais táxons não possuem espécies sem cribelo. Reproduzido e adaptado de Griswold et al., 1999. 
A múltipla perda do cribelo e a menor diversificação desses grupos cribelados nos levam a pensar nos fatores associados à sua perda em detrimento de outras estratégias de forrageamento possíveis. Apesar da filogenia de Araneae ainda estar sendo consolidada e definida, o acúmulo de trabalhos é suficiente para que diversos ramos da filogenia possam ser usados em estudos comparativos entre aranhas cribeladas e ecribeladas.

A idéia de superioridade da teia orbicular, ideal de otimização de material e organização da armadilha, ainda permeia as hipóteses explicativas para a grande diversificação de Araneoidea apesar deste não ser o único ponto da filogenia em que há perda do cribelo. $\mathrm{O}$ foco de muitos trabalhos sobre a diversificação das orbitelas (v. Capítulo 1) está nas aranhas de teia viscosa e, sendo assim, qualquer característica presente nestas e ausente no grupo irmão cribelado menos especioso (Deinopoidea) poderia ser usada como adaptação-chave, ou seja, como a característica que teria surgido no grupo e levado a este aumento no número de espécies. Até mesmo características menos populares, como a presença de um fio de quadro secundário (Capítulo 1, tabela 1) ou mesmo as características morfológicas exclusivas de Araneoidea poderiam ser propostas como adaptações-chave. A ocorrência de outras perdas independentes do cribelo no panorama mais geral das Araneomorphae permite e favorece análises mais consistentes e nos levam a questionar: será que a perda do cribelo é a responsável pela grande diversificação dentro de Araneomorphae, inclusive no clado Orbiculariae? 


\section{INVESTIGANDO A DIVERSIFICAÇÃO DAS ARANHAS}

O padrão de diversificação dos organismos ao longo das filogenias apresenta inúmeros casos em que um grupo taxonômico é maior do que seu grupo irmão (Slowinski \& Guyer, 1993). O mesmo ocorre ao longo da filogenia de Araneae. Bond \& Opell (1998) demonstram que Araneae apresenta significativamente mais nós desbalanceados do que o previsto pelo modelo nulo (Markoviano), e que parte dessa diversificação pode ser atribuída à causas determinísticas (p.e. radiação adaptativa). Tendo Orbiculariae como o grupo de aranhas mais estudado e estabelecido na época, Bond \& Opell (1998) testaram a hipótese da maior diversificação do grupo ecribelado (Araneoidea) em relação ao seu grupo-irmão menos especioso cribelado (Deinopoidea) usando o modelo proposto por Sanderson \& Donoghue (1994) para um ramo composto por três táxons terminais e que tem como foco a amplitude da diversificação em contraste com um modelo nulo de diversificação aleatória. Este teste foi desenvolvido justamente para analisar um evento que ocorreu somente uma vez na filogenia dos vegetais, o surgimento das flores.

O uso de grupos-irmãos é a forma mais simples de igualar o tempo de diversificação entre dois grupos que serão comparados. Grupos-irmãos especiaram no mesmo momento evolutivo, originando-se de um mesmo ancestral e, portanto, tiveram o mesmo tempo evolutivo para sua diversificação; mesmo assim, um ou outro destes grupos pode apresentar diferenças nas taxas de extinção e/ou especiação que podem ser atribuídas a alguma característica, ou adaptação-chave, presente em um dos ramos. Porém, a opção por um modelo que verifica a diversificação e radiação adaptativa em um único ramo na filogenia é fortemente questionável (Mitter et al., 1988; Slowinski \& Guyer, 1993) já que ao testar somente um evento de diversificação (ao usar apenas um par de grupos-irmãos), a radiação verificada pode estar associada a qualquer característica que tenha surgido na base do grupo que se 
diversificou de forma mais pronunciada.

Tendo em vista o panorama mais amplo da evolução das Araneomorphae, repleto de perdas homoplásticas do cribelo, percebemos que a constatação de que a radiação de Araneoidea está associada a adaptações-chave presentes somente nessa família precisa ser revista e comparada com as demais perdas na busca de regras mais gerais para o fenômeno. Não há como distinguir e analisar qual adaptação-chave é responsável pela maior diversificação de Araneoidea, se tomarmos apenas um único par de grupos-irmãos (Deinopoidea/Araneoidea) onde tais adaptações-chave evoluíram, como pretendiam Bond \& Opell (1998). Dentre as características que diferenciam Deinopoidea e Araneoidea, portanto, dentre as possíveis adaptações-chave que explicariam a maior diversidade de Araneoidea, a perda do cribelo é uma das que podem ser testadas, tendo em vista a grande quantidade de perdas independentes ao longo da filogenia. O presente trabalho, então, pretende comparar os resultados obtidos por Bond \& Opell (1998) com um possível padrão mais geral para a diversificação de Araneoidea. Assim, o que se busca testar é se a maior diversificação de Araneoidea faz parte de um fenômeno mais geral, qual seja, o de um aumento da diversidade como fruto da perda do cribelo. Para tanto, foi feito um levantamento exaustivo na literatura acerca dos momentos independentes de perda de cribelo ao longo da filogenia de Araneomorphae.

\subsection{Análises dos dados de diversidade em Araneomorphae}

A escolha de ramos cribelado/ecribelado permite que comparemos padrões de diversificação em grupos que tiveram o mesmo tempo para se diversificarem. Mitter et al. (1988) usam o Sign Test (Sokal \& Rohlf, 1987) para verificar a diversificação diferenciada de grupos de insetos que se tornaram herbívoros. Este teste é apropriado para analisar, em 
diversos ramos independentes na filogenia, se a herbívoria, por exemplo, leva a mais especiação, mas não se preocupa com a amplitude dessa diversificação.

O modelo proposto por Slowinski \& Guyer (1993) prevê extinções e especiações aleatórias, e é mais sensível para verificar um padrão de diversificação em vários ramos independentes na filogenia, considerando tanto a quantidade de ramos mais diversos quanto a amplitude da especiação. Para comparar a diversificação, em número de espécies, das aranhas que mantiveram o cribelo e os grupos-irmãos que perderam a estrutura, usamos a fõrmula $\mathrm{Pc}=$ $(n-r) /(n-1)$, proposta por Slowinski \& Guyer (1993) para calcular a probabilidade dos ramos terem taxas diferentes de especiação, onde $\mathbf{n}$ é a quantidade total de espécies do clado, e r é o número de espécies no ramo com a característica estudada. No presente trabalho, $\mathrm{r}$ é o ramo que perdeu o cribelo. A estatística usada foi a probabilidade combinada de Fisher $^{5}$ (Sokal \& Rohlf, 1987) com distribuição $\mathrm{X}^{2}$ com $2 k$ de graus de liberdade, onde $k$ é o número de probabilidades calculadas. Foram selecionados somente táxons de trabalhos que propunham filogenia dos grupos (tabela 1), evitamos: a) filogenias pouco estáveis, ou seja, com elevada quantidade de árvores igualmente parcimoniosas; e b) filogenias em que os autores previam futuras mudanças, como para o par ecribelado/cribelado Urocteninae/Oecobiinae, subfamílias de Oecobiidae, ou o par Calocteninae/Acanthocteninae, subfamílias de Ctenidae, casos nos quais os autores do trabalho colocavam em dúvida a relação de grupos-irmãos entre os clados citados.

\footnotetext{
${ }^{5}$ A fórmula do teste de Fisher é $-2 \Sigma \ln p i$, onde $p i$ é a iésima probabilidade obtida pela fórmula $\mathrm{Pc}=(\mathrm{n}-\mathrm{r}) /(\mathrm{n}-1)$.
} 


\begin{tabular}{|c|c|c|}
\hline clado & táxon & trabalhos usados \\
\hline 1 & $\begin{array}{l}\text { gradungulideos ecribelados/Prograndungula+ Macrogradungula } \\
\text { (Grandungulidae) }\end{array}$ & Forster et al., 1987 \\
\hline 2 & outras Haplogynae/Filistatidae & Platnick et al., 1991 \\
\hline 3 & Araneoidea/Deinopoidea & Griswold et al., 1998 \\
\hline 4 & Nicodaminae/Megadictyninae (Nicodamidae) & Harvey, 1995 \\
\hline 5 & Carbinea/Kababina (Kababininae) & Davies, 1999 \\
\hline 6 & Magua+Keera/Quemusia (Metaltellinae, Amphinectidae) & Davies, 1998 \\
\hline 7 & $\begin{array}{l}\text { Jalkaraburra+Buyna+Calacadia+Penaoola+Austmusia /Cunnawara } \\
\text { (Metaltellinae, Amphinectidae) }\end{array}$ & Davies, 1998 \\
\hline 8 & Oxyopidae+Senoculidae/Psechridae (higher lycosoids) & Davila, 2003 \\
\hline
\end{tabular}

Tabela 1. Táxons ecribelado/cribelado escolhidos para a análise. $O$ número dos clados correspondem aos números na filogenia da figura 2 .

Usando o catálogo de Platnick (2007) atualizamos o número de espécies em cada ramo dos clados analisados, calculamos o valor correspondente a Pc cujos valores estão sumarizados na tabela 2, e o índice de Fisher. A diversidade significativamente maior dos ramos ecribelados $($ Fisher $=33,83, \mathrm{p}<0,01$ e $\mathrm{GL}=16)$ mostra que a perda do cribelo realmente é responsável por sua diversificação dentro de Araneomorphae, o que inclui a diversificação presente em Araneoidea, no clado Orbiculariae.

\begin{tabular}{llccc}
\hline clado & \multicolumn{1}{c}{ táxon } & n & r & Pc \\
\hline $\mathbf{1}$ & $\begin{array}{l}\text { gradungulideos ecribelados/ } \\
\text { Prograndungula+Macrogradungula (Grandungulidae) }\end{array}$ & 16 & 13 & 0,200 \\
$\mathbf{2}$ & outras Haplogynae/Filistatidae & 3257 & 3147 & 0,034 \\
$\mathbf{3}$ & Araneoidea/Deinopoidea & 11521 & 11201 & 0,028 \\
$\mathbf{4}$ & Nicodaminae/Megadictyninae (Nicodamidae) & 29 & 27 & 0,071 \\
$\mathbf{5}$ & Carbinea/Kababina (Kababininae, Amphinectidae) & 13 & 0,750 \\
$\mathbf{6}$ & $\begin{array}{l}\text { Magua+Keera/Quemusia (Metaltellinae, Amphinectidae) } \\
\mathbf{7}\end{array} \quad \begin{array}{l}\text { Jalkaraburra+Buyna+Calacadia+Penaoola+Austmusia } \\
\text { /Cunnawara (Metaltellinae, Amphinectidae) }\end{array}$ & 6 & 2 & 0,800 \\
$\mathbf{8}$ & Oxyopidae+Senoculidae/Psechridae (higher lycosoids) & 19 & 17 & 0,111 \\
\hline
\end{tabular}

Tabela 2. Pc é a probabilidade calculada segundo a fórmula $\mathrm{Pc}=(\mathrm{n}-\mathrm{r}) /(\mathrm{n}-1)$; $\mathbf{n}$ é o total de espécies do clado; e r é a quantidade de espécies no ramo com a característica testada, ausência de cribelo. 


\subsection{CONSIDERAÇÕES SOBRE OS GRUPOS NãO ANALISADOS}

Forster (Forster, 1970; Forster \& Wilton, 1973; Forster et al., 1987) descreveu diversas aranhas na Nova Zelândia, muitas delas cribeladas e pertencentes a famílias classicamente consideradas ecribeladas como, p.e. Agelenidae. Sua percepção sobre o padrão de perda do cribelo está resumida no trecho a seguir:

"The loss of the functional cribellum is obviously related to the adaptive change from a behaviour pattern based on the use of a snare to a active hunting where the production of specialized tangling or stick silk ceases to have any survival value." (Forster, 1970).

Apesar dessa afirmação, ainda não é possível verificar essa hipótese pois os grupos aqui testados não adotam o hábito de vida predominantemente andarilho, muitas ainda são construtoras de teia, e as informações sobre história natural de vários grupos ainda não está disponível na literatura (tabela 3). Além disso, para que possamos explorar a tendência de hábitos de vida dos grupos que perderam o cribelo a filogenia das Araneomorphae precisa estar melhor estabelecida, já que muitos grupos ainda sem filogenia são andarilhos. Entre os pares de aranhas ecribelada/cribelada que não foram usadas devido à instabilidade da filogenia apresentada temos: a ecribelada Urocteninae (19 espécies) e a cribelada Oecobiinae (83 espécies) pertencentes à família Oecobiidae; a família cribelada Eresidae apresenta, atualmente, um único gênero ecribelado Wajane (2 espécies), porém, esse gênero ainda é considerado atípico e pode mudar de família em trabalhos futuros (Griswold et al., 2005). 


\begin{tabular}{|c|c|c|}
\hline clado & táxon & estratégia de captura do táxon ecribelado \\
\hline 1 & $\begin{array}{l}\text { gradungulideos ecribelados/Prograndungula+ } \\
\text { Macrogradungula (Grandungulidae) }\end{array}$ & andarilhas \\
\hline 2 & outras Haplogynae/Filistatidae & $\begin{array}{l}\text { construtoras de teia, tubo de seda, e } \\
\text { andarilhas }\end{array}$ \\
\hline 3 & Araneoidea/Deinopoidea & $\begin{array}{l}\text { construtora de teia com fio de captura } \\
\text { viscoso }\end{array}$ \\
\hline 4 & Nicodaminae/Megadictyninae (Nicodamidae) & $\begin{array}{l}\text { construtoras de teias tênues sem fio } \\
\text { adesivo, perto do solo }\end{array}$ \\
\hline 5 & Carbinea/Kababina (Kababininae) & $?$ \\
\hline 6 & $\begin{array}{l}\text { Magua+Keera/Quemusia (Metaltellinae, } \\
\text { Amphinectidae) }\end{array}$ & $?$ \\
\hline 7 & $\begin{array}{l}\text { Jalkaraburra+Buyna+Calacadia }+ \text { Penaoola }+ \\
\text { Austmusia/Cunnawara (Metaltellinae, } \\
\text { Amphinectidae) }\end{array}$ & $?$ \\
\hline 8 & $\begin{array}{l}\text { Oxyopidae+Senoculidae/Psechridae (higher } \\
\text { lycosoids) }\end{array}$ & andarilhas, caçadoras ativas \\
\hline
\end{tabular}

Tabela 3. Estratégia de captura adotada pelos ramos que perderam o cribelo. Os pontos de interrogação indicam as descrições que não descrevem hábito de vida.

Outros grupos de aranhas ecribelada/cribelada encontram-se em outros pontos da filogenia (figura 2), mas sem estrutura filogenética interna definida. Algumas famílias promissoras para futuras análises estão listadas a seguir:

a) Agelenidae, com 52 espécies cribeladas contra 452 espécies ecribeladas. Três gêneros (Mahura, Porotaka e Tararua) possuem membros cribelados e ecribelados (Lehtinen, 1967; Forster \& Wilton, 1973; Platnick, 2007). São andarilhas e construtoras de teia;

b) Amphinectidae, com 187 espécies das quais cerca de 39 espécies são cribeladas (Lehtinen, 1967; Forster \& Wilton, 1973; Platnick, 2007). As cribeladas geralmente constróem teias pequenas que se estendem a partir do refúgio, e as ecribeladas geralmente são andarilhas; 
c) Stiphidiidae, com 94 espécies das quais cerca de 29 são cribeladas (Lehtinen, 1967; Forster \& Wilton, 1973; Platnick, 2007). Geralmente são construtoras de teia, e as aranhas ecribeladas são consideradas recentes na filogenia;

d) Desidae, com 182 espécies das quais cerca de 65 são cribeladas (Lehtinen, 1967; Forster, 1970; Platnick, 2007). Geralmente constróem refúgios em forma de tubo de seda ou são andarilhas; muitas estão associadas à água e zonas de marés nas praias;

e) Amaurobiidae, com 660 espécies das quais pelo menos 168 espécies são cribeladas (Lehtinen, 1967; Forster \& Wilton, 1973; Platnick, 2007). A taxonomia desta família é bastante instável e muda constantemente. Provavelmente, uma revisão intensiva é necessária antes mesmo que uma filogenia seja proposta para o grupo;

f) Ctenidae, com 39 gêneros e 450 espécies, onde somente quatro gêneros são cribelados (Acanthoctenus, Gephyroctenus, Nothroctenus e Viracucha) que somam 30 espécies cribeladas (Lehtinen, 1967; Griswold et al., 2005; Platnick, 2007). Sua estrutura filogenética ainda é bastante está indefinida e está sujeita a modificações.

As informações listadas acima mostram que futuras análises tendem a confirmar os resultados do presente trabalho. A resolução da filogenia irá permitir verificar a tendência das mudanças e hábitos de vida, e o contexto paleoecológico que, ainda hoje, tem favorecido a perda do cribelo e que, em um primeiro momento, havia favorecido a diversificação em Araneomorphae. As informações presentes na literatura mostram, ainda, que há uma tendência de aumento no padrão geral de atividade dessas aranhas. 


\section{Considerações Finais}

As aranhas construtoras de teia orbicular são as mais conhecidas e estudadas. São as orbitelas que encontramos em nossos jardins, são as teias regulares e geométricas que nos têm encantado e inspirado, inclusive artisticamente. As pesquisas com orbitelas refletem, até hoje, a idéia de superioridade e perfeição da teia orbicular. Um primeiro golpe nessa idéia de superioridade do padrão orbicular de teia foi a perda do padrão orbicular nos grupos mais derivados da filogenia de Orbiculariae. Nosso resultado soma-se a esse primeiro golpe ao mostrar que a perda do cribelo (um fenômeno recorrente, não exclusivo das orbitelas) e não as adaptações-chave listadas por Bond \& Opell (1998), leva ao aumento no número de espécies em relação ao grupo-irmão cribelado e é fonte de um padrão geral de radiação adaptativa em Araneomorphae.

Bond \& Opell (1998) procuraram confirmar a idéia geral de superioridade da teia orbicular viscosa, porém, sua metodologia não é adequada já que testa a ocorrência de um único evento de especiação cuja adaptação-chave associada pode ser qualquer característica que diferencia o ramo cribelado do ramo ecribelado. Para testar as adaptações-chave listadas pelos autores é necessário encontrar outras ocorrências independentes de tais adaptações na filogenia, como foi feito para a perda do cribelo, no presente trabalho. O surgimento do fio adesivo viscoso (uma das prováveis adaptações-chave, entre as listadas por Bond \& Opell) é um caso interessante a se investigar já que foi detectada a presença de nódulos higroscópicos (possíveis intermediários entre o fio cribelado e o viscoso) em muitos exemplares cribelados (p.e. Austrochilidae, Griswold, et al., 2005); além disso foi demonstrado o surgimento independente de seda viscosa em Pholcidae (Japyassú \& Macagnan, 2004) é mais uma prova de que muitas características encontradas em Orbiculariae podem não ser esclusivas desse clado e devem ser testadas em um panorama evolutivo mais amplo. A presença de viscosidade 
nas teias de Pholcidae é uma oportunidade para se analisar as possíveis vantagens do surgimento do fio viscoso dentro da abordagem que propomos.

O surgimento do cribelo, em um primeiro momento da história evolutiva de Araneomorphae, favoreceu uma grande diversificação do grupo haja visto sua presença conspícua na base de todos os seus grandes grupos taxonômicos. O surgimento do fio cribelado conferiu vantagem adaptativa ao aumentar a capacidade de retenção da presa, tendo em vista ter sido o primeiro fio adesivo a surgir na filogenia das aranhas. Essa adaptação-chave pode ter sido favorecida, ainda, por um contexto de grande escassez e flutuação de presas, situação em que uma estratégia mais séssil através de uma armadilha de seda de longa duração é mais vantajosa. Provavelmente, a tendência para o aumento no grau de atividade durante o forrageio levando a mudanças para um hábito de vida mais andarilho, ou para a construção de teias mais baratas, é um efeito mais recente e pode estar associado a alguma mudança paleoecológica ainda não identificada. No entanto, a falta de dados acerca da história natural de muitos grupos não permite que façamos maiores inferências quanto a essa questão.

A perda do cribelo pode estar associada não apenas ao surgimento de um modo de forrageamento mais andarilho, como sugeriu Forster (1970), e sim, de forma mais geral, a um aumento no grau de atividade (ou seja, redução na tenacidade), caso este que incluiria a transição evolutiva entre Deinopoidea e Araneoidea (capítulo 1). Ao deixar de construir um fio cribelado de alto custo, estas aranhas acabaram tendo uma diminuição significativa em seu comprometimento energético diário (capítulo 2), de modo a dispor de energia para um forrageamento mais ativo. A consequência natural deste processo seria a exposição a ambientes mais diversificados, o que poderia, no tempo evolutivo, levar ao aumento observado no número de espécies. 
ANDERSON, J.F. Metabolic rates of spiders. Comparative Biochemistry and Physiology, v. 33, p. $51-72,1970$.

ANDERSON, J.F. \& PRESTWICH, K.N. The fluid pressure pumps of spiders (Chelicerata, Araneae). Z. Morph. Tiere, v. 81, $257-277,1975$.

BELL, J.R., BOHAN, D.A., SHAW, E.M. \& WEYMAN, G.S. Ballooning dispersal using silk: world fauna, phylogenies, genetics and models. Bulletin of Entomological Research, v. 95, p. 69-114, 2005.

BILDE, T., MAKLAKOV, A.A., TAYLOR, P.W. \& LUBIN, Y. State-dependent decisions in nest site selection by a web-building spider. Animal Behaviour, v. 64, n. 3, p. 447-452, 2002 .

BOND, J.E. \& OPELL, B.D. Testing adaptive radiation and key innovation hypotheses in spiders. Evolution, v. 52, p. 403 - 414, 1998.

BRUCE M.J., HEILING A.M. \& HERBERSTEIN M.E. Spider signals: Are web decorations visible to birds and bees? Biology Letters, v. 1, n. 3, p. 299-302, 2005.

CODDINGTON, J.A. The monophyletic origin of the orb web. In Shear, W.A. (Org.) Spiders: Webs, Behavior and Evolution, Standford, Standford University Press, 1986, p. 319 363.

CODDINGTON, J.A. \& LEVI, H.W. Systematics and evolution of spiders (Araneae). Annual Review of Ecology and Systematics. 22: 565 - 592, 1991.

COLEBOURN, P.H. The influence of habitat structure on the distribution of Araneus diadematus Clerck. Journal of Animal Ecology, v. 43, n. 2, p. 401 - 409, 1974.

CRAIG, C.L. Alternative foraging modes of orb web weaving spiders. Biotropica, v. 21, n. 3, p. $257-264,1989$.

CRAIG, C.L. \& EBERT, K. Colour and pattern in predator-prey interactions: the bright body colours and patterns of a tropical orb-spinning spider attract flower-seeking prey. Functional Ecology, v. 8, p. 616-620, 1994.

CRAIG, C.L. \& FREEMAN, C.R. Effects of predator visibility on prey encounter: a case study on aerial web weaving spiders. Behavioral Ecology and Sociobiology, v. 29, p. 249 $-254,1991$.

CRAIG, C.L., BERNARD, G.D. \& CODDINGTON, J.A. Evolutionary shifts in the spectral properties of spider silk. Evolution, v. 48, p. 287 - 296, 1994.

DAVIES, V.T. A revision of the Australian metaltellines (Araneae: Amaurobioidea: Amphinectidae: Metaltellinae). Invertebrate Taxonomy, v. 12, p. 211 - 243, 1998.

DAVIES, V.T. Carbinea, a new spider genus from North Queensland, Australia (Araneae, 
Amaurobioidea, Kababininae). The Journal of Arachnology, v. 27, p. 25 - 36, 1999.

DAVILA, D.S. Higher-level relationships of the spider family Ctenidae (Araneae: Ctenoidea).

Bulletin of the American Museum of Natural History, v. 274, p. 1 - 86, 2003.

EBERHARD, W.G. The ecology of the web of Uloborus diversus (Araneae: Uloboridae). Oecologia, v. 6, p. $328-342,1971$.

EBERHARD, W.G. Rates of egg production by tropical spiders in field. Biotropica, v. 11, n. 4, p. $292-300,1979$.

EBERHARD, W.G. Persistent stickiness of cribellum silk. The Journal of Arachnology, v. 8, p. 283, 1980.

EBERHARD, W.G. Construction behaviour of non-orb weaving cribellate spiders and the evolutionary origin of orb webs. Bulletin of the British Arachnogical Society, v. 7, n. 6, p. $175-178,1987$.

EBERHARD, W.G. Combing and sticky silk attachment behaviour by cribellate spiders and its taxonomic implications. Bulletin of the British Arachnogical Society, v. 7, n. 8, p. 247 $251,1988$.

EBERHARD, W.G. Effects of orb web orientation and spider size on prey retention. Bulletin of the British Arachnogical Society, v. 8, n. 2, p. 45 - 48, 1989.

ENDERS, F. Effects of prey capture, web destruction and habitat physiognomy on web-site tenacity of Argiope spiders (Araneidae). The Journal of Arachnology, v. 3, p. $75-82$, 1975.

FOELIX, R.F. The Biology of Spiders. Cambridge, Harvard University Press, 1996, p. 306.

FORSTER, R.R. The spiders of New Zealand, Part III. Otago Museum Bulletin, v. 3, p. 1 $184,1970$.

FORSTER, R.R. \& WILTON, C.L. The spiders of New Zealand, Part IV. Otago Museum Bulletin, v. 4, p. $1-309,1973$.

FORSTER, R.R., PLATNICK, N.I. \& GRAY, M.R. A review of the spider superfamilies Hypochiloidea and Austrochiloidea (Araneae, Araneomorphae). Bulletin of the American Museum of Natural History, V. 185, P. 1 - 116, 1987.

FOWLER, J., COHEN, L. \& JARVIS, P. Practical statistics for field biology. Chichester, John Wiley \& Sons, 1998, p. 259.

GILLESPIE, R.G. The quest for prey by the web-building spider Amaurobius similis (Blackwell), Animal Behavior, v. 29, p. 953 - 954, 1981.

GILLESPIE, R.G. The mechanism of habitat selection in the long-jawed orb-weaving spider Tetragnatha elongata (Araneae, Tetragnathidae). The Journal of Arachnology, v. 15, p. $81-89,1987$.

GILLESPIE, R.G. \& CARACO, T. Risk-sensitive strategies of two spider populations. Ecology, v. 68, p. $887-899,1987$. 
GONZAGA, M.O., LEINER, N.O. \& SANTOS, A.J. On the sticky cobwebs of two theridiid spiders (Araneae: Theridiidae). Journal of Natural History, v. 40, n. 5-6, p. 293-306, 2006.

GREENSTONE, M.H. \& BENNETT, A.F. Foraging strategy and metabolic rate in spiders. Ecology, v. 61, n. 5, p. 1255 - 1259, 1980.

GRISWOLD, C.E., CODDINGTON, J.A., HORMIGA, G. \& SCHARFF, N. Phylogeny of the orb-web building spiders (Araneae, Orbiculariae: Deinopoidea, Araneoidea). Zoological Journal of the Linnean Society, v. 123, p. 1 - 99, 1998.

GRISWOLD, C.E., CODDINGTON, J.A., PLATNICK, N.I. \& FORSTER, R.R. Towards a phylogeny of entelegyne spiders (Araneae, Entelegynae). The Journal of Arachnology, v. 27, p. $53-63,1999$.

GRISWOLD, C.E., RAMÍRES, M.J., CODDINGTON, J.A. \& PLATNICK, N.I. Atlas of phylogenetic data for Entelegyne spiders (Araneae: Araneomorphae: Entelegynae) with comments on their phylogeny. Proceedings of the California Academy of Science, v. 56, supplement II, p. 1 - 324, 2005.

GROSS A. J. \& CLARK V. A. Survival distributions: reliability applications in the biomedical sciences. New York, Wiley, p. 331. 1975.

GUNNARSSON, B. Fractal dimension of plants and body size distribution in spiders. Functional Ecology, v. 6, p. 636 - 641, 1992.

HARVEY, M.S. The systematics of the spider family Nicodamidae (Araneae: Amaurobioidea). Invertebrate Taxonomy, v. 9, p. $279-386,1995$.

HAWTHORN, A.C. \& OPELL, B.D. Evolution of adhesive mechanisms in cribellar spider prey capture threads: evidence for van der Waals and hygroscopic forces. Biological Journal of the Linnean Society, v. 77, p. 1 - 8, 2002.

HAWTHORN, A.C. \& OPELL, B.D. van der Waals and hygroscopic forces of adhesion generated by spider capture threads. Journal of Experimental Biology, v. 206, p. 3905 3911, 2003.

HENSCHEL, J.R. \& LUBIN, Y.D. A test of habitat selection at two spatial scales in a sit-andwait predator: a web spider in the Namib Desert dunes. Journal of Animal Ecology, v. 66, p. $401-413,1997$.

HERBERSTEIN, M.E., CRAIG, C.L., CODDINGTON, J.A. \& ELGAR, M.A. The functional significance of silk decorations of orb-web spiders: a critical review of the empirical evidence. Biological Review, v. 75, p. 649 - 669, 2000.

HIGGINS, L.E. Direct evidence for trade-offs between foraging and growth in a juvenile spider. The Journal of Arachnology, v. 23, p. 37 - 43, 1995.

HIGGINS, L.E., TOWNLEY, M.A., TILLINGHAST, E.K. \& RANKIN, M.A. Variation in the chemical composition of orb webs built by the spider Nephila clavipes (Araneae, Tetragnathidae). The Journal of Arachnology, v. 29, p. 82 - 94, 2001.

ICHINOSE, K., RINALDI, I. \& FORTI, L.C. Winged leaf-cutting ants on nuptial flights used as transport by Attacobius spiders for dispersal. Ecological Entomology, v. 29, p. 628- 
$631,2004$.

JACKSON R.R., POLLARD S.D. \& CERVEIRA A.M. Opportunistic use of cognitive smokescreens by araneophagic jumping spiders. Animal Cognition, v. 5, n. 3, p. 147 $157,2002$.

JANETOS, A.C. Foraging tactics of two guilds of web-spinning spiders. Behavioral Ecology and Sociobiology, v. 10, p. $19-27,1982$.

JANETOS, A.C. Web-site selection: Are we asking the right questions? In Shear, W.A. (Org.) Spiders: Webs, Behavior and Evolution, Standford, Standford University Press, 1986, p. $9-22$.

JAPYASSÚ, H.F. De orbicular a semi-orbicular : transições e instabilidades no desenvolvimento da teia de Nephilengys Cruentata (Araneae, tetragnathidae). 1998. 125 f. (Doutorado em Psicologia Experimental) - Instituto de Psicologia, Universidade de São Paulo, São Paulo, 21.10.1998.

JAPYASSÚ, H.F. \& MACAGNAN, C.R. Fishing for prey: the evolution of a new predatory tactic among spiders (Araneae, Pholcidae). Revista de Etologia, v. 6, n. 2, p. $79-94$, 2004.

JOCQUÉ, R. On reduced size in spiders from marginal habitats. Oecologia, v. 49, p. $404-$ 408, 1981.

KIM, K.W. Dispersal behaviour in a subsocial spider: group conflict and the effect of food availability. Behavioral Ecology and Sociobiology, v. 48, p.182-187, 2000.

KÖHLER, T. \& VOLLRATH, F. Thread biomechanics in the two orb-weaving spiders Araneus diadematus (Araneae, Araneidae) and Uloborus walckenaerius (Araneae, Uloboridae). Journal of Experimental Zoology, v. 271, p. 1 - 17, 1995.

KUNO, E. Dispersal and the persistence of populations in unstable habitats: a theoretical note. Oecologia. v. 49, p. $123-126,1981$.

KUNTNER, M. Phylogenetic systematics of the Gondwanan nephilid spider lineage Clitaetrinae (Araneae, Nephilidae). Zoologica Scripta, v. 35, p. 19 - 62, 2006.

LEHTINEN, P.T. Classification of the Cribellate spiders and some allied families, with notes on the evolution of the suborder Araneomorphae. Annales Zoologici Fennici, v. 4, n. 3, 1967.

LI, D., LIM, M.L.M., SEAH, W.K. \& TAY, S.L. Prey attraction as a possible function of discoid stabilimenta of juvenile orb-spinning spiders. Animal Behaviour, v. 68, n. 2, p. $629-635,2004$.

LIGHTON, J.R.B., BROWNELL, P.H., JOOS, B. \& TURNER, R.J. Low metabolic rate in scorpions: Implications for population biomass and cannibalism. Journal of Experimental Biology, v. 204, p. $607-613,2001$.

LUBIN, Y.D. Web building and prey capture in the Uloboridae. In Shear, W.A. (Org.) Spiders: Webs, Behavior and Evolution, Standford, Standford University Press, 1986, p.132 171. 
LUBIN, Y.D., ELLNER, S. \& KOTZMAN, M. Web relocation and habitat selection in a desert widow spider. Ecology, v. 74, n. 7, p. 1915 - 1928, 1993.

MARUSIK, Y.M. \& LEHTINEN, P.T. Synaphridae Wunderlich, 1986 (Araneae: Araneoidea), a new family status, with a description of a new species from Turkmenistan. Arthropoda Selecta, v. 11, p. 143-152, 2003.

MITTER, C., FARRELL, B. \& WIEGMANN, B. The phylogenetic study of adaptive zones: has phytophagy promoted insect diversification? The American Naturalist, v. 132, p. 107 $-128,1988$.

MOTULSKY, H. Intuitive biostatistics. Oxford, Oxford University Press, 1995, p. 386.

NAKATA, K., USHIMARU, A. \& WATANABE, T. Using past experience in web relocation decisions enhances the foraging efficiency of the spider Cyclosa argenteoalba. Journal of Insects Behavior. v. 16, p. $371-380,2003$.

OLIVE, C.W. Optimal phenology and body-size of orb-weaving spiders: foraging constraints. Oecologia, v. 49, p. $83-87,1981$.

OPELL, B.D. Revision of the genera and tropical American species of the spider family Uloboridae. Bulletin of the Museum of Comparative Zoology, v. 148, n. 10, p. $443-$ $549,1979$.

OPELL, B.D. Functional similarities of spider webs with diverse architectures. American Naturalist, v. 148, p. $630-648,1996$.

OPELL, B.D. Economics of spider orb-webs: the benefits of producing adhesive capture thread and of recycling silk. Functional Ecology, v. 12, p. 613 - 624, 1998 a.

OPELL, B.D. Economics of spider orb-webs: the benefits of producing adhesive capture thread and of recycling silk. Functional Ecology, v. 12, p. 613 - 624, 1998 b.

OPELL, B.D. Changes in spinning anatomy and thread stickiness associated with origin of orb-weaving spiders. Biological Journal of the Linnean Society, v. 68, p. $593-612$, 1999.

OPELL, B.D. \& BOND, J.E. Capture thread extensibility of orb-weaving spiders: testing punctuated and associative explanations of character evolution. Biological Journal of the Linnean Society, v. 70, p. $107-120,2000$.

OPELL, B.D. \& EBERHARD, W.G. Resting postures of orb-weaving uloborid spiders (Araneae, Uloboridae). The Journal of Arachnology, v. 11, p. 369 - 376, 1984.

OPELL, B.D., BOND, J.E. \& WARNER, D.A. The effects of capture spiral composition and orb-web orientation on prey interception. Zoology, v. 109, p. $339-345,2006$.

PASQUET, A., RIDWAN, A. \& LEBORGNE, R. Presence of potencial prey affects webbuilding in an orb-weaving spider Zygiella x-notata. Animal Behavior, v. 47, p. 477 480, 1994.

PEAKALL, D.B. \& WITT, P.N. The energy budget of an orb web-building spider. Comparative Biochemistry and Physiology, v. 54A, p. 187 - 190, 1976. 
PETERS, H.M. Fine structure and function of capture threads. In Nentwig, W. (Org.). Ecophysiology of Spiders. Berlim, Springer Verlag, 1987, p. 187-202.

PLATNICK, N. I. 2007. The world spider catalog, version 7.5. American Museum of Natural History, disponível em <http://research.amnh.org/entomology/spiders/catalog/index>, Acesso em 01.02.2007.

PLATNICK, N.I., CODDINGTON, J.A., FORSTER, R.R. \& GRISWOLD, C.E. Spinneret morphology and the phylogeny of haplogyne spiders (Araneae, Araneomorphae). American Museum Novitates, v. 3016, p. 1 - 73, 1991.

POST, W.M. \& RIECHERT, S.E. Initial investigation into the structure of spider communities. Journal of Animal Ecology, v. 46, p. 729 - 749, 1977.

PRESTWICH, K.N. The energetics of web-building in spiders. Comparative Biochemistry and Physiology, v. 57A, p. $321-326,1977$.

PULZ, R. Thermal and water relations. In Nentwig, W. (Org.). Ecophysiology of Spiders. Berlim, Springer Verlag, 1987, p. $26-55$.

REINHOLD, K. Energetically costly behaviour and the evolution of resting metabolic rate in insects. Functional Ecology, v. 16, p. 217 - 224, 1999.

RIECHERT, S.E. \& GILLESPIE, R.G. Habitat choice and utilization in web-building spiders. In Shear, W.A. (Org.) Spiders: Webs, Behavior and Evolution, Standford, Standford University Press, 1986, p. 23 - 48.

RIECHERT, S.E. \& TRACY, R. Thermal balance and prey availability: bases for a model relating web-site characteristics to spider reproductive success. Ecology, v. 56, p. $265-$ 284, 1975.

ROBINSON, J.V. The effect of architectural variation in habitat on a spider community: an experimental field study. Ecology, v. 62, p. 73 - 80, 1981.

RYPSTRA, A.L. Aggregations of Nephila clavipes (L.) (Araneae, Araneidae) in relation to prey availability. The Journal of Arachnology, v. 13, p. 71 - 78, 1985.

SANDERSON, M,J. \& DONOGHUE, M.J. Shifts in diversification rate with the origin of angiosperms. Science, v. 264, p. 1590 - 1593, 1994.

SANDOVAL, C.P. Plasticity in web design in the spider Parawixia bistriata: a response to variable prey type. Functional Ecology, v. 8, p. 701 - 707, 1994.

SCHUCK-PAIM, C. Orb-webs as extended-phenotypes: web design and size assessment in contests between Nephilengys cruentata females (Araneae, Tetragnathidae). Behaviour, v. 137, n. 10, p. $1331-1347,2000$.

SCHUCK-PAIM, C. \& ALONSO, W. Deciding where to settle: conspecific attraction and web site selection in the orb-web spider Nephilengys cruentata. Animal Behavior, v. 62, n. 5, p. $1007-1012,2001$.

SHEAR, W.A. The evolution of web-building behavior in spiders: a third generation of hypothesis. In Shear, W.A. (Org.) Spiders: Webs, Behavior and Evolution, Standford, Standford University Press, 1986, p. 492. 
SHERMAN, P.M. The orb-web: an energetic and behavioral estimator of a spider's dynamic foraging and reproductive strategies. Animal Behavior, v. 48, p. 19 - 34, 1994.

SLOWINSKI, J.B. \& GUYER, C. Testing whether certain traits have caused amplified diversification: an improved method based on a model of random speciation and extinction. The American Naturalist, v. 142, n.6, p. 1019 - 1024, 1993.

SOKAL, R.R. \& ROHLF, F.J. Introduction to Biostatistics. $2^{\mathrm{a}}$ ed., New York, Freeman, 1987, p. 363.

TARSITANO M., JACKSON R.R. \& KIRCHNER W.H. Signals and signal choices made by the araneophagic jumping spider Portia fimbriata while hunting the orb-weaving web spiders Zygiella x-notata and Zosis geniculatus. Ethology, v. 106, n. 7, p. 595 - 615, 2000.

UETZ, G.W. Foraging strategies of spiders. Trends in Ecology and Evolution, v. 7, n. 5, p. $155-159,1992$.

UETZ, G.W., HALAJ, J. \& CADY, A.B. Guild structure of spiders in major crops. The Journal of Arachnology, v. 27, p. 270 - 280, 1999.

VOLLRATH, F. Web spider's dilemma: a risky move or site dependent growth. Oecologia, v. 68, p. $69-72,1985$.

VOLLRATH\& F. \& HOUSTON, A. Previous experience and site tenacity in the orb spider Nephila (Araneae, Araneidae). Oecologia, v. 70, p. 305 - 308, 1986.

VOLLRATH, F. \& SAMU, F. The effect of starvation on web geometry in an orb-weaving spider. Bulletin of the British Arachnogical Society, v. 10, p. 295 - 298, 1997.

WATANABE, T. Prey attraction as a possible function of the silk decoration of the uloborid spider Octonoba sybotides. Behavioral Ecology, v. 10, n. 5, p. 607 - 311, 1999.

WISE, D.H. Effects of an experimental increase in prey abundance upon the reproductive rates of two orb-weaving spider species (Araneae: Araneidae). Oecologia, v. 41, p. $289-300$, 1979 .

WISE, D.H. Spiders in ecological webs. Cambridge, Cambridge University Press, 1993, p. 328.

WITHERS, P.C. Comparative animal physiology. Fort Worth, Saunders College Pub., 1992, p. 949.

ZSCHOKKE, S. Ultraviolet reflectance of spiders and their webs. The Journal of Arachnology, v. 30, p. 246-254. 2002.

ZSCHOKKE, S. \& VOLLRATH, F. Unfreezing the behaviour of two orb spiders. Physiology and Behavior, v. 58, p. 1167 - 1173, 1995a.

ZSCHOKKE, S. \& VOLLRATH, F. Web construction patterns in a range of orb-weaving spiders (Araneae). European Journal of Entomology, v. 92, p. 523 - 541, 1995b. 


\section{Anexos}




\section{$\operatorname{Anexo} A$}

Planilha do experimento de redução progressiva da dieta de Metazygia rogenhoferi

\begin{tabular}{|c|c|c|c|c|c|c|c|c|c|c|}
\hline & $\begin{array}{l}\mathrm{tpl} \\
(\mathrm{mm})\end{array}$ & dia & $\begin{array}{l}\text { dias sem } \\
\text { reconstruir }\end{array}$ & data & $\begin{array}{c}\text { espiral de } \\
\text { captura }(\mathrm{cm})\end{array}$ & $\begin{array}{l}\text { área }\left(\mathrm{cm}^{2}\right) \\
\text { reconstruída }\end{array}$ & $\begin{array}{l}\text { densidade de fios } \\
\text { (espira/área) }\end{array}$ & $\begin{array}{c}\text { diâmetro } \\
\text { vertical }\end{array}$ & $\begin{array}{c}\text { diâmetro } \\
\text { horizontal }\end{array}$ & $\begin{array}{c}\text { distância } \\
\text { centro/refúgio }\end{array}$ \\
\hline $\mathrm{G} 2$ & 2,6 & 9 & & 05.07 .05 & 542,3000 & 179,50 & 3,02 & 23,0 & 7,0 & 11,3 \\
\hline \multirow[t]{6}{*}{ controle } & & 10 & 0 & 06.07 .05 & 268,2000 & 116,27 & 2,31 & 18,0 & 14,5 & 12,5 \\
\hline & & 19 & 8 & 15.07 .05 & 389,7000 & 147,06 & 2,65 & 18,5 & 13,5 & 18,0 \\
\hline & & 24 & 4 & 20.07 .05 & 296,5000 & 88,48 & 3,35 & 15,4 & 12,2 & 17,0 \\
\hline & & 30 & 5 & 26.07 .05 & 232,9000 & 100,26 & 2,32 & 14,0 & 13,0 & 17,5 \\
\hline & & 36 & 5 & 01.08 .05 & 248,4100 & 62,44 & 3,98 & 17,5 & 12,4 & 15,5 \\
\hline & & 43 & morte & 08.08 .05 & & & & & & \\
\hline G11 & 2,5 & 9 & & 05.07 .05 & 378,750 & 94,42 & 4,01 & 15,5 & 11,3 & 11,5 \\
\hline \multirow[t]{4}{*}{ experimental } & & 15 & 5 & 11.07 .05 & 458,000 & 152,99 & 2,99 & 18,5 & 15,5 & 9,5 \\
\hline & & 18 & 2 & 14.07 .05 & 199,750 & 56,34 & 3,55 & 18,5 & 13,3 & 10,2 \\
\hline & & 24 & 4 & 20.07 .05 & 458,200 & 221,82 & 2,07 & 21,0 & 17,0 & 13,4 \\
\hline & & 26 & morte & 22.07 .05 & & & & & & \\
\hline $\mathrm{G} 13$ & 3,0 & 13 & 3 & 09.07 .05 & 151,2000 & 62,77 & 2,41 & 11,7 & 9,8 & 8,0 \\
\hline \multirow[t]{5}{*}{ experimental } & & 23 & 9 & 19.07 .05 & 214,7000 & 86,04 & 2,50 & 13,0 & 10,0 & 24,3 \\
\hline & & 26 & 2 & 22.07 .05 & 146,5000 & 35,82 & 4,09 & 9,1 & 8,0 & 7,0 \\
\hline & & 30 & 3 & 26.07 .05 & 159,3000 & 43,84 & 3,63 & 11,3 & 8,5 & 22,5 \\
\hline & & 32 & 1 & 28.07 .05 & 108,6000 & 27,07 & 4,01 & 10,3 & 11,0 & 4,0 \\
\hline & & 36 & fuga & 01.08 .05 & & & & & & \\
\hline G14 & 2,9 & 9 & & 05.07 .05 & 267,1400 & 120,76 & 2,21 & 12,5 & 11,5 & 14,0 \\
\hline \multirow[t]{3}{*}{ controle } & & 22 & 12 & 18.07 .05 & 69,3100 & 34,91 & 1,99 & 11,8 & 9,5 & 10,0 \\
\hline & & 32 & 9 & 28.07 .05 & 60,3300 & 52,34 & 1,15 & 10,0 & 6,8 & 7,5 \\
\hline & & 43 & fuga & 08.08 .05 & & & & & & \\
\hline G17 & 2,8 & 9 & & 05.07 .05 & 449,0600 & 124,39 & 3,61 & 15,5 & 10,0 & 9,0 \\
\hline \multirow[t]{4}{*}{ experimental } & & 13 & 3 & 09.07 .05 & 184,0400 & 42,49 & 4,33 & 8,5 & 9,0 & 14,0 \\
\hline & & 22 & 8 & 18.07 .05 & 305,8000 & 86,34 & 3,54 & 15,6 & 11,4 & 9,5 \\
\hline & & 30 & 7 & 26.07 .05 & 189,6000 & 26,22 & 7,23 & 14,6 & 8,8 & 8,4 \\
\hline & & 43 & morte & 08.08 .05 & & & & & & \\
\hline $\mathrm{G} 18$ & 3,0 & 9 & & 05.07 .05 & 397,830 & 301,67 & 1,32 & 26,0 & 15,5 & 14,0 \\
\hline \multirow[t]{3}{*}{ controle } & & 13 & 3 & 09.07 .05 & 266,220 & 96,63 & 2,76 & 20,2 & 14,8 & 14,5 \\
\hline & & 16 & 2 & 12.07 .05 & 272,530 & 99,84 & 2,73 & 18,9 & 11,5 & 15,0 \\
\hline & & 28 & morte & 24.07 .05 & & & & & & \\
\hline $\mathrm{G} 20$ & 2,7 & 9 & & 05.07 .05 & 391,27 & 145,53 & 2,69 & 19,5 & 12,2 & 11,0 \\
\hline \multirow[t]{9}{*}{ experimental } & & 13 & 3 & 09.07 .05 & 372,01 & 118,37 & 3,14 & 16,1 & 13,5 & 11,0 \\
\hline & & 15 & 1 & 11.07 .05 & 444,66 & 137,50 & 3,23 & 20,3 & 18,5 & 11,5 \\
\hline & & 18 & 2 & 14.07 .05 & 456,57 & 254,00 & 1,80 & 21,8 & 17,5 & 11,8 \\
\hline & & 19 & 0 & 15.07 .05 & 441,37 & 191,10 & 2,31 & 21,5 & 19,0 & 11,5 \\
\hline & & 22 & 2 & 18.07 .05 & 466,22 & 154,29 & 3,02 & 21,5 & 18,0 & 12,5 \\
\hline & & 24 & 1 & 20.07 .05 & 234,44 & 63,62 & 3,69 & 20,4 & 18,2 & 11,6 \\
\hline & & 29 & 4 & 25.07 .05 & 125,83 & 30,01 & 4,19 & 7,8 & 6,8 & 4,4 \\
\hline & & 30 & 0 & 26.07 .05 & 378,27 & 148,02 & 2,56 & 16,5 & 18,5 & 10,8 \\
\hline & & 44 & morte & 09.08 .05 & & & & & & \\
\hline
\end{tabular}




\begin{tabular}{|c|c|c|c|c|c|c|c|c|c|c|}
\hline & $\begin{array}{c}\mathrm{tpl} \\
(\mathrm{mm})\end{array}$ & dia & $\begin{array}{l}\text { dias sem } \\
\text { reconstruir }\end{array}$ & data & $\begin{array}{c}\text { espiral de } \\
\text { captura (cm) }\end{array}$ & $\begin{array}{l}\text { área }\left(\mathrm{cm}^{2}\right) \\
\text { reconstruída }\end{array}$ & $\begin{array}{c}\text { densidade de fios } \\
\text { (espira/área) }\end{array}$ & $\begin{array}{c}\text { diâmetro } \\
\text { vertical }\end{array}$ & $\begin{array}{l}\text { diâmetro } \\
\text { horizontal }\end{array}$ & $\begin{array}{c}\text { distância } \\
\text { centro/refúgio }\end{array}$ \\
\hline $\mathrm{G} 22$ & 2,6 & 9 & & 05.07 .05 & 572,8900 & 164,51 & 3,48 & 18,0 & 15,5 & 11,5 \\
\hline \multirow[t]{6}{*}{ controle } & & 11 & 1 & 07.07 .05 & 405,7100 & 95,13 & 4,26 & 22,5 & 14,1 & 10,7 \\
\hline & & 13 & 1 & 09.07 .05 & 220,1800 & 57,13 & 3,85 & 18,2 & 12,7 & 10,7 \\
\hline & & 19 & 5 & 15.07 .05 & 161,8700 & 39,82 & 4,07 & 12,0 & 7,5 & 6,0 \\
\hline & & 30 & 10 & 26.07 .05 & 229,2500 & 74,46 & 3,08 & 15,0 & 9,5 & 8,0 \\
\hline & & 36 & 5 & 01.08 .05 & 120,9100 & 44,14 & 2,74 & 14,3 & 9,5 & 7,5 \\
\hline & & 52 & morte & 17.08 .05 & & & & & & \\
\hline $\mathrm{G} 25$ & 3,0 & 9 & & 05.07 .05 & 490,5200 & 246,90 & 1,99 & 22,2 & 11,0 & 11 \\
\hline \multirow[t]{6}{*}{ controle } & & 22 & 12 & 18.07 .05 & 105,6000 & 19,84 & 5,32 & 6,8 & 5,0 & \\
\hline & & 23 & 0 & 19.07 .05 & 210,6300 & 71,51 & 2,95 & 12,7 & 12,5 & 11,5 \\
\hline & & 26 & 2 & 22.07 .05 & 260,2800 & 62,95 & 4,13 & 15,5 & 12,0 & 12,2 \\
\hline & & 30 & 3 & 26.07 .05 & 235,1700 & 83,27 & 2,82 & 16,8 & 14,4 & 11,7 \\
\hline & & 36 & 5 & 01.08 .05 & 218,4300 & 57,17 & 3,82 & 19,3 & 11,5 & 16,5 \\
\hline & & 43 & fuga & 08.08 .05 & & & & & & \\
\hline $\mathrm{G} 28$ & 2,6 & 13 & 3 & 09.07 .05 & 629,0000 & 172,40 & 3,65 & 19,3 & 8,5 & 15,0 \\
\hline \multirow[t]{12}{*}{ experimental } & & 15 & 1 & 11.07 .05 & 449,4400 & 96,27 & 4,67 & 23,3 & 15,5 & 18,0 \\
\hline & & 18 & 2 & 14.07 .05 & 429,6800 & 158,04 & 2,72 & 27,0 & 13,5 & 15,0 \\
\hline & & 22 & 3 & 18.07 .05 & 679,5700 & 167,37 & 4,06 & 25,0 & 19,0 & 16,0 \\
\hline & & 25 & 2 & 21.07 .05 & 477,7500 & 135,14 & 3,54 & 23,5 & 17,5 & 15,5 \\
\hline & & 26 & 0 & 22.07 .05 & 458,6900 & 116,87 & 3,92 & 26,0 & 16,7 & 14,5 \\
\hline & & 30 & 3 & 26.07 .05 & 723,0200 & 205,54 & 3,52 & 25,4 & 16,0 & 13,8 \\
\hline & & 33 & 2 & 29.07 .05 & 614,3200 & 169,35 & 3,63 & 26,0 & 15,7 & 14,0 \\
\hline & & 36 & 2 & 01.08 .05 & 431,3400 & 184,45 & 2,34 & 24,8 & 16,4 & 14,7 \\
\hline & & 38 & 1 & 03.08 .05 & 165,1200 & 141,22 & 1,17 & 25,0 & 16,8 & 13,6 \\
\hline & & 43 & 4 & 08.08 .05 & 113,3900 & 80,67 & 1,41 & 25,2 & 16,0 & 13,5 \\
\hline & & 48 & 5 & 13.08 .05 & 265,6800 & 112,11 & 2,37 & 23,7 & 16,5 & 13,5 \\
\hline & & & não foge & & & & & & & \\
\hline
\end{tabular}

conclusão 


\section{Anexo B}

Planilha do experimento de redução progressiva da dieta de Zosis geniculata

\begin{tabular}{|c|c|c|c|c|c|c|c|c|c|c|}
\hline & $\begin{array}{c}\mathrm{tpl} \\
(\mathrm{mm})\end{array}$ & dia & $\begin{array}{l}\text { dias sem } \\
\text { reconstruir }\end{array}$ & data & $\begin{array}{l}\text { espiral de } \\
\text { captura (cm) }\end{array}$ & $\begin{array}{l}\text { área }\left(\mathrm{cm}^{2}\right) \\
\text { reconstruída }\end{array}$ & $\begin{array}{l}\text { densidade de fios } \\
\text { (espira/área) }\end{array}$ & diâmetro 1 & diâmetro 2 & ootecas \\
\hline S1 & 3,5 & 9 & & 05.07 .05 & 281,1100 & 115,62 & 2,43 & 21,1 & 14,0 & 1 \\
\hline \multirow[t]{15}{*}{ controle } & & 11 & 1 & 07.07.05 & 202,7000 & 226,60 & 0,89 & 21,3 & 16,5 & 1 \\
\hline & & 15 & 3 & 11.07 .05 & 74,8200 & 152,73 & 0,49 & 20,0 & 16,8 & 2 \\
\hline & & 18 & 2 & 14.07 .05 & 125,1500 & 68,33 & 1,83 & 21,5 & 15,0 & 2 \\
\hline & & 22 & 3 & 18.07 .05 & 73,5700 & 44,16 & 1,67 & 18,0 & 16,5 & 2 \\
\hline & & 23 & 0 & 19.07 .05 & 265,0300 & 134,13 & 1,98 & 22,0 & 15,6 & 2 \\
\hline & & 26 & 3 & 22.07 .05 & 396,7100 & 156,96 & 2,53 & 21,7 & 18,2 & 2 \\
\hline & & 36 & 9 & 01.08 .05 & 40,3800 & 24,72 & 1,63 & 20,0 & 19,5 & 3 \\
\hline & & 38 & 1 & 03.08 .05 & 644,2300 & 202,34 & 3,18 & 22,6 & 17,5 & 3 \\
\hline & & 43 & 4 & 08.08 .05 & 176,7000 & 70,73 & 2,50 & 22,0 & 17,8 & 3 \\
\hline & & 46 & 2 & 11.08 .05 & 249,5800 & 105,00 & 2,38 & 23,3 & 20,3 & 3 \\
\hline & & 50 & 3 & 15.08 .05 & 28,6800 & 20,27 & 1,41 & 22,8 & 19,0 & 3 \\
\hline & & 54 & 3 & 19.08 .05 & 177,6200 & 91,81 & 1,93 & 21,3 & 26,7 & 4 \\
\hline & & 59 & 4 & 24.08 .05 & 158,8900 & 54,37 & 2,92 & 22,0 & 23,5 & 4 \\
\hline & & 64 & 4 & 29.08 .05 & 588,9100 & 125,69 & 4,69 & 26,7 & 26,0 & 4 \\
\hline & & & não foge & & & & & & & \\
\hline S2 & 4 & 9 & & 05.07.05 & 290,25 & 116,60 & 2,49 & 11,0 & 13,4 & 1 \\
\hline \multirow[t]{6}{*}{ experimental } & & 25 & 15 & 21.07.05 & 215,7 & 129,96 & 1,66 & 15,0 & 16,5 & 2 \\
\hline & & 26 & 0 & 22.07.05 & 29,88 & 21,15 & 1,41 & 12,0 & 14,3 & 2 \\
\hline & & 29 & 2 & 25.07 .05 & 133,39 & 74,02 & 1,80 & 14,0 & 14,3 & 2 \\
\hline & & 36 & 6 & 01.08 .05 & 83,13 & 36,91 & 2,25 & 13,6 & 15,8 & 2 \\
\hline & & 50 & 14 & 15.08 .05 & 435,77 & 146,79 & 2,97 & 15,5 & 15,4 & 2 \\
\hline & & 64 & fuga & 29.08 .05 & & & & & & \\
\hline S4 & 3,2 & 9 & & 05.07 .05 & 241,03 & 109,16 & 2,21 & 13,5 & 11,7 & 0 \\
\hline \multirow[t]{7}{*}{ experimental } & & 10 & 0 & 06.07 .05 & 387,89 & 255,07 & 1,52 & 23,0 & 18,0 & 1 \\
\hline & & 15 & 3 & 11.07 .05 & 161,35 & 87,89 & 1,84 & 21,0 & 15,5 & 1 \\
\hline & & 18 & 2 & 14.07 .05 & 643,98 & 196,17 & 3,28 & 19,5 & 23,4 & 1 \\
\hline & & 22 & 2 & 18.07 .05 & 21,11 & 178,08 & 0,12 & 20,0 & 17,0 & 1 \\
\hline & & 33 & 9 & 29.07 .05 & 74,01 & 41,13 & 1,80 & 23,6 & 23,4 & 2 \\
\hline & & 50 & 16 & 15.08 .05 & 543,68 & 127,44 & 4,27 & 25,6 & 23,9 & \\
\hline & & 67 & fuga & 01.09 .05 & & & & & & \\
\hline S5 & 3,6 & 9 & & 05.07 .05 & 345,96 & 482,88 & 0,72 & 15,5 & 24,5 & 0 \\
\hline \multirow[t]{5}{*}{ experimental } & & 10 & 0 & 06.07 .05 & 229,03 & 92,48 & 2,48 & 14,5 & 19,5 & 1 \\
\hline & & 15 & 4 & 11.07 .05 & 414,71 & 93,55 & 4,43 & 15,0 & 24,5 & 1 \\
\hline & & 22 & 6 & 18.07.05 & 224,88 & 31,54 & 7,13 & 15,0 & 24,0 & 1 \\
\hline & & 36 & 11 & 01.08 .05 & 268,47 & 48,26 & 5,56 & 14,2 & 23,5 & 2 \\
\hline & & 59 & fuga & 24.08 .05 & & & & & & \\
\hline S6 & 3,4 & 9 & & 05.07 .05 & 208,1500 & 70,22 & 2,96 & 7,0 & 18,0 & 0 \\
\hline \multirow[t]{5}{*}{ controle } & & 22 & 12 & 18.07.05 & 402,6700 & 168,91 & 2,38 & 14,0 & 20,5 & 1 \\
\hline & & 26 & 3 & 22.07 .05 & 69,8000 & 12,95 & 5,39 & 14,5 & 18,0 & 1 \\
\hline & & 50 & 23 & 15.08 .05 & 65,4200 & 14,02 & 4,67 & 22,3 & 13,8 & 2 \\
\hline & & 61 & 10 & 26.08 .05 & 152,2400 & 44,59 & 3,41 & 20,5 & 13,5 & 3 \\
\hline & & & não foge & & & & & & & \\
\hline
\end{tabular}




\begin{tabular}{|c|c|c|c|c|c|c|c|c|c|c|}
\hline & $\begin{array}{c}\mathrm{tpl} \\
(\mathrm{mm})\end{array}$ & dia & $\begin{array}{l}\text { dias sem } \\
\text { reconstruir }\end{array}$ & data & $\begin{array}{c}\text { espiral de } \\
\text { captura (cm) }\end{array}$ & $\begin{array}{l}\text { área }\left(\mathrm{cm}^{2}\right) \\
\text { reconstruída }\end{array}$ & $\begin{array}{l}\text { densidade de fios } \\
\text { (espira/área) }\end{array}$ & diâmetro 1 & diâmetro 2 & ootecas \\
\hline S7 & 3,9 & 9 & & 05.07 .05 & 195,81 & 48,65 & 4,02 & 15,0 & 18,3 & 1 \\
\hline \multirow[t]{2}{*}{ experimental } & & 22 & 12 & 18.07 .05 & 155,97 & 29,35 & 5,31 & 16,0 & 19,0 & 1 \\
\hline & & 28 & fuga & 24.07.05 & & & & & & \\
\hline S8 & 4,2 & 19 & 8 & 15.07 .05 & 282,0500 & 85,99 & 3,28 & 19,7 & 14,7 & 1 \\
\hline \multirow[t]{10}{*}{ controle } & & 22 & 2 & 18.07 .05 & 204,5700 & 49,19 & 4,16 & 18,5 & 12,0 & 1 \\
\hline & & 36 & 13 & 01.08 .05 & 42,5500 & 16,03 & 2,65 & 17,2 & 11,4 & 2 \\
\hline & & 38 & 1 & 03.08 .05 & 355,4000 & 77,38 & 4,59 & 23,8 & 13,1 & 2 \\
\hline & & 43 & 4 & 08.08 .05 & 457,9000 & 85,59 & 5,35 & 21,0 & 16,5 & 2 \\
\hline & & 45 & 1 & 10.08 .05 & 249,6700 & 57,14 & 4,37 & 18,2 & 14,6 & 2 \\
\hline & & 57 & 11 & 22.08 .05 & 116,1200 & 19,53 & 5,95 & 20,4 & 13,5 & 3 \\
\hline & & 59 & 1 & 24.08 .05 & 47,2900 & 27,68 & 1,71 & 19,0 & 13,3 & 3 \\
\hline & & 64 & 4 & 29.08 .05 & 267,6400 & 47,53 & 5,63 & 19,2 & 13,5 & 3 \\
\hline & & 66 & 1 & 31.08 .05 & 712,2900 & 268,99 & 2,65 & 19,0 & 23,6 & 3 \\
\hline & & & não foge & & & & & & & \\
\hline S9 & 3,5 & 9 & & 05.07.05 & 403,4500 & 113,82 & 3,54 & 22,8 & 23,5 & 0 \\
\hline \multirow[t]{11}{*}{ controle } & & 13 & 3 & 09.07 .05 & 498,7900 & 145,55 & 3,43 & 22,3 & 12,5 & 0 \\
\hline & & 17 & 3 & 13.07 .05 & 327,5600 & 74,32 & 4,41 & 14,6 & 11,6 & 0 \\
\hline & & 22 & 4 & 18.07 .05 & 204,8200 & 171,49 & 1,19 & 15,0 & 14,0 & 0 \\
\hline & & 26 & 3 & 22.07 .05 & 77,5900 & 58,86 & 1,32 & 8,0 & 9,8 & 1 \\
\hline & & 29 & 2 & 25.07 .05 & 412,2400 & 212,99 & 1,94 & 15,7 & 19,6 & 1 \\
\hline & & 31 & 1 & 27.07 .05 & 531,9900 & 197,4 & 2,69 & 22,8 & 20,0 & 1 \\
\hline & & 43 & 12 & 08.08 .05 & 344,9000 & 112,34 & 3,07 & 23,0 & 21,8 & 2 \\
\hline & & 50 & 6 & 15.08 .05 & 688,7300 & 187,02 & 3,68 & 21,5 & 24,5 & 2 \\
\hline & & 64 & 13 & 29.08 .05 & 157,3900 & 68,30 & 2,30 & 22,8 & 20,5 & 3 \\
\hline & & 66 & 1 & 31.08 .05 & 592,7300 & 182,31 & 3,25 & 18,5 & 24,2 & 3 \\
\hline & & & não foge & & & & & & & \\
\hline S13 & 3,5 & 9 & & 05.07 .05 & 800,23 & 112,11 & 7,14 & 9,8 & 21,0 & 1 \\
\hline \multirow[t]{6}{*}{ controle } & & 22 & 12 & 18.07 .05 & 159,86 & 30,69 & 5,21 & 19,8 & 11,0 & 1 \\
\hline & & 31 & 6 & 27.07 .05 & 187,12 & 28,35 & 6,60 & 21,7 & 10,4 & 2 \\
\hline & & 39 & 7 & 04.08 .05 & 322,64 & 28,87 & 11,18 & 22,0 & 11,6 & 2 \\
\hline & & 51 & 11 & 16.08 .05 & 390,15 & 95,09 & 4,10 & 23,0 & 11,6 & 3 \\
\hline & & 57 & 5 & 22.08 .05 & 437,13 & 70,29 & 6,22 & 23,0 & 11,5 & \\
\hline & & & não foge & & & & & & & \\
\hline S14 & 4,6 & 9 & & 05.07 .05 & 321,79 & 106,24 & 3,03 & 12,5 & 11,5 & 0 \\
\hline \multirow[t]{5}{*}{ experimental } & & 22 & 12 & 18.07 .05 & 37,67 & 20,15 & 1,87 & 19,0 & 14,5 & 0 \\
\hline & & 24 & 1 & 20.07 .05 & 266,48 & 90,78 & 2,94 & 13,0 & 13,5 & 1 \\
\hline & & 29 & 2 & 25.07 .05 & 479,79 & 103,83 & 4,62 & 17,0 & 21,6 & 1 \\
\hline & & 54 & 24 & 19.08 .05 & 27,24 & 17,22 & 1,58 & 17,0 & 21,6 & 1 \\
\hline & & 61 & fuga & 26.08 .05 & & & & & & \\
\hline
\end{tabular}




\section{Anexo C}

Planilha do experimento de redução abrupta da dieta de Metazygia rogenhoferi

\begin{tabular}{|c|c|c|c|c|c|c|c|c|c|c|c|c|c|c|}
\hline & $\begin{array}{l}\text { tpl } \\
(\mathrm{mm})\end{array}$ & dia & $\begin{array}{l}\text { dias sem } \\
\text { reconstruir }\end{array}$ & data & $\begin{array}{c}\text { espira de } \\
\text { captura }(\mathrm{cm})\end{array}$ & $\begin{array}{l}\text { área }\left(\mathrm{cm}^{2}\right) \\
\text { reconstruída }\end{array}$ & $\begin{array}{c}\text { área }\left(\mathrm{cm}^{2}\right) \\
\text { central }\end{array}$ & $\begin{array}{c}\text { área }\left(\mathrm{cm}^{2}\right) \\
\text { total }\end{array}$ & $\begin{array}{l}\text { área }\left(\mathrm{cm}^{2}\right) \\
\text { de captura }\end{array}$ & $\begin{array}{c}\text { reconstrução } \\
(\%)\end{array}$ & $\begin{array}{l}\text { densidade de } \\
\text { fios }\left(\mathrm{cm} / \mathrm{cm}^{2}\right)\end{array}$ & $\begin{array}{l}\text { diâmetro } \\
\text { vertical }\end{array}$ & $\begin{array}{c}\text { diâmetro } \\
\text { horizontal }\end{array}$ & $\begin{array}{c}\text { distância } \\
\text { centro/refúgio }\end{array}$ \\
\hline \multirow[t]{24}{*}{$\mathrm{Mr} 1$} & 2,9 & 0 & - & 09.02 .06 & - & - & - & - & & - & - & 21,5 & 11,7 & 11,8 \\
\hline & & 1 & 0 & 10.02 .06 & 627,96 & 248,90 & 12,16 & 248,90 & 236,74 & $100 \%$ & 2,65 & 21,8 & 23,8 & 20,5 \\
\hline & & 2 & 0 & 11.02 .06 & 204,57 & 64,97 & 12,96 & 305,58 & 292,62 & $21 \%$ & 3,93 & 21,5 & 22,5 & 20,0 \\
\hline & & 5 & 2 & 14.02 .06 & 620,24 & 258,92 & 18,13 & 364,89 & 346,76 & $71 \%$ & 2,58 & 21,3 & 20,0 & 19,8 \\
\hline & & 8 & 2 & 17.02 .06 & 205,86 & 110,16 & 17,80 & 339,62 & 321,82 & $32 \%$ & 2,23 & 20,0 & 20,5 & 19,0 \\
\hline & & 10 & 1 & 19.02 .06 & 939,47 & 442,72 & 23,28 & 442,72 & 419,44 & $100 \%$ & 2,24 & 23,8 & 26,3 & 19,0 \\
\hline & & 11 & 0 & 20.02 .06 & 913,13 & 465,84 & 19,53 & 465,84 & 446,31 & $100 \%$ & 2,05 & 24,5 & 25,7 & 18,4 \\
\hline & & 13 & 1 & 22.02.06 & 1134,75 & 535,33 & 21,14 & 535,33 & 514,19 & $100 \%$ & 2,21 & 27,8 & 25,5 & 18,5 \\
\hline & & 15 & 1 & 24.02 .06 & 969,19 & 388,78 & 16,59 & 520,01 & 503,42 & $75 \%$ & 2,60 & 25,5 & 26,7 & 18,5 \\
\hline & & 16 & 0 & 25.02 .06 & 1084,93 & 506,74 & 16,38 & 541,20 & 524,82 & $94 \%$ & 2,21 & 25,4 & 26,3 & 18,5 \\
\hline & & 17 & 0 & 26.02 .06 & 560,31 & 191,09 & 17,14 & 518,99 & 501,85 & $37 \%$ & 3,22 & 26,7 & 24,5 & 18,0 \\
\hline & & 19 & 1 & 28.02.06 & 632,28 & 257,13 & 15,52 & 487,04 & 471,52 & $53 \%$ & 2,62 & 26,2 & 25,7 & 28,7 \\
\hline & & 20 & 0 & 01.03 .06 & 644,02 & 223,46 & 17,70 & 441,21 & 423,51 & $51 \%$ & 3,13 & 26,0 & 26,1 & 18,7 \\
\hline & & 22 & 1 & 03.03 .06 & 756,95 & 280,89 & 14,95 & 440,74 & 425,79 & $64 \%$ & 2,85 & 24,5 & 26,5 & 18,8 \\
\hline & & 26 & 3 & 07.03 .06 & 464,57 & 193,58 & 18,58 & 444,70 & 426,12 & $44 \%$ & 2,65 & 25,4 & 27,0 & 17,4 \\
\hline & & 28 & 1 & 09.03 .06 & 705,99 & 433,60 & 18,27 & 462,23 & 443,96 & $94 \%$ & 1,70 & 25,1 & 25,2 & 16,5 \\
\hline & & 29 & 0 & 10.03 .06 & 901,77 & 440,79 & 24,28 & 440,79 & 416,51 & $100 \%$ & 2,17 & 24,0 & 25,0 & 17,4 \\
\hline & & 32 & 2 & 13.03 .06 & 923,26 & 453,69 & 18,30 & 453,69 & 435,39 & $100 \%$ & 2,12 & 25,0 & 22,2 & 16,9 \\
\hline & & 34 & 1 & 15.03 .06 & 909,69 & 508,75 & 24,35 & 508,75 & 484,40 & $100 \%$ & 1,88 & 25,0 & 26,1 & 17,0 \\
\hline & & 37 & 2 & 18.03.06 & 769,00 & 480,60 & 19,64 & 480,60 & 460,96 & $100 \%$ & 1,67 & 25,7 & 24,5 & 17,4 \\
\hline & & 40 & 2 & 21.03 .06 & 962,48 & 518,74 & 24,42 & 518,74 & 494,32 & $100 \%$ & 1,95 & 26,4 & 26,6 & 17,0 \\
\hline & & 43 & 2 & 24.03 .06 & 851,07 & 444,64 & 18,33 & 444,64 & 426,31 & $100 \%$ & 2,00 & 25,8 & 26,9 & 16,5 \\
\hline & & 50 & 6 & 31.03 .06 & 626,26 & 256,92 & 17,24 & 461,74 & 444,50 & $56 \%$ & 2,61 & 25,0 & 26,0 & 26,1 \\
\hline & & 57 & 6 & 07.04 .06 & fuga & & & & & & & & & \\
\hline \multirow[t]{11}{*}{ Mr2 } & 3,0 & 0 & - & 09.02 .06 & - & - & - & - & - & - & - & 6,0 & 20,8 & 5,5 \\
\hline & & 5 & 4 & 14.02 .06 & 133,35 & 19,48 & 0,91 & 19,48 & 18,57 & $100 \%$ & 7,18 & 15,0 & 6,5 & 7,5 \\
\hline & & 6 & 0 & 15.02 .06 & 387,74 & 109,80 & 8,78 & 109,80 & 101,02 & $100 \%$ & 3,84 & 17,8 & 13,0 & 7,5 \\
\hline & & 8 & 1 & 17.02 .06 & 612,86 & 256,42 & 14,29 & 256,42 & 242,13 & $100 \%$ & 2,53 & 26,0 & 20,0 & 12,0 \\
\hline & & 10 & 1 & 19.02 .06 & 459,96 & 210,29 & 15,22 & 338,82 & 323,60 & $62 \%$ & 2,36 & 19,8 & 18,0 & 20,5 \\
\hline & & 11 & 0 & 20.02 .06 & 487,77 & 237,97 & 19,59 & 349,77 & 330,18 & $68 \%$ & 2,23 & 22,2 & 16,0 & 23,5 \\
\hline & & 15 & 3 & 24.02 .06 & 497,78 & 228,90 & 12,08 & 236,18 & 224,10 & $97 \%$ & 2,30 & & & \\
\hline & & 18 & 2 & 27.02 .06 & 322,34 & 157,30 & 14,40 & 261,63 & 247,23 & $60 \%$ & 2,26 & 22,0 & 21,7 & 14,0 \\
\hline & & 25 & 6 & 06.03 .06 & 516,79 & 185,24 & 17,91 & 316,32 & 298,41 & $59 \%$ & 3,09 & 21,2 & 22,8 & 14,0 \\
\hline & & 27 & 1 & 08.03.06 & 860,46 & 422,22 & 23,07 & 422,22 & 399,15 & $100 \%$ & 2,16 & 23,5 & 21,7 & 13,0 \\
\hline & & 30 & $z$ & 11.03 .06 & fuga & & & & & & & & & \\
\hline \multirow[t]{3}{*}{ Mr3 } & 3,0 & 0 & - & 09.02 .06 & - & - & - & - & - & - & - & & & \\
\hline & & 1 & 0 & 10.02 .06 & 382,21 & 153,67 & 13,94 & 153,67 & 139,73 & $100 \%$ & 2,74 & 21,4 & 17,5 & 8,5 \\
\hline & & 9 & 7 & 18.02.06 & fuga & & & & & & & & & \\
\hline \multirow[t]{4}{*}{$\mathrm{Mr} 4$} & 3,2 & 0 & - & 09.02 .06 & - & - & - & - & - & - & - & 21,3 & 8,0 & 11,5 \\
\hline & & 3 & 2 & 12.02 .06 & 350,99 & 89,49 & 8,44 & 115,82 & 107,38 & $77 \%$ & 4,33 & 20,0 & 14,5 & 11,2 \\
\hline & & 7 & 3 & 16.02 .06 & 181,73 & 62,28 & 8,68 & 120,98 & 112,30 & $51 \%$ & 3,39 & 22,8 & 11,0 & 8,0 \\
\hline & & 8 & $\theta$ & 17.02 .06 & fuga & & & & & & & & & \\
\hline \multirow[t]{9}{*}{ Mr5 } & 3,3 & 0 & - & 09.02 .06 & sem teia & - & - & - & - & - & - & & & \\
\hline & & 1 & 0 & 10.02 .06 & 384,55 & 148,46 & 13,30 & 148,46 & 135,16 & $100 \%$ & 2,85 & 20,8 & 17,2 & 17,3 \\
\hline & & 3 & 1 & 12.02 .06 & 552,76 & 171,07 & 10,39 & 171,07 & 160,68 & $100 \%$ & 3,44 & 19,8 & 19,0 & 16,8 \\
\hline & & 7 & 3 & 16.02 .06 & 485,65 & 168,38 & 11,56 & 267,50 & 255,94 & $63 \%$ & 3,10 & 21,2 & 18,2 & 15,5 \\
\hline & & 8 & 0 & 17.02 .06 & 139,84 & 54,03 & 11,20 & 216,75 & 205,55 & $25 \%$ & 3,27 & 22,0 & 17,0 & 14,8 \\
\hline & & 10 & 1 & 19.02 .06 & 448,86 & 144,09 & 13,57 & 196,20 & 182,63 & $73 \%$ & 3,44 & 20,0 & 18,2 & 15,0 \\
\hline & & 11 & 0 & 20.02 .06 & 543,20 & 212,82 & 12,60 & 224,90 & 212,30 & $95 \%$ & 2,71 & 21,6 & 15,0 & 15,4 \\
\hline & & 14 & 2 & 23.02 .06 & 859,72 & 388,84 & 21,92 & 388,84 & 366,92 & $100 \%$ & 2,34 & 22,5 & 21,0 & 15,5 \\
\hline & & 28 & 13 & 09.03 .06 & fuga & & & & & & & & & \\
\hline \multirow[t]{6}{*}{ Mr6 } & 3,2 & 0 & - & 09.02 .06 & - & - & - & - & - & - & - & 26,8 & 21,7 & 10,5 \\
\hline & & 1 & 0 & 10.02 .06 & 515,17 & 135,97 & 6,22 & 184,77 & 178,55 & $74 \%$ & 3,97 & 25,0 & 22,5 & 11,0 \\
\hline & & 2 & 0 & 11.02 .06 & 560,34 & 176,07 & 10,68 & 176,07 & 165,39 & $100 \%$ & 3,39 & 22,8 & 18,4 & 11,5 \\
\hline & & 7 & 4 & 16.02 .06 & 680,19 & 324,93 & 16,84 & 324,93 & 308,09 & $100 \%$ & 2,21 & 25,0 & 19,1 & 10,5 \\
\hline & & 10 & 2 & 19.02 .06 & 574,31 & 282,93 & 15,24 & 292,52 & 277,28 & $97 \%$ & 2,15 & 21,0 & 17,2 & 10,0 \\
\hline & & 26 & 15 & 07.03 .06 & morte & & & & & & & & & \\
\hline
\end{tabular}




\begin{tabular}{|c|c|c|c|c|c|c|c|c|c|c|c|c|c|c|}
\hline & $\begin{array}{c}\text { tpl } \\
(\mathrm{mm})\end{array}$ & dia & $\begin{array}{l}\text { dias sem } \\
\text { reconstruir }\end{array}$ & data & $\begin{array}{c}\text { espira de } \\
\text { captura (cm) }\end{array}$ & $\begin{array}{c}\text { área }\left(\mathrm{cm}^{2}\right) \\
\text { reconstruída }\end{array}$ & $\begin{array}{c}\text { área }\left(\mathrm{cm}^{2}\right) \\
\text { central }\end{array}$ & $\begin{array}{c}\text { área }\left(\mathrm{cm}^{2}\right) \\
\text { total }\end{array}$ & $\begin{array}{l}\text { área }\left(\mathrm{cm}^{2}\right) \\
\text { de captura }\end{array}$ & $\begin{array}{c}\text { reconstrução } \\
(\%)\end{array}$ & $\begin{array}{l}\text { densidade de } \\
\text { fios }\left(\mathrm{cm} / \mathrm{cm}^{2}\right)\end{array}$ & $\begin{array}{c}\text { diâmetro } \\
\text { vertical }\end{array}$ & $\begin{array}{l}\text { diâmetro } \\
\text { horizontal }\end{array}$ & $\begin{array}{c}\text { distância } \\
\text { centro/refúgio }\end{array}$ \\
\hline \multirow[t]{6}{*}{$\mathrm{Mr} 7$} & 2,4 & 0 & - & 09.02 .06 & - & - & - & - & - & - & - & 8,5 & 2,0 & 5,0 \\
\hline & & 2 & 1 & 11.02 .06 & 174,18 & 32,52 & 4,20 & 32,52 & 28,32 & $100 \%$ & 6,15 & 10,0 & 7,5 & 6,8 \\
\hline & & 6 & 3 & 15.02 .06 & 201,96 & 67,25 & 10,53 & 82,76 & 72,23 & $81 \%$ & 3,56 & 10,6 & 8,5 & 7,3 \\
\hline & & 12 & 5 & 21.02 .06 & 403,15 & 109,06 & 12,83 & 109,06 & 96,23 & $100 \%$ & 4,19 & 12,8 & 9,7 & 6,5 \\
\hline & & 15 & 2 & 24.02 .06 & 523,04 & 177,02 & 12,30 & 177,02 & 164,72 & $100 \%$ & 3,18 & 17,6 & 11,0 & 8,2 \\
\hline & & 24 & 8 & 03.03 .06 & morte & & & & & & & & & \\
\hline \multirow[t]{3}{*}{$\mathrm{Mr} 9$} & 3,0 & 0 & - & 09.02 .06 & - & - & - & - & - & - & - & 25,0 & 21,2 & 15,0 \\
\hline & & 2 & 1 & 11.02 .06 & 561,65 & 208,82 & 9,04 & 208,82 & 199,78 & $100 \%$ & 2,81 & 22,8 & 19,0 & 15,5 \\
\hline & & 7 & 4 & 16.02 .06 & fuga & & & & & & & & & \\
\hline \multirow[t]{7}{*}{ Mr10 } & 3,3 & 0 & - & 09.02 .06 & - & - & - & - & - & - & - & 20,0 & 16,6 & 14,8 \\
\hline & & 2 & 1 & 11.02 .06 & 698,58 & 194,76 & 8,80 & 194,76 & 185,96 & $100 \%$ & 3,76 & 24,5 & 21,0 & 14,0 \\
\hline & & 6 & 3 & 15.02 .06 & 243,03 & 59,04 & 10,89 & 194,55 & 183,66 & $30 \%$ & 5,05 & 24,5 & 21,0 & 14,0 \\
\hline & & 8 & 1 & 17.02 .06 & 520,32 & 158,10 & 10,73 & 319,35 & 308,62 & $50 \%$ & 3,53 & 19,7 & 21,2 & 12,9 \\
\hline & & 25 & 16 & 06.03 .06 & 409,97 & 148,64 & 12,75 & 269,81 & 257,06 & $55 \%$ & 3,02 & 22,6 & 19,2 & 12,0 \\
\hline & & 28 & 2 & 09.03 .06 & 514,41 & 229,52 & 12,98 & 255,49 & 242,51 & $90 \%$ & 2,38 & 18,7 & 18,5 & 10,2 \\
\hline & & 34 & 5 & 25.03 .06 & fuga & & & & & & & & & \\
\hline \multirow[t]{16}{*}{ Mr12 } & 2,8 & 0 & - & 09.02 .06 & - & - & - & - & - & - & - & 26,0 & 12,0 & 9,0 \\
\hline & & 2 & 1 & 11.02 .06 & 396,43 & 126,55 & 10,16 & 141,39 & 131,23 & $90 \%$ & 3,41 & 22,0 & 17,0 & 8,5 \\
\hline & & 5 & 2 & 14.02 .06 & 28,69 & 10,07 & 4,08 & 141,12 & 137,04 & $7 \%$ & 4,79 & 22,0 & 17,0 & 8,5 \\
\hline & & 6 & 0 & 15.02 .06 & 590,20 & 264,06 & 17,29 & 264,06 & 246,77 & $100 \%$ & 2,39 & 20,5 & 17,0 & 7,5 \\
\hline & & 8 & 1 & 17.02 .06 & 407,86 & 135,34 & 9,30 & 249,76 & 240,46 & $54 \%$ & 3,24 & 19,2 & 19,0 & 7,3 \\
\hline & & 13 & 4 & 22.02.06 & 521,80 & 300,85 & 18,14 & 343,67 & 325,53 & $88 \%$ & 1,85 & 21,8 & 16,6 & 15,5 \\
\hline & & 14 & 0 & 23.02 .06 & 611,31 & 278,61 & 18,94 & 321,31 & 302,37 & $87 \%$ & 2,35 & 22,6 & 16,0 & 14,7 \\
\hline & & 18 & 3 & 27.02 .06 & 558,42 & 214,07 & 15,10 & 318,20 & 303,10 & $67 \%$ & 2,81 & 22,5 & 16,0 & 14,0 \\
\hline & & 22 & 3 & 03.03 .06 & 747,00 & 344,21 & 18,40 & 387,13 & 368,73 & $89 \%$ & 2,29 & 22,0 & 20,5 & 13,3 \\
\hline & & 27 & 4 & 08.03.06 & 205,80 & 73,42 & 11,01 & 176,44 & 165,43 & $42 \%$ & 3,30 & 24,3 & 14,8 & 13,0 \\
\hline & & 28 & 0 & 09.03 .06 & 645,16 & 331,20 & 36,58 & 348,61 & 312,03 & $95 \%$ & 2,19 & 25,1 & 19,0 & 12,0 \\
\hline & & 30 & 1 & 11.03 .06 & 578,84 & 257,97 & 12,78 & 300,90 & 288,12 & $86 \%$ & 2,36 & 24,3 & 17,2 & 12,5 \\
\hline & & 34 & 3 & 15.03 .06 & 543,91 & 199,03 & 10,85 & 254,48 & 243,63 & $78 \%$ & 2,89 & 20,0 & 15,2 & 10,6 \\
\hline & & 37 & 2 & 18.03 .06 & 568,22 & 245,28 & 16,23 & 245,28 & 229,05 & $100 \%$ & 2,48 & 18,0 & 18,5 & 10,5 \\
\hline & & 52 & 14 & 02.04 .06 & 439,39 & 177,92 & 17,04 & 241,18 & 224,14 & $74 \%$ & 2,73 & 22,3 & 17,8 & 8,7 \\
\hline & & 74 & 21 & 24.04 .06 & fuga & & & & & & & & & \\
\hline \multirow[t]{4}{*}{$\mathrm{Mr13}$} & 2,7 & 0 & - & 09.02 .06 & - & - & - & - & - & - & - & 22,5 & 17,0 & 10,6 \\
\hline & & 1 & 0 & 10.02 .06 & 474,02 & 139,29 & 5,73 & 156,50 & 150,77 & $89 \%$ & 3,55 & 18,5 & 17,0 & 10,4 \\
\hline & & 4 & 2 & 13.02 .06 & 239,05 & 83,58 & 13,60 & 237,33 & 223,73 & $35 \%$ & 3,42 & 18,5 & 17,0 & 10,4 \\
\hline & & 7 & $z$ & 16.02.06 & morte & & & & & & & & & \\
\hline \multirow[t]{3}{*}{$\mathrm{Mr} 14$} & 3,0 & 0 & - & 09.02 .06 & - & - & - & - & - & - & - & 23,5 & 20,0 & 16,0 \\
\hline & & 4 & 3 & 13.02 .06 & 89,59 & 19,00 & 3,85 & 222,20 & 218,35 & $9 \%$ & 5,91 & 10,5 & 8,0 & 7,0 \\
\hline & & 9 & 4 & 18.02.06 & morte & & & & & & & & & \\
\hline \multirow[t]{3}{*}{ Mr15 } & 2,6 & 0 & - & 09.02 .06 & - & - & - & - & - & - & - & 21,0 & 15,5 & 11,0 \\
\hline & & 2 & 1 & 11.02 .06 & 278,02 & 94,48 & 10,74 & 198,52 & 187,78 & $48 \%$ & 3,32 & 23,0 & 13,0 & 13,0 \\
\hline & & 5 & $z$ & 14.02.06 & fuga & & & & & & & & & \\
\hline \multirow[t]{6}{*}{ Mr16 } & 3,0 & 0 & - & 09.02 .06 & - & - & - & - & - & - & - & 14,3 & 21,0 & 11,5 \\
\hline & & 2 & 1 & 11.02 .06 & 367,28 & 122,62 & 5,49 & 127,06 & 121,57 & $97 \%$ & 3,14 & 18,0 & 19,0 & 11,3 \\
\hline & & 5 & 2 & 14.02 .06 & 483,89 & 213,08 & 10,74 & 234,98 & 224,24 & $91 \%$ & 2,39 & 17,8 & 14,2 & 11,7 \\
\hline & & 6 & 0 & 15.02 .06 & 315,29 & 108,89 & 8,86 & 190,12 & 181,26 & $57 \%$ & 3,15 & 19,0 & 12,5 & 10,0 \\
\hline & & 7 & 0 & 16.02 .06 & 180,98 & 42,16 & 5,91 & 194,20 & 188,29 & $22 \%$ & 4,99 & 19,0 & 12,5 & 9,0 \\
\hline & & 17 & 9 & 26.02 .06 & fuga & & & & & & & & & \\
\hline \multirow[t]{3}{*}{ Mr17 } & 3,0 & 0 & - & 09.02 .06 & - & - & - & - & - & - & - & 16,0 & 14,0 & 11,5 \\
\hline & & 11 & 10 & 20.02 .06 & 339,32 & 142,96 & 12,38 & 142,96 & 130,58 & $100 \%$ & 2,60 & 14,0 & 13,0 & 8,0 \\
\hline & & 26 & 14 & 07.03 .06 & fuga & & & & & & & & & \\
\hline
\end{tabular}

continuação 


\begin{tabular}{|c|c|c|c|c|c|c|c|c|c|c|c|c|c|c|}
\hline & $\begin{array}{c}\mathrm{tpl} \\
(\mathrm{mm})\end{array}$ & dia & $\begin{array}{l}\text { dias sem } \\
\text { reconstruir }\end{array}$ & data & $\begin{array}{c}\text { espira de } \\
\text { captura (cm) }\end{array}$ & $\begin{array}{c}\text { área }\left(\mathrm{cm}^{2}\right) \\
\text { reconstruída }\end{array}$ & $\begin{array}{c}\text { área }\left(\mathrm{cm}^{2}\right) \\
\text { central }\end{array}$ & $\begin{array}{l}\text { área }\left(\mathrm{cm}^{2}\right) \\
\text { total }\end{array}$ & $\begin{array}{l}\text { área }\left(\mathrm{cm}^{2}\right) \\
\text { de captura }\end{array}$ & $\begin{array}{c}\text { reconstrução } \\
(\%)\end{array}$ & $\begin{array}{l}\text { densidade de } \\
\text { fios }\left(\mathrm{cm} / \mathrm{cm}^{2}\right)\end{array}$ & $\begin{array}{c}\text { diâmetro } \\
\text { vertical }\end{array}$ & $\begin{array}{c}\text { diâmetro } \\
\text { horizontal }\end{array}$ & $\begin{array}{l}\text { distância } \\
\text { centro/refúgio }\end{array}$ \\
\hline \multirow[t]{12}{*}{ Mr20 } & 2,9 & 0 & - & 09.02 .06 & - & - & - & - & - & - & - & 20,7 & 13,2 & 11,0 \\
\hline & & 2 & 1 & 11.02 .06 & 877,10 & 284,15 & 14,01 & 284,15 & 270,14 & $100 \%$ & 3,25 & 24,0 & 18,0 & 11,0 \\
\hline & & 5 & 2 & 14.02.06 & 586,07 & 174,32 & 8,73 & 364,92 & 356,19 & $48 \%$ & 3,54 & 18,0 & 18,0 & 11,2 \\
\hline & & 9 & 3 & 18.02 .06 & 569,47 & 167,19 & 13,62 & 287,35 & 273,73 & $58 \%$ & 3,71 & 22,1 & 17,3 & 9,5 \\
\hline & & 11 & 1 & 20.02 .06 & 930,29 & 366,03 & 16,99 & 402,57 & 385,58 & $91 \%$ & 2,67 & 23,7 & 18,0 & 10,3 \\
\hline & & 15 & 3 & 24.02 .06 & 669,33 & 195,49 & 12,49 & 374,67 & 362,18 & $52 \%$ & 3,66 & 23,0 & 18,8 & 10,5 \\
\hline & & 25 & 9 & 06.03 .06 & 205,72 & 81,70 & 9,37 & 421,99 & 412,62 & $19 \%$ & 2,84 & 22,8 & 18,9 & 10,2 \\
\hline & & 28 & 2 & 09.03.06 & 637,45 & 358,15 & 22,54 & 445,58 & 423,04 & $80 \%$ & 1,90 & 23,4 & 14,0 & 11,3 \\
\hline & & 35 & 6 & 16.03.06 & 741,27 & 276,49 & 12,26 & 346,22 & 333,96 & $80 \%$ & 2,81 & 22,7 & 13,0 & 11,0 \\
\hline & & 36 & 0 & 17.03.06 & 773,59 & 353,85 & 12,81 & 390,59 & 377,78 & $91 \%$ & 2,27 & 24,2 & 15,3 & 11,8 \\
\hline & & 39 & 2 & 20.03 .06 & 646,66 & 285,37 & 14,32 & 348,65 & 334,33 & $82 \%$ & 2,39 & 24,0 & 15,3 & 11,2 \\
\hline & & 63 & 23 & 13.04 .06 & fuga & & & & & & & & & \\
\hline \multirow[t]{6}{*}{ Mr21 } & 3,0 & 0 & - & 09.02 .06 & sem teia & - & - & - & - & - & - & & & \\
\hline & & 3 & 2 & 12.02 .06 & 388,12 & 107,36 & 4,88 & 107,36 & 102,48 & $100 \%$ & 3,79 & 16,5 & 15,0 & 16,0 \\
\hline & & 7 & 3 & 16.02.06 & 363,35 & 165,98 & 10,73 & 204,13 & 193,40 & $81 \%$ & 2,34 & 17,6 & 14,3 & 14,3 \\
\hline & & 10 & 2 & 19.02.06 & 230,66 & 89,86 & 5,20 & 89,86 & 84,66 & $100 \%$ & 2,72 & 13,3 & 12,5 & 7,3 \\
\hline & & 12 & 1 & 21.02 .06 & 405,71 & 155,50 & 9,27 & 155,50 & 146,23 & $100 \%$ & 2,77 & 17,3 & 14,8 & 14,5 \\
\hline & & $z \theta$ & 7 & 01.03 .06 & morte & & & & & & & & & \\
\hline \multirow[t]{4}{*}{ Mr22 } & 2,8 & 0 & - & 09.02 .06 & - & - & - & - & - & - & - & 9,3 & 15,4 & 8,5 \\
\hline & & 6 & 5 & 15.02 .06 & 247,97 & 95,43 & 8,63 & 95,43 & 86,80 & $100 \%$ & 2,86 & 10,9 & 9,8 & 6,8 \\
\hline & & 10 & 3 & 19.02.06 & 524,85 & 261,37 & 23,17 & 261,37 & 238,20 & $100 \%$ & 2,20 & 22,8 & 17,8 & 10,0 \\
\hline & & 11 & $\theta$ & 20.02 .06 & morte & & & & & & & & & \\
\hline \multirow[t]{10}{*}{$\mathrm{MrC}$} & 3,0 & 0 & - & 09.02 .06 & sem teia & - & - & - & - & - & - & & & \\
\hline & & 1 & 0 & 10.02 .06 & 392,80 & 143,49 & 13,05 & 143,49 & 130,44 & $100 \%$ & 3,01 & 13,8 & 13,0 & 6,0 \\
\hline & & 3 & 1 & 12.02 .06 & 234,01 & 29,18 & 3,78 & 141,30 & 137,52 & $21 \%$ & 9,21 & 14,6 & 13,0 & 10,0 \\
\hline & & 7 & 3 & 16.02 .06 & 606,18 & 298,74 & 11,94 & 298,74 & 286,80 & $100 \%$ & 2,11 & 18,7 & 14,4 & 10,0 \\
\hline & & 8 & 0 & 17.02.06 & 727,59 & 353,00 & 12,33 & 353,00 & 340,67 & $100 \%$ & 2,14 & 23,4 & 18,5 & 12,0 \\
\hline & & 10 & 1 & 19.02.06 & 784,18 & 379,59 & 16,39 & 384,82 & 368,43 & $99 \%$ & 2,16 & 24,2 & 21,0 & 13,6 \\
\hline & & 11 & 0 & 20.02 .06 & 558,48 & 227,35 & 14,29 & 362,92 & 348,63 & $63 \%$ & 2,62 & 23,7 & 21,0 & 14,0 \\
\hline & & 13 & 1 & 22.02 .06 & 616,58 & 231,96 & 15,70 & 357,10 & 341,40 & $65 \%$ & 2,85 & 20,5 & 20,8 & 13,8 \\
\hline & & 15 & 1 & 24.02.06 & 545,16 & 190,51 & 9,58 & 435,89 & 426,31 & $44 \%$ & 3,01 & 20,7 & 23,4 & 12,6 \\
\hline & & 24 & 8 & 05.03 .06 & morte & & & & & & & & & \\
\hline
\end{tabular}

conclusão 


\section{Anexo D}

Planilha do experimento de redução abrupta da dieta de Zosis geniculata

\begin{tabular}{|c|c|c|c|c|c|c|c|c|c|c|c|c|c|c|}
\hline & $\begin{array}{c}\mathrm{tpl} \\
(\mathrm{mm})\end{array}$ & dia & $\begin{array}{l}\text { dias sem } \\
\text { reconstruir }\end{array}$ & data & $\begin{array}{c}\text { espira de } \\
\text { captura }(\mathrm{cm})\end{array}$ & $\begin{array}{l}\text { área }\left(\mathrm{cm}^{2}\right) \\
\text { reconstruída }\end{array}$ & $\begin{array}{c}\text { área }\left(\mathrm{cm}^{2}\right) \\
\text { central }\end{array}$ & $\begin{array}{c}\text { área }\left(\mathrm{cm}^{2}\right) \\
\text { total }\end{array}$ & $\begin{array}{l}\text { área }\left(\mathrm{cm}^{2}\right) \\
\text { de captura }\end{array}$ & $\begin{array}{l}\text { reconstrução } \\
(\%)\end{array}$ & $\begin{array}{l}\text { densidade de } \\
\text { fios }\left(\mathrm{cm} / \mathrm{cm}^{2}\right)\end{array}$ & $\begin{array}{l}\text { diâmetro } \\
\text { vertical }\end{array}$ & $\begin{array}{l}\text { diâmetro } \\
\text { horizontal }\end{array}$ & ootecas \\
\hline \multirow[t]{17}{*}{$\mathrm{Zg1}$} & 3,9 & 0 & - & 09.02 .06 & sem teia & - & - & - & - & - & - & - & - & - \\
\hline & & 1 & 0 & 10.02 .06 & 33,26 & 13,39 & 3,23 & 13,39 & 10,16 & $100 \%$ & 3,27 & 5,0 & 2,2 & 1 \\
\hline & & 2 & 0 & 11.02 .06 & 163,17 & 72,39 & 10,45 & 72,39 & 61,94 & $100 \%$ & 2,63 & 10,5 & 7,7 & 1 \\
\hline & & 6 & 3 & 15.02 .06 & 189,01 & 109,50 & 40,57 & 146,42 & 105,85 & $75 \%$ & 2,74 & 15,5 & 9,5 & 1 \\
\hline & & 7 & 0 & 16.02.06 & 47,30 & 34,33 & 21,13 & 139,97 & 118,84 & $25 \%$ & 3,58 & 16,6 & 9,0 & 1 \\
\hline & & 10 & 2 & 19.02.06 & 109,10 & 46,43 & 8,92 & 137,82 & 128,90 & $34 \%$ & 2,91 & 17,0 & 9,2 & 1 \\
\hline & & 11 & 0 & 20.02 .06 & 115,75 & 51,90 & 9,71 & 136,95 & 127,24 & $38 \%$ & 2,74 & 12,3 & 10,3 & 1 \\
\hline & & 12 & 0 & 21.02 .06 & 361,37 & 147,84 & 11,01 & 230,88 & 219,87 & $64 \%$ & 2,64 & 14,0 & 17,0 & 2 \\
\hline & & 15 & 2 & 24.02 .06 & 571,86 & 238,62 & 16,19 & 406,76 & 390,57 & $59 \%$ & 2,57 & 23,2 & 17,2 & 2 \\
\hline & & 16 & 0 & 25.02 .06 & 396,03 & 155,16 & 13,80 & 376,55 & 362,75 & $41 \%$ & 2,80 & 23,0 & 17,4 & 2 \\
\hline & & 23 & 6 & 04.03.06 & 167,89 & 70,28 & 13,70 & 394,28 & 380,58 & $18 \%$ & 2,97 & 24,4 & 17,3 & 3 \\
\hline & & 26 & 2 & 07.03.06 & 16,29 & 17,10 & 13,86 & 412,65 & 398,79 & $4 \%$ & 5,03 & 22,5 & 16,3 & 3 \\
\hline & & 29 & 2 & 10.03 .06 & 560,69 & 221,09 & 18,08 & 521,22 & 503,14 & $42 \%$ & 2,76 & 22,9 & 26,1 & 3 \\
\hline & & 35 & 5 & 16.03 .06 & 35,90 & 18,79 & 12,38 & 520,33 & 507,95 & $4 \%$ & 5,60 & 22,7 & 25,1 & 3 \\
\hline & & 42 & 6 & 23.03.06 & 31,40 & 17,56 & 11,87 & 521,52 & 509,65 & $3 \%$ & 5,52 & 22,5 & 25,0 & 3 \\
\hline & & 44 & 1 & 25.03 .06 & 56,70 & 23,78 & 7,32 & 522,54 & 515,22 & $5 \%$ & 3,44 & 23,7 & 25,2 & 3 \\
\hline & & 53 & 8 & 03.04 .06 & fuga & & & & & & & & & \\
\hline \multirow[t]{12}{*}{$\mathrm{Zg} 2$} & 4,6 & 0 & - & 09.03.06 & - & - & - & - & - & - & - & 18,5 & 8,5 & 1 \\
\hline & & 2 & 1 & 11.03 .06 & 249,05 & 83,39 & 13,81 & 140,63 & 126,82 & $59 \%$ & 3,58 & 17,8 & 11,2 & 1 \\
\hline & & 6 & 3 & 15.02 .06 & 794,88 & 228,47 & 20,53 & 250,88 & 230,35 & $91 \%$ & 3,82 & 26,0 & 13,5 & 1 \\
\hline & & 10 & 3 & 19.02 .06 & 247,89 & 75,63 & 13,37 & 264,54 & 251,17 & $29 \%$ & 3,98 & 25,0 & 14,0 & 1 \\
\hline & & 12 & 1 & 21.02 .06 & 36,37 & 20,11 & 0,00 & 263,06 & 263,06 & $8 \%$ & 1,81 & 25,0 & 14,0 & 1 \\
\hline & & 13 & 0 & 22.02 .06 & 70,15 & 36,54 & 12,80 & 242,12 & 229,32 & $15 \%$ & 2,95 & 20,2 & 14,5 & 2 \\
\hline & & 14 & 0 & 23.02.06 & 817,40 & 376,45 & 72,69 & 438,22 & 365,53 & $86 \%$ & 2,69 & 28,2 & 17,5 & 2 \\
\hline & & 15 & 0 & 24.02.06 & 130,44 & 57,87 & 27,48 & 415,51 & 388,03 & $14 \%$ & 4,29 & 26,4 & 17,8 & 2 \\
\hline & & 18 & 2 & 27.02 .06 & 43,52 & 25,78 & 16,06 & 415,34 & 399,28 & $6 \%$ & 4,48 & 26,4 & 17,8 & 2 \\
\hline & & 20 & 1 & 01.03 .06 & 431,64 & 114,21 & 18,09 & 416,23 & 398,14 & $27 \%$ & 4,49 & 27,6 & 17,7 & 2 \\
\hline & & 26 & 5 & 07.03.06 & 421,18 & 186,94 & 13,19 & 444,10 & 430,91 & $42 \%$ & 2,42 & 26,9 & 17,3 & 3 \\
\hline & & 44 & 7 & 25.03 .06 & morte & & & & & & & & & \\
\hline \multirow[t]{8}{*}{$\mathrm{Zg} 3$} & 4,1 & 0 & - & 09.02 .06 & sem teia & - & - & - & - & - & - & - & - & - \\
\hline & & 4 & 3 & 13.02.06 & 76,99 & 53,81 & 12,09 & 53,81 & 41,72 & $100 \%$ & 1,85 & 7,4 & 8,9 & 1 \\
\hline & & 6 & 1 & 15.02 .06 & 654,82 & 310,15 & 14,24 & 310,15 & 295,91 & $100 \%$ & 2,21 & 16,3 & 22,2 & 1 \\
\hline & & 11 & 4 & 20.02 .06 & 189,45 & 67,83 & 11,50 & 303,27 & 291,77 & $22 \%$ & 3,36 & 16,0 & 21,3 & 1 \\
\hline & & 17 & 5 & 26.02 .06 & 113,50 & 45,34 & 11,34 & 277,81 & 266,47 & $16 \%$ & 3,34 & 15,5 & 22,8 & 2 \\
\hline & & 21 & 3 & 02.03.06 & 509,72 & 166,76 & 15,79 & 340,17 & 324,38 & $49 \%$ & 3,38 & 23,5 & 23,3 & 2 \\
\hline & & 40 & 18 & 21.03 .06 & 11,17 & 2,22 & 0,00 & 338,52 & 338,52 & $1 \%$ & 5,03 & 23,5 & 23,3 & 3 \\
\hline & & 51 & 10 & 01.04 .06 & morte & & & & & & & & & \\
\hline \multirow[t]{3}{*}{$\mathrm{Zg4}$} & 4,2 & 0 & - & 09.02 .06 & sem teia & - & - & - & - & - & - & - & - & - \\
\hline & & 3 & 2 & 12.02 .06 & 85,15 & 39,13 & 4,74 & 39,13 & 34,39 & $100 \%$ & 2,48 & 3,5 & 13,3 & 0 \\
\hline & & 6 & $z$ & 15.02 .06 & fuga & & & & & & & & & \\
\hline \multirow[t]{7}{*}{ Zg5 } & 3,4 & 0 & - & 09.02.06 & - & - & - & - & - & - & - & 19,0 & 10,5 & 0 \\
\hline & & 2 & 1 & 11.02 .06 & 187,58 & 87,72 & 13,56 & 186,78 & 173,22 & $47 \%$ & 2,53 & 19,4 & 11,5 & 0 \\
\hline & & 10 & 7 & 19.02.06 & 302,85 & 133,23 & 19,05 & 161,24 & 142,19 & $83 \%$ & 2,65 & 20,9 & 10,0 & 0 \\
\hline & & 15 & 4 & 24.02.06 & 107,95 & 68,63 & 16,31 & 148,98 & 132,67 & $46 \%$ & 2,06 & 17,1 & 9,2 & 0 \\
\hline & & 25 & 9 & 06.03 .06 & 119,98 & 61,03 & 18,44 & 182,99 & 164,55 & $33 \%$ & 2,82 & 19,5 & 10,2 & 1 \\
\hline & & 28 & 2 & 09.03.06 & 204,48 & 93,70 & 16,58 & 205,99 & 189,41 & $45 \%$ & 2,65 & 4,6 & 9,6 & 1 \\
\hline & & 92 & 64 & 12.05 .06 & fuga & & & & & & & & & \\
\hline
\end{tabular}




\begin{tabular}{|c|c|c|c|c|c|c|c|c|c|c|c|c|c|c|}
\hline & $\begin{array}{c}\mathrm{tpl} \\
(\mathrm{mm})\end{array}$ & dia & $\begin{array}{c}\text { dias sem } \\
\text { reconstruir }\end{array}$ & data & $\begin{array}{c}\text { espira de } \\
\text { captura (cm) }\end{array}$ & $\begin{array}{l}\text { área }\left(\mathrm{cm}^{2}\right) \\
\text { reconstruída }\end{array}$ & $\begin{array}{l}\text { área }\left(\mathrm{cm}^{2}\right) \\
\text { central }\end{array}$ & $\begin{array}{c}\text { área }\left(\mathrm{cm}^{2}\right) \\
\text { total }\end{array}$ & $\begin{array}{l}\text { área }\left(\mathrm{cm}^{2}\right) \\
\text { de captura }\end{array}$ & $\begin{array}{c}\text { reconstrução } \\
(\%)\end{array}$ & $\begin{array}{l}\text { densidade de } \\
\text { fios }\left(\mathrm{cm} / \mathrm{cm}^{2}\right)\end{array}$ & $\begin{array}{l}\text { diâmetro } \\
\text { vertical }\end{array}$ & $\begin{array}{c}\text { diâmetro } \\
\text { horizontal }\end{array}$ & ootecas \\
\hline \multirow[t]{12}{*}{$\mathrm{Zg} 6$} & 3,7 & 0 & - & 09.02 .06 & sem teia & - & - & - & - & - & - & - & - & - \\
\hline & & 1 & 0 & 10.02 .06 & 28,68 & 41,00 & 29,00 & 41,00 & 12,00 & $100 \%$ & 2,39 & 8,5 & 8,2 & 1 \\
\hline & & 2 & 0 & 11.02 .06 & 720,69 & 400,67 & 129,09 & 400,67 & 271,58 & $100 \%$ & 2,65 & 22,5 & 24,7 & 1 \\
\hline & & 3 & 0 & 12.02 .06 & 245,39 & 108,92 & 31,56 & 400,67 & 369,11 & $27 \%$ & 3,17 & 22,5 & 24,7 & 1 \\
\hline & & 6 & 2 & 15.02 .06 & 784,64 & 196,77 & 22,41 & 538,20 & 515,79 & $37 \%$ & 4,50 & 27,1 & 25,0 & 1 \\
\hline & & 10 & 3 & 19.02 .06 & 567,46 & 137,83 & 22,91 & 527,01 & 504,10 & $26 \%$ & 4,94 & 26,0 & 25,7 & 1 \\
\hline & & 18 & 7 & 27.02 .06 & 963,97 & 182,36 & 0,00 & 584,19 & 584,19 & $31 \%$ & 5,29 & 25,5 & 25,3 & 1 \\
\hline & & 19 & 0 & 28.02 .06 & 412,24 & 88,67 & 0,00 & 583,96 & 583,96 & $15 \%$ & 4,65 & 27,2 & 25,2 & 1 \\
\hline & & 20 & 0 & 01.03 .06 & 319,23 & 117,02 & 37,48 & 595,53 & 558,05 & $20 \%$ & 4,01 & 27,3 & 25,5 & 1 \\
\hline & & 26 & 5 & 07.03 .06 & 123,75 & 55,83 & 23,56 & 621,32 & 597,76 & $9 \%$ & 3,83 & 27,2 & 25,6 & 3 \\
\hline & & 29 & 2 & 10.03 .06 & 364,11 & 99,17 & 19,04 & 567,00 & 547,96 & $17 \%$ & 4,54 & 28,0 & 25,5 & 3 \\
\hline & & 59 & 29 & 09.04 .06 & fuga & & & & & & & & & \\
\hline \multirow[t]{15}{*}{$\mathrm{Zg} 7$} & 4,0 & 0 & - & 09.02 .06 & sem teia & - & - & - & - & - & - & - & - & - \\
\hline & & 3 & 2 & 12.02 .06 & 778,86 & 376,16 & 15,33 & 376,16 & 360,83 & $100 \%$ & 2,16 & 20,4 & 20,4 & 0 \\
\hline & & 4 & 0 & 13.02 .06 & 194,83 & 78,17 & 0,00 & 361,76 & 361,76 & $22 \%$ & 2,49 & 23,5 & 20,0 & 0 \\
\hline & & 5 & 0 & 14.02 .06 & 550,33 & 232,98 & 13,18 & 414,64 & 401,46 & $56 \%$ & 2,50 & 23,5 & 20,5 & 0 \\
\hline & & 6 & 0 & 15.02 .06 & 821,59 & 341,57 & 14,14 & 451,98 & 437,84 & $76 \%$ & 2,51 & 21,6 & 20,5 & 0 \\
\hline & & 9 & 2 & 18.02 .06 & 680,30 & 276,52 & 18,57 & 467,01 & 448,44 & $59 \%$ & 2,64 & 24,2 & 21,2 & 0 \\
\hline & & 10 & 0 & 19.02 .06 & 445,92 & 174,98 & 13,88 & 463,23 & 449,35 & $38 \%$ & 2,77 & 24,5 & 20,5 & 0 \\
\hline & & 13 & 2 & 22.02 .06 & 316,87 & 132,96 & 17,71 & 387,50 & 369,79 & $34 \%$ & 2,75 & 25,9 & 22,2 & 1 \\
\hline & & 15 & 1 & 24.02 .06 & 974,28 & 315,78 & 17,03 & 578,53 & 561,50 & $55 \%$ & 3,26 & 26,3 & 25,0 & 1 \\
\hline & & 18 & 2 & 27.02 .06 & 858,66 & 233,97 & 13,60 & 585,31 & 571,71 & $40 \%$ & 3,90 & 24,7 & 25,0 & 1 \\
\hline & & 24 & 5 & 05.03 .06 & 145,98 & 50,90 & 11,09 & 613,13 & 602,04 & $8 \%$ & 3,67 & 22,5 & 24,4 & 2 \\
\hline & & 25 & 0 & 06.03 .06 & 461,56 & 141,83 & 16,20 & 650,00 & 633,80 & $22 \%$ & 3,67 & 24,5 & 25,8 & 2 \\
\hline & & 30 & 4 & 11.03 .06 & 307,64 & 94,37 & 14,16 & 689,23 & 675,07 & $14 \%$ & 3,84 & 25,2 & 25,3 & 2 \\
\hline & & 44 & 13 & 25.03 .06 & 524,01 & 140,59 & 13,79 & 624,46 & 610,67 & $23 \%$ & 4,13 & 26,3 & 26,5 & 2 \\
\hline & & 49 & 4 & 30.03 .06 & fuga & & & & & & & & & \\
\hline \multirow[t]{13}{*}{$\mathrm{Zg8}$} & 3,7 & 0 & - & 09.02 .06 & - & - & - & - & - & - & - & 14,8 & 22,3 & 0 \\
\hline & & 3 & 2 & 12.02 .06 & 338,71 & 148,47 & 16,84 & 148,47 & 131,63 & $100 \%$ & 2,57 & 14,5 & 14,8 & 0 \\
\hline & & 6 & 2 & 15.02 .06 & 127,51 & 77,38 & 17,00 & 143,38 & 126,38 & $54 \%$ & 2,11 & 14,5 & 14,8 & 1 \\
\hline & & 7 & 0 & 16.02 .06 & 578,26 & 229,06 & 18,81 & 229,06 & 210,25 & $100 \%$ & 2,75 & 21,0 & 15,4 & 1 \\
\hline & & 10 & 2 & 19.02 .06 & 780,01 & 291,96 & 15,01 & 379,65 & 364,64 & $77 \%$ & 2,82 & 23,0 & 22,4 & 1 \\
\hline & & 12 & 1 & 21.02 .06 & 112,76 & 44,01 & 14,06 & 380,00 & 365,94 & $12 \%$ & 3,76 & 22,5 & 21,4 & 1 \\
\hline & & 14 & 1 & 23.02 .06 & 290,41 & 89,68 & 14,76 & 378,91 & 364,15 & $24 \%$ & 3,88 & 22,4 & 22,3 & 1 \\
\hline & & 19 & 4 & 28.02 .06 & 555,18 & 164,86 & 12,62 & 391,60 & 378,98 & $42 \%$ & 3,65 & 25,2 & 23,3 & 2 \\
\hline & & 21 & 1 & 02.03 .06 & 625,04 & 173,26 & 13,78 & 421,04 & 407,26 & $41 \%$ & 3,92 & 23,4 & 25,2 & 2 \\
\hline & & 24 & 2 & 05.03 .06 & 106,73 & 35,74 & 10,94 & 452,17 & 441,23 & $8 \%$ & 4,30 & 25,5 & 24,3 & 2 \\
\hline & & 29 & 4 & 10.03 .06 & 60,81 & 25,87 & 9,14 & 462,23 & 453,09 & $6 \%$ & 3,63 & 25,0 & 23,2 & 3 \\
\hline & & 32 & 2 & 13.03 .06 & 218,10 & 58,01 & 11,62 & 447,48 & 435,86 & $27 \%$ & 4,70 & 24,8 & 22,7 & 3 \\
\hline & & 54 & 21 & 04.04 .06 & fuga & & & & & & & & & \\
\hline \multirow[t]{10}{*}{$\mathrm{Zg} 9$} & 3,6 & 0 & - & 09.02 .06 & sem teia & - & - & - & - & - & - & - & - & - \\
\hline & & 1 & 0 & 10.02 .06 & 145,56 & 51,15 & 9,08 & 73,25 & 64,17 & $70 \%$ & 3,46 & 8,5 & 10,5 & 0 \\
\hline & & 6 & 4 & 15.02 .06 & 524,09 & 275,52 & 14,12 & 275,52 & 261,40 & $100 \%$ & 2,00 & 18,8 & 19,0 & 0 \\
\hline & & 10 & 3 & 19.02 .06 & 225,17 & 79,85 & 9,54 & 277,03 & 267,49 & $29 \%$ & 3,20 & 17,3 & 20,3 & 0 \\
\hline & & 13 & 2 & 22.02 .06 & 78,47 & 26,73 & 8,67 & 298,44 & 289,77 & $9 \%$ & 4,34 & 15,8 & 21,2 & 1 \\
\hline & & 15 & 1 & 24.02 .06 & 715,59 & 206,57 & 11,31 & 298,59 & 287,28 & $69 \%$ & 3,66 & 13,4 & 20,5 & 1 \\
\hline & & 21 & 5 & 02.03 .06 & 427,17 & 127,71 & 11,64 & 348,57 & 336,93 & $37 \%$ & 3,68 & 13,5 & 24,4 & 1 \\
\hline & & 25 & 3 & 06.03 .06 & 33,12 & 15,50 & 9,56 & 331,68 & 322,12 & $5 \%$ & 5,58 & 13,3 & 26,5 & 2 \\
\hline & & 37 & 11 & 18.03 .06 & 163,23 & 55,17 & 7,99 & 330,26 & 322,27 & $17 \%$ & 3,46 & 13,0 & 22,3 & 2 \\
\hline & & 49 & 11 & 30.03 .06 & fuga & & & & & & & & & \\
\hline \multirow[t]{4}{*}{$\mathrm{Zg} 10$} & 4,0 & 0 & - & 09.02 .06 & - & - & - & - & - & - & - & 12,3 & 20,2 & 0 \\
\hline & & 3 & 2 & 12.02 .06 & 998,14 & 460,24 & 17,61 & 460,24 & 442,63 & $100 \%$ & 2,26 & 26,0 & 19,8 & 0 \\
\hline & & 6 & 2 & 15.02 .06 & 376,55 & 229,00 & 20,36 & 441,08 & 420,72 & $52 \%$ & 1,80 & 23,8 & 20,0 & 0 \\
\hline & & 9 & $z$ & 17.02 .06 & fuga & & & & & & & & & \\
\hline
\end{tabular}




\begin{tabular}{|c|c|c|c|c|c|c|c|c|c|c|c|c|c|c|}
\hline & $\begin{array}{c}\mathrm{tpl} \\
(\mathrm{mm})\end{array}$ & dia & $\begin{array}{l}\text { dias sem } \\
\text { reconstruir }\end{array}$ & data & $\begin{array}{c}\text { espira de } \\
\text { captura (cm) }\end{array}$ & $\begin{array}{l}\text { área }\left(\mathrm{cm}^{2}\right) \\
\text { reconstruída }\end{array}$ & $\begin{array}{c}\text { área }\left(\mathrm{cm}^{2}\right) \\
\text { central }\end{array}$ & $\begin{array}{l}\text { área }\left(\mathrm{cm}^{2}\right) \\
\text { total }\end{array}$ & $\begin{array}{l}\text { área }\left(\mathrm{cm}^{2}\right) \\
\text { de captura }\end{array}$ & $\begin{array}{c}\text { reconstrução } \\
(\%)\end{array}$ & $\begin{array}{l}\text { densidade de } \\
\text { fios }\left(\mathrm{cm} / \mathrm{cm}^{2}\right)\end{array}$ & $\begin{array}{c}\text { diâmetro } \\
\text { vertical }\end{array}$ & $\begin{array}{l}\text { diâmetro } \\
\text { horizontal }\end{array}$ & ootecas \\
\hline \multirow[t]{12}{*}{$\mathrm{Zg11}$} & 3,5 & 0 & - & 09.02 .06 & - & - & - & - & - & - & - & 5,3 & 17,0 & 1 \\
\hline & & 3 & 2 & 12.02 .06 & 713,12 & 234,46 & 10,91 & 269,51 & 258,60 & $87 \%$ & 3,19 & 16,8 & 15,5 & 1 \\
\hline & & 6 & 2 & 15.02 .06 & 235,98 & 58,96 & 10,39 & 275,05 & 264,66 & $21 \%$ & 4,86 & 16,0 & 16,0 & 1 \\
\hline & & 8 & 1 & 17.02 .06 & 589,22 & 165,72 & 12,52 & 298,07 & 285,55 & $56 \%$ & 3,85 & 16,2 & 16,5 & 1 \\
\hline & & 11 & 2 & 20.02 .06 & 159,02 & 40,55 & 10,33 & 301,56 & 291,23 & $13 \%$ & 5,26 & 17,8 & 18,9 & 1 \\
\hline & & 14 & 2 & 23.02 .06 & 132,93 & 40,81 & 8,23 & 283,35 & 275,12 & $14 \%$ & 4,08 & 16,6 & 17,3 & 2 \\
\hline & & 16 & 1 & 25.02 .06 & 605,29 & 143,39 & 11,20 & 342,01 & 330,81 & $42 \%$ & 4,58 & 16,8 & 17,0 & 2 \\
\hline & & 18 & 1 & 27.02 .06 & 409,53 & 90,10 & 0,00 & 327,60 & 327,60 & $28 \%$ & 4,55 & 16,4 & 18,2 & 2 \\
\hline & & 23 & 4 & 04.03 .06 & 30,35 & 14,80 & 10,34 & 306,33 & 295,99 & $5 \%$ & 6,80 & 16,4 & 19,7 & 3 \\
\hline & & 24 & 0 & 05.03 .06 & 694,36 & 319,02 & 47,81 & 522,19 & 474,38 & $61 \%$ & 2,56 & 27,7 & 24,0 & 3 \\
\hline & & 25 & 0 & 06.03 .06 & 85,00 & 42,24 & 10,37 & 512,39 & 502,02 & $8 \%$ & 2,67 & 27,7 & 24,0 & 3 \\
\hline & & 45 & 19 & 26.03 .06 & morte & & & & & & & & & \\
\hline \multirow[t]{7}{*}{$\mathrm{Zg} 12$} & 3,7 & 0 & - & 09.02 .06 & sem teia & - & - & - & - & - & - & - & - & - \\
\hline & & 3 & 2 & 12.02 .06 & 889,94 & 458,77 & 22,05 & 458,77 & 436,72 & $100 \%$ & 2,04 & 18,5 & 22,8 & 0 \\
\hline & & 9 & 5 & 18.02 .06 & 80,11 & 51,59 & 30,09 & 443,71 & 413,62 & $12 \%$ & 3,73 & 18,7 & 24,0 & 1 \\
\hline & & 10 & 0 & 19.02 .06 & 214,45 & 139,48 & 22,44 & 483,78 & 461,34 & $29 \%$ & 1,83 & 19,0 & 23,5 & 1 \\
\hline & & 14 & 3 & 23.02 .06 & 133,99 & 60,89 & 21,45 & 487,92 & 466,47 & $12 \%$ & 3,40 & 19,2 & 23,2 & 1 \\
\hline & & 24 & 9 & 05.03 .06 & 122,53 & 58,44 & 14,93 & 492,40 & 477,47 & $12 \%$ & 2,82 & 18,7 & 24,7 & 2 \\
\hline & & 32 & 7 & 12.03 .06 & morte & & & & & & & & & \\
\hline \multirow[t]{11}{*}{$\mathrm{Zg} 14$} & 4,0 & 0 & - & 09.02 .06 & - & - & - & - & - & - & - & 13,2 & 16,8 & 1 \\
\hline & & 2 & 1 & 11.02 .06 & 329,17 & 132,41 & 24,87 & 198,28 & 173,41 & $67 \%$ & 3,06 & 26,7 & 17,0 & 1 \\
\hline & & 6 & 3 & 15.02 .06 & 88,15 & 84,79 & 3,99 & 217,53 & 213,54 & $39 \%$ & 1,09 & 24,7 & 14,7 & 1 \\
\hline & & 10 & 3 & 19.02 .06 & 552,86 & 160,56 & 15,32 & 328,70 & 313,38 & $49 \%$ & 3,81 & 29,0 & 16,0 & 2 \\
\hline & & 12 & 1 & 21.02 .06 & 725,85 & 225,99 & 17,05 & 466,97 & 449,92 & $48 \%$ & 3,47 & 27,8 & 23,3 & 2 \\
\hline & & 15 & 2 & 24.02 .06 & 551,83 & 130,26 & 0,00 & 447,12 & 447,12 & $29 \%$ & 4,24 & 27,5 & 24,2 & 2 \\
\hline & & 20 & 4 & 01.03 .06 & 192,43 & 54,87 & 12,30 & 488,26 & 475,96 & $11 \%$ & 4,52 & 28,3 & 24,4 & 3 \\
\hline & & 25 & 4 & 06.03 .06 & 354,96 & 71,38 & 11,84 & 452,60 & 440,76 & $16 \%$ & 5,96 & 28,0 & 24,4 & 3 \\
\hline & & 36 & 10 & 17.03 .06 & 72,37 & 31,77 & 14,21 & 463,70 & 449,49 & $7 \%$ & 4,12 & 29,3 & 23,9 & 4 \\
\hline & & 44 & 7 & 25.03 .06 & 490,66 & 130,32 & 17,32 & 461,68 & 444,36 & $28 \%$ & 4,34 & & & \\
\hline & & 51 & 6 & 01.04 .06 & morte & & & & & & & & & \\
\hline \multirow[t]{10}{*}{$\mathrm{Zg} 15$} & 3,7 & 0 & - & 09.02 .06 & - & - & - & - & - & - & - & 22,0 & 16,0 & 1 \\
\hline & & 6 & 5 & 15.02 .06 & 317,66 & 143,09 & 18,38 & 272,18 & 253,80 & $53 \%$ & 2,55 & 20,5 & 14,5 & 1 \\
\hline & & 8 & 1 & 17.02 .06 & 9,57 & 12,89 & 0,00 & 272,18 & 272,18 & $5 \%$ & 0,74 & 21,5 & 12,6 & 1 \\
\hline & & 10 & 1 & 19.02 .06 & 39,27 & 24,69 & 11,70 & 286,71 & 275,01 & $9 \%$ & 3,02 & 22,5 & 12,3 & 2 \\
\hline & & 11 & 0 & 20.02 .06 & 376,10 & 139,30 & 12,30 & 314,10 & 301,80 & $44 \%$ & 2,96 & 22,3 & 12,8 & 2 \\
\hline & & 16 & 4 & 25.02 .06 & 535,45 & 201,95 & 15,97 & 421,74 & 405,77 & $48 \%$ & 2,88 & 22,7 & 17,8 & 2 \\
\hline & & 21 & 4 & 02.03 .06 & 32,06 & 16,32 & 10,01 & 421,74 & 411,73 & $4 \%$ & 5,08 & 22,6 & 17,8 & 3 \\
\hline & & 22 & 0 & 03.03 .06 & 244,26 & 85,41 & 10,71 & 419,93 & 409,22 & $20 \%$ & 3,27 & 20,4 & 19,1 & 3 \\
\hline & & 40 & 17 & 21.03 .06 & 344,64 & 111,83 & 13,46 & 381,56 & 368,10 & $29 \%$ & 3,50 & 23,5 & 18,3 & 3 \\
\hline & & 56 & 15 & 06.04 .06 & fuga & & & & & & & & & \\
\hline \multirow[t]{7}{*}{ Zg16 } & 3,2 & 0 & - & 09.02 .06 & - & - & - & - & - & - & - & 19,0 & 17,0 & 1 \\
\hline & & 6 & 5 & 15.02 .06 & 206,41 & 78,90 & 19,61 & 222,35 & 202,74 & $35 \%$ & 3,48 & 18,0 & 13,6 & 1 \\
\hline & & 10 & 3 & 19.02 .06 & 82,38 & 87,34 & 55,48 & 209,29 & 153,81 & $42 \%$ & 2,59 & 21,0 & 14,7 & 1 \\
\hline & & 18 & 7 & 27.02 .06 & 147,07 & 86,46 & 19,67 & 208,54 & 188,87 & $41 \%$ & 2,20 & 21,5 & 15,2 & 1 \\
\hline & & 25 & 6 & 06.03 .06 & 203,86 & 92,52 & 17,08 & 201,88 & 184,80 & $46 \%$ & 2,70 & 15,6 & 15,5 & 1 \\
\hline & & 30 & 4 & 11.03 .06 & 19,06 & 7,04 & 0,00 & 175,03 & 175,03 & $4 \%$ & 2,71 & 17,7 & 14,5 & 1 \\
\hline & & 34 & $\theta$ & 12.03 .06 & fuga & & & & & & & & & \\
\hline \multirow[t]{8}{*}{$\mathrm{Zg} 17$} & 3,6 & 0 & - & 09.02 .06 & - & - & - & - & - & - & - & 22,0 & 15,5 & 0 \\
\hline & & 3 & 2 & 12.02 .06 & 1315,09 & 494,67 & 43,59 & 526,32 & 482,73 & $94 \%$ & 2,92 & 25,0 & 26,0 & 0 \\
\hline & & 9 & 5 & 18.02 .06 & 152,47 & 58,68 & 12,99 & 525,12 & 512,13 & $11 \%$ & 3,34 & 26,5 & 22,6 & 0 \\
\hline & & 10 & 0 & 19.02 .06 & 143,91 & 49,68 & 12,47 & 527,01 & 514,54 & $9 \%$ & 3,87 & 25,5 & 25,0 & 1 \\
\hline & & 14 & 3 & 23.02 .06 & 387,53 & 84,13 & 14,41 & 562,49 & 548,08 & $15 \%$ & 5,56 & 26,0 & 27,5 & 1 \\
\hline & & 18 & 3 & 27.02 .06 & 703,88 & 145,48 & 13,60 & 579,54 & 565,94 & $25 \%$ & 5,34 & 26,5 & 29,6 & 1 \\
\hline & & 26 & 7 & 07.03.06 & 64,17 & 23,26 & 9,48 & 643,44 & 633,96 & $4 \%$ & 4,66 & 26,1 & 29,6 & 2 \\
\hline & & 49 & २2 & 30.03 .06 & fuga & & & & & & & & & \\
\hline
\end{tabular}




\begin{tabular}{|c|c|c|c|c|c|c|c|c|c|c|c|c|c|c|}
\hline & $\begin{array}{c}\mathrm{tpl} \\
(\mathrm{mm})\end{array}$ & dia & $\begin{array}{l}\text { dias sem } \\
\text { reconstruir }\end{array}$ & data & $\begin{array}{c}\text { espira de } \\
\text { captura (cm) }\end{array}$ & $\begin{array}{c}\text { área }\left(\mathrm{cm}^{2}\right) \\
\text { reconstruída }\end{array}$ & $\begin{array}{c}\text { área }\left(\mathrm{cm}^{2}\right) \\
\text { central }\end{array}$ & $\begin{array}{l}\text { área }\left(\mathrm{cm}^{2}\right) \\
\text { total }\end{array}$ & $\begin{array}{l}\text { área }\left(\mathrm{cm}^{2}\right) \\
\text { de captura }\end{array}$ & $\begin{array}{c}\text { reconstrução } \\
(\%)\end{array}$ & $\begin{array}{l}\text { densidade de } \\
\text { fios }\left(\mathrm{cm} / \mathrm{cm}^{2}\right)\end{array}$ & $\begin{array}{c}\text { diâmetro } \\
\text { vertical }\end{array}$ & $\begin{array}{c}\text { diâmetro } \\
\text { horizontal }\end{array}$ & ootecas \\
\hline \multirow[t]{3}{*}{$\mathrm{Zg} 18$} & 3,2 & 0 & - & 09.02.06 & sem teia & - & - & - & - & - & - & - & - & - \\
\hline & & 4 & 3 & 13.02 .06 & 228,25 & 87,02 & 9,48 & 87,02 & 77,54 & $100 \%$ & 2,94 & 12,6 & 9,7 & 0 \\
\hline & & 5 & $\theta$ & 14.02 .06 & fuga & & & & & & & & & \\
\hline \multirow[t]{10}{*}{$\mathrm{Zg} 19$} & 3,5 & 0 & - & 09.02 .06 & - & - & - & - & - & - & - & 16,0 & 12,3 & 1 \\
\hline & & 2 & 1 & 11.02 .06 & 326,98 & 56,36 & 8,57 & 77,92 & 69,35 & $72 \%$ & 6,84 & 15,0 & 17,5 & 1 \\
\hline & & 6 & 3 & 15.02 .06 & 343,98 & 76,10 & 9,50 & 183,41 & 173,91 & $41 \%$ & 5,16 & 13,8 & 18,0 & 1 \\
\hline & & 7 & 0 & 16.02 .06 & 329,72 & 73,19 & 6,00 & 199,09 & 193,09 & $37 \%$ & 4,91 & 15,5 & 18,5 & 1 \\
\hline & & 10 & 2 & 19.02 .06 & 256,34 & 59,01 & 9,85 & 206,48 & 196,63 & $29 \%$ & 5,21 & 15,0 & 18,2 & 1 \\
\hline & & 16 & 5 & 25.02 .06 & 350,98 & 102,12 & 11,98 & 216,14 & 204,16 & $47 \%$ & 3,89 & 16,7 & 17,8 & 2 \\
\hline & & 19 & 2 & 28.02 .06 & 204,47 & 56,43 & 10,19 & 222,70 & 212,51 & $25 \%$ & 4,42 & 18,4 & 18,2 & 2 \\
\hline & & 30 & 10 & 11.03 .06 & 127,42 & 52,11 & 15,71 & 223,64 & 207,93 & $23 \%$ & 3,50 & 17,6 & 17,5 & 2 \\
\hline & & 43 & 12 & 24.03 .06 & 143,38 & 54,55 & 0,00 & 204,43 & 204,43 & $27 \%$ & 2,63 & 17,5 & 18,7 & 2 \\
\hline & & 61 & 17 & 11.04 .06 & 177,88 & 58,64 & 11,10 & 195,13 & 184,03 & $30 \%$ & 3,74 & 18,5 & 18,7 & 2 \\
\hline \multirow[t]{8}{*}{$\mathrm{Zg} 20$} & $(\mathrm{~mm})$ & 0 & - & 09.02 .06 & - & - & - & - & - & - & - & 13,8 & 13,0 & 1 \\
\hline & & 6 & 5 & 15.02 .06 & 317,38 & 173,81 & 19,28 & 190,56 & 171,28 & $91 \%$ & 2,05 & 21,6 & 11,3 & 1 \\
\hline & & 12 & 5 & 21.02 .06 & 86,65 & 34,07 & 10,87 & 188,00 & 177,13 & $18 \%$ & 3,73 & 18,0 & 14,0 & 2 \\
\hline & & 14 & 1 & 23.02 .06 & 530,41 & 215,74 & 0,00 & 283,87 & 283,87 & $76 \%$ & 2,46 & 21,3 & 19,2 & 2 \\
\hline & & 18 & 3 & 27.02 .06 & 24,41 & 16,59 & 12,76 & 283,87 & 271,11 & $6 \%$ & 6,37 & 21,8 & 18,5 & 2 \\
\hline & & 23 & 4 & 04.03 .06 & 398,39 & 117,38 & 14,26 & 317,77 & 303,51 & $37 \%$ & 3,86 & 21,0 & 18,1 & 3 \\
\hline & & 36 & 12 & 17.03 .06 & 585,11 & 153,88 & 11,95 & 399,83 & 387,88 & $38 \%$ & 4,12 & 22,3 & 24,5 & 3 \\
\hline & & 52 & 15 & $\theta 2.04 .06$ & fuga & & & & & & & & & \\
\hline
\end{tabular}

conclusão 


\section{Anexo E}

Tabela de fugas do experimento de redução progressiva da dieta

\begin{tabular}{|c|c|c|c|c|c|c|c|c|c|c|c|c|c|c|c|c|c|c|c|c|c|}
\hline & & \multicolumn{20}{|c|}{ período controle } \\
\hline espécie & grupo & 1 & 2 & 3 & 4 & 5 & 6 & 7 & 8 & 9 & 10 & 11 & 12 & 13 & 14 & 15 & 16 & 17 & 18 & 19 & 20 \\
\hline \multirow{2}{*}{ M. rogenhoferi } & controle & & & & & & & & & & & & & & & & & & & & \\
\hline & experimental & & & & & & & & & & & & & & & & & & & & \\
\hline \multirow{2}{*}{ Z. geniculata } & controle & & & & & & & & & & & & & & & & & & & & \\
\hline & experimental & & & & & & & & & & & & & & & & & & & & \\
\hline
\end{tabular}

\begin{tabular}{|c|c|c|c|c|c|c|c|c|c|c|c|c|c|c|c|c|c|c|c|c|c|c|}
\hline \multirow[b]{2}{*}{ espécie } & \multirow[b]{2}{*}{ grupo } & \multicolumn{20}{|c|}{ período de alimentação reduzida } & \multirow[b]{2}{*}{41} \\
\hline & & 21 & 22 & 23 & 24 & 25 & 26 & 27 & 28 & 29 & 30 & 31 & 32 & 33 & 34 & 35 & 36 & 37 & 38 & 39 & 40 & \\
\hline \multirow{2}{*}{ M. rogenhoferi } & controle & & & & 1 & & & & & & & & & & & & & & & & & \\
\hline & experimento & & & 1 & & & & & & & & & & & & & & 1 & & & & \\
\hline \multirow{2}{*}{ Z. geniculata } & controle & & & & & & & & & & & & & & & & & & & & & \\
\hline & experimento & & & & & & & & & & & & & & & & & & & & & \\
\hline
\end{tabular}

\begin{tabular}{|c|c|c|c|c|c|c|c|c|c|c|c|c|c|c|c|c|c|c|c|c|c|c|c|c|c|c|c|}
\hline & & \multicolumn{25}{|c|}{ período sem alimentação } & \\
\hline espécie & grupo & 42 & 43 & 44 & 45 & 46 & 47 & 48 & 49 & 50 & 51 & 52 & 53 & 54 & 55 & 56 & 57 & 58 & 59 & 60 & \begin{tabular}{|l|l|}
61 & 6 \\
\end{tabular} & \begin{tabular}{l|l|}
62 & 63 \\
\end{tabular} & \begin{tabular}{ll|l}
364 & 6 \\
\end{tabular} & \begin{tabular}{c|c|}
65 & 66 \\
\end{tabular} & $5 \mid 67$ & \begin{tabular}{l|l|}
68 & 69 \\
\end{tabular} & \\
\hline \multirow{2}{*}{ M. rogenhoferi } & controle & & \begin{tabular}{l|l}
12 \\
\end{tabular} & 1 & & & & & & & & & & & & & & & & & & & & & & & 0 \\
\hline & experimental & & 1 & & & & & & & & & 1 & & & & & & & & & & & & & & & $\left.1\right|_{0} ^{\circ}$ \\
\hline \multirow{2}{*}{ Z. geniculata } & controle & & & & & & & & & & & & & & & & & & & & & & & & & & 5 \\
\hline & \begin{tabular}{|l|} 
experimental \\
\end{tabular} & & & & & & & & & & & & & & & & & & 1 & & \begin{tabular}{|c|ccc}
1 & & $l$ & $l$
\end{tabular} & & 1 & & 1 & & 0 \\
\hline
\end{tabular}

As marcas rosas e amarelas a cada quatro dias na tabela indicam os dias em que as aranhas foram alimentadas, com grilos de três semanas e recém-nascidos, respectivamente. A marca vermelha mostra o primeiro dia em que a alimentação deixa de ocorrer. Os números em vermelho representam as mortes. $\mathrm{O}$ grupo controle de $M$. rogenhoferi começa com $\mathrm{n}=5$ e o grupo experimental com $\mathrm{n}=5$, e o grupo controle de Z. geniculata começa com $n=5$ e o grupo experimental com $n=5$. A área hachurada ( $M$ ) da tabela indica os dias em que as teias não foram medidas. 


\section{Anexo F}

Tabela de fugas e mortes do experimento de redução abrupta da dieta

período controle - alimentação

\begin{tabular}{|c|c|c|c|c|c|c|c|c|c|c|c|c|c|c|c|c|c|c|c|c|c|}
\hline & DIA & 1 & 2 & 3 & 4 & 5 & 6 & 7 & 8 & 9 & 10 & 11 & 12 & 13 & 14 & 15 & 16 & 17 & 18 & 19 & \begin{tabular}{l|l|}
20 & 21 \\
\end{tabular} \\
\hline \multirow{2}{*}{ M. rogenhoferi } & fuga & & & & & 1 & & 1 & 1 & 1 & & & & & & & & 1 & & & \\
\hline & morte & & & & & & & 1 & & 1 & & 1 & & & & & & & & & 1 \\
\hline \multirow{2}{*}{ Z. geniculata } & fuga & & & & & 1 & 1 & 1 & & 1 & & & & & & & & & & & \\
\hline & morte & & & & & & & & & & & & & & & & & & & & \\
\hline
\end{tabular}

período sem alimentação

\begin{tabular}{|l|l|r|r|r|r|r|r|r|r|r|r|r|r|r|r|r|r|r|r|r|r|r|}
\hline & DIA & 22 & 23 & 24 & 25 & 26 & 27 & 28 & 29 & 30 & 31 & 32 & 33 & 34 & 35 & 36 & 37 & 38 & 39 & 40 & 41 & 42 \\
\hline \multirow{2}{*}{ M. rogenhoferi } & fuga & & & & & 1 & & 1 & & 1 & & & & 1 & & & & & & & & \\
\hline & morte & & & 2 & & 1 & & & & & & & & & & & & & & & & \\
\hline \multirow{2}{*}{$\begin{array}{l}\text { Z. geniculata } \\
\text { fuga }\end{array}$} & & & & & & & & & & 1 & & & & & & & & & & & \\
\hline
\end{tabular}

período sem alimentação

\begin{tabular}{|l|l|r|r|r|r|r|r|r|r|r|r|r|r|r|r|r|r|r|r|r|r|r|r|r|}
\hline & DIA & 43 & 44 & 45 & 46 & 47 & 48 & 49 & 50 & 51 & 52 & 53 & 54 & 55 & 56 & 57 & 58 & 59 & 60 & 61 & 62 & 63 & $64-100$ & \\
\hline \multirow{2}{*}{ M. rogenhoferi } & fuga & & & & & & & 1 & & & & & & & & 1 & & & & & & 1 & 1 & 13 \\
& morte & & & & & & & & & & & & & & & & & & & & & & & 7 \\
\hline \multirow{2}{*}{ Z. geniculata } & fuga & & & & & & & 3 & & & 1 & 1 & 1 & & 1 & & & 1 & & & & & & 1 \\
\cline { 2 - 15 } & morte & & 1 & 1 & & & & & 1 & 1 & & & & & & & & & & & & & & 1 \\
\hline
\end{tabular}

As marcas rosas a cada quatro dias indicam os dias em que as aranhas foram alimentadas. A marca vermelha mostra o primeiro dia em que a alimentação deixa de ocorrer. A última $M$. rogenhoferi fugiu no $74^{\circ}$ dia experimental (57 dias sem alimentação). Duas $Z$. geniculata excederam o prazo de término do experimento (dado pelo $63^{\circ}$ dia da tabela). Uma fugiu no $92^{\circ}$ dia ( 75 dias sem alimentação) e a outra morreu no $100^{\circ}$ dia (79 dias sem alimentação). $\mathrm{N}=20$ para cada espécie. 


\section{Anexo G \\ Como foi construída a caixa respirométrica para a medida de construção da teia orbicular}

\section{MATERIAL:}

- caixa plástica (Plastitecnica ${ }^{\circledR} \mathrm{n}^{\mathrm{0}}$ 604);

- tubos de plástico de $0,5 \mathrm{~cm}$ de diâmetro cortados em segmentos de $4 \mathrm{~cm}$

- mangueiras de plástico de $0,5 \mathrm{~cm}$ de diâmetro

- mangueiras de silicone com diâmetro interno de $0,5 \mathrm{~cm}$ cortados em segmentos de $5 \mathrm{~cm}$ (conectores)

- bexigas (vedação)

- adesivo instantâneo universal (Super Bonder ${ }^{\circledR}$ )

- cola quente

\section{Montagem:}

1. fazer furos diametralmente opostos na caixa com uma mini-retífica,

2. ajustar os tubos de plásticos nos furos fazendo que a extremidade interna fique alinhada com a superfície interna da caixa,

3. Com os tubos alinhados, usar bastante cola quente para colar e apoiar os tubos,

4. cortar as bexigas ao meio e lavar

5. com as bexigas bem secas, colar uma das extremidades da bexiga na borda da caixa com o adesivo instantâneo universal (é necessário manter pressionada ponta da bexiga com a ponta da caixa por pelo menos 10 segundos para que ela não solte na fase seguinte,

6. com a extremidade bem presa, estica-se trechos pequenos de bexiga (uns $3 \mathrm{~cm}$ ) passando o adesivo instantâneo universal na beirada da caixa a ser colada logo abaixo da bexiga esticada, unindo os trechos de bexiga com beirada de caixa sucessivamente,

7. terminada a colagem da bexiga, corta-se os excessos fora e verifica-se a vedação da caixa mergulhando a em um recipiente com água

8. pequenos ajustes podem ser feitos com cola quente, adesivo instantâneo universal, e esmalte, dependendo do tamanho e tipo de furo que está permitindo que a água entre. 